\title{
Plant Succession, Ecological Restoration and the Skinks of Stephens Island / Takapourewa
}

\author{
Cielle Stephens
}

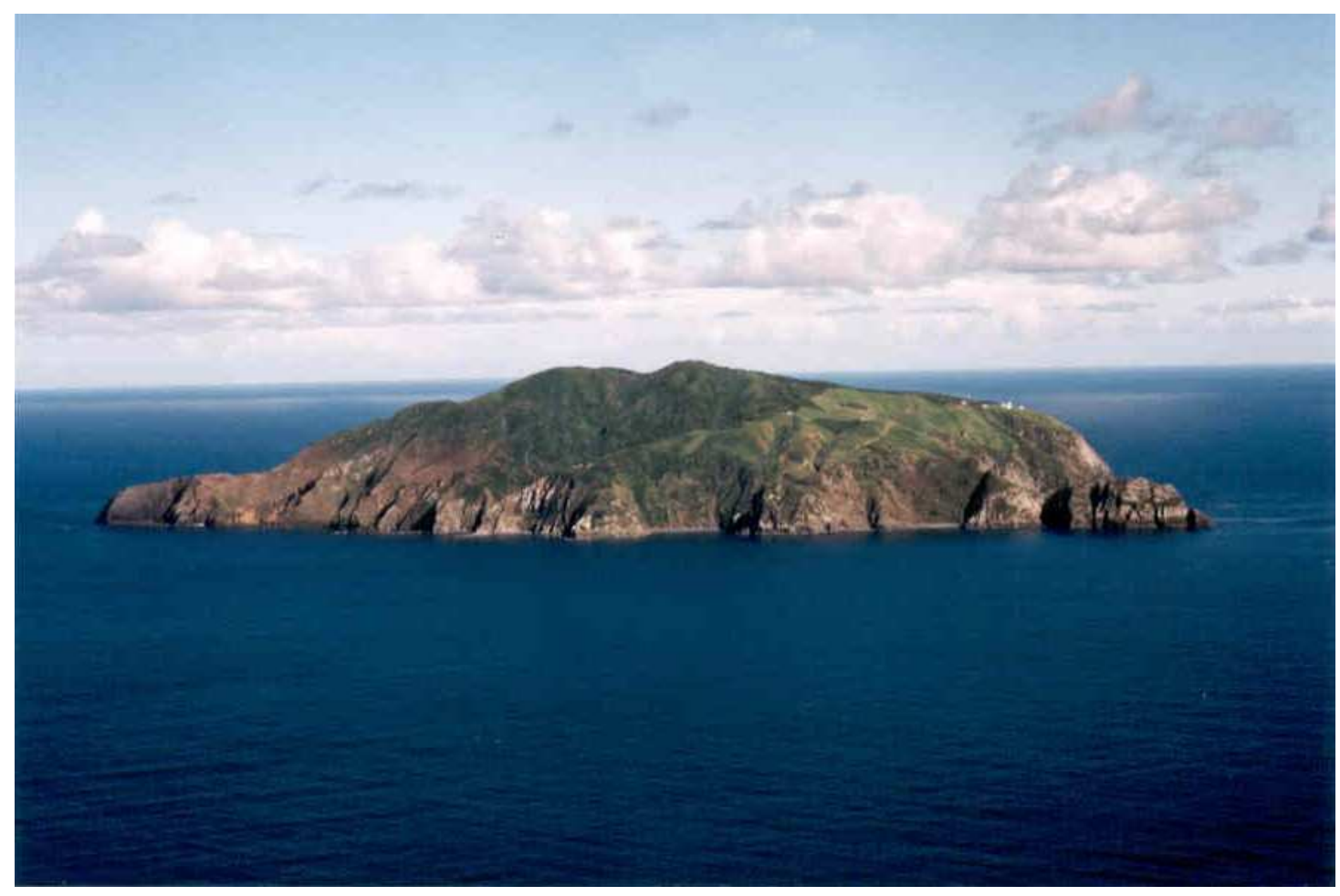

Thesis submitted for a Masters in Science in Ecology and Biodiversity April 2004

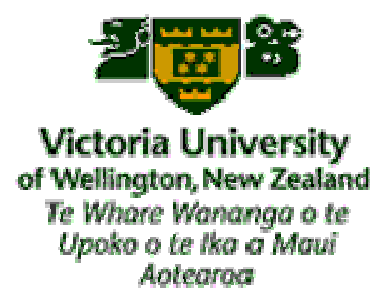




\section{Abstract}

Ecological restoration often involves revegetation. I have investigated the impact of revegetation on the distribution, abundance and body condition of skinks on Stephens Island (Takapourewa). I tested the prediction that only one, Oligosoma infrapunctatum, of the four skink species (Oligosoma lineoocellatum, O. nigriplantare polychroma, $O$. infrapunctatum and O. zelandicum) will benefit in terms of abundance and distribution from revegetation. Stephens Island is a Wildlife Sanctuary in the north-western Marlborough Sounds, New Zealand. The island is known for its diverse and abundant reptile community. Prior to the mid $19^{\text {th }}$ century Stephens Island was covered in forest. Nearly $80 \%$ of this forest was destroyed following the establishment of a lighthouse and farm on the island in 1894. In 1989, when the control of Stephens Island passed to the Department of Conservation, reforestation became a key conservation goal. Stephens Island is currently a mosaic of different habitat types from pasture to coastal forest. Pitfall traps caught skinks for a mark-recapture study in four replicated habitat types: forest, tussock, pasture and replanted.

Oligosoma lineoocellatum comprised $75 \%$ of all individuals caught. Densities of $O$. lineoocellatum were higher in replanted habitat (3020/ha in December and 3770/ha in March) than tussock (2690/ha in December and 2560/ha in March) and lowest in the pasture (1740/ha in December and 1960/ha in March). Rates of captures were too low to perform density estimates for the other three species. Trap occupancy rates indicate $O$. nigriplantare polychroma is more common in the tussock habitat, and $O$. infrapunctatum is more common in the replanted habitat. Few O. zelandicum were found, primarily in the tussock habitat. Pasture areas replanted 13 years ago (now scrub habitat) support a higher diversity and abundance of skinks. Forest areas remain depauperate of skinks. Skink preference for replanted areas suggests that, for now, revegetation benefits their populations, possibly due to greater food sources, lower predation pressure and a wider thermal range.

Body condition (log weight/ log snout-vent length) and proportion of tail loss of skinks were similar in the different habitat types. However, both $O$. nigriplantare polychroma and $O$. lineoocellatum had higher body condition in the replanted than the tussock habitat. Juvenile skinks had significantly lower body condition and a lower proportion of tail loss. Skink body condition was not negatively affected by revegetation or by different habitats, despite the large differences between the habitats.

Revegetation currently benefits skink populations. Maintaining a mosaic of habitat types is recommended, because, should revegetation create more forest habitat through plantations or plant succession, it is likely that the population of all four species of skink will decline. 


\section{Acknowledgements}

Thank you to my supervisors, Charles Daugherty and Nicola Nelson, for their inspiration, guidance, support and critical analysis of my work. Thanks to Shirley Pledger for the many hours she spent explaining the finer points of statistics to me and without whom the MARK programme would have left me completely baffled. I really appreciate your help. Thanks to the Department of Conservation and in to particular Peter Gaze and to Bruce and Carol Knight for their help and support and to the local iwi, Ngati Koata, for their permission to work on such a wonderful, amazing place.

Thank you to my field assistances/slaves, Andrew Martin, Andrea Stephens, Scott Carver, Peter Martin and Rhys Mills. Thank you for getting up at 6.30am for me and writing numerous numbers on bits of paper for me. Thank you to all the people that helped me dig holes all over Stephens Island and thanks to Sue Keall and Kelly Hare for their technical assistance. Thank you Nicky, for helping me with all my little problems on Stephens Island.

Big thanks to all those who gave up their time to help me through the writing and editing phase, in particular to Nicky Nelson, Charles Daugherty, Bob and Alison Stephens, Jamie Beban, Anna Kaiser, Kylie Mason, the hatchet gang and Andrea Stephens. Thanks to Tim Markwell, Ben Bell and Rod Hitchmough for their informative help, to Tim for the use of his bug data, and to Tony Whitaker for the use of his photos. Thanks to Bruce Norris, Veronica Gailitis and Greg Stephens for solving all my numerous computer glitches.

Lastly, thanks to my family, Snuffy's Army, the occupants of room KK702 and other friends for keeping me sane over the last two years. Thanks for your help procrastinating (;). 


\section{CONTENTS}

ABSTRACT

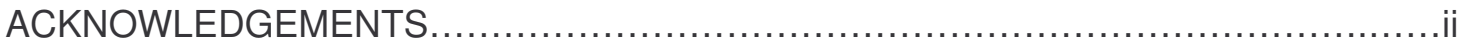

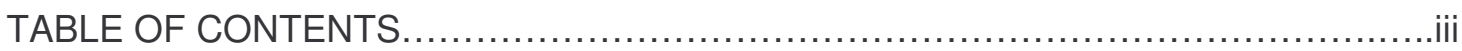

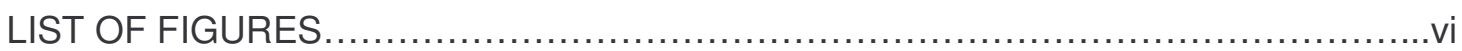

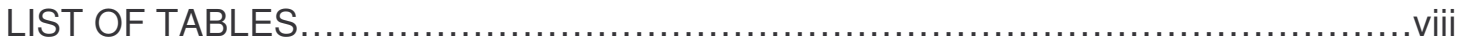

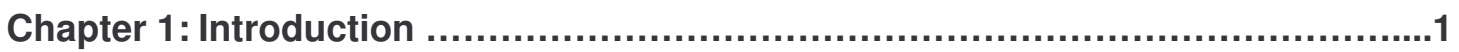

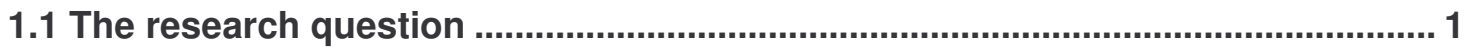

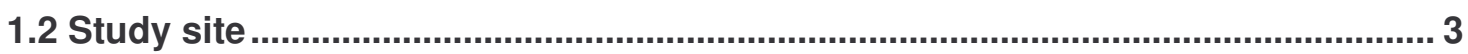

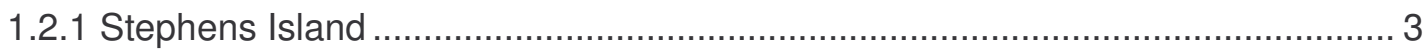

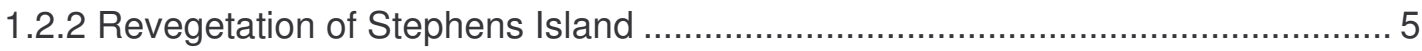

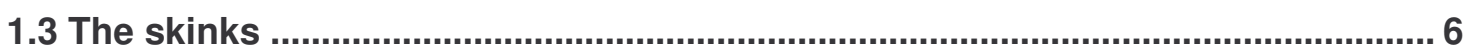

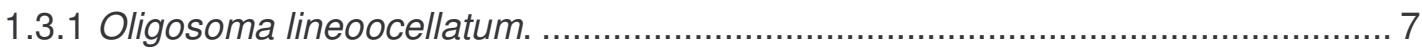

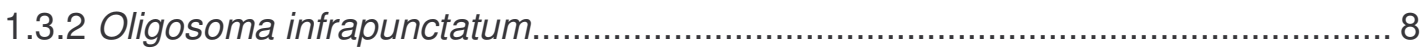

1.3.3 Oligosoma nigriplantare polychroma......................................................... 8

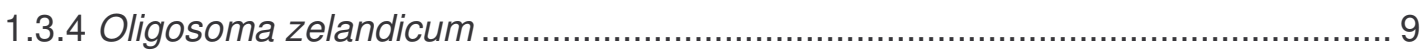

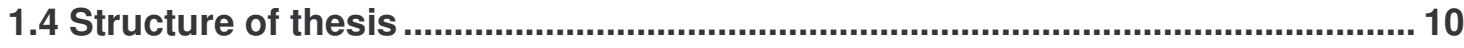

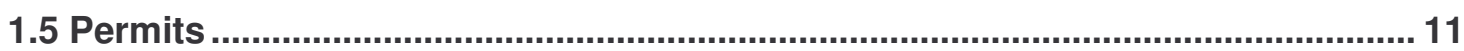

Chapter two: Abundance and distribution ...................................................................... 12

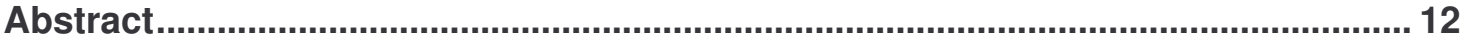

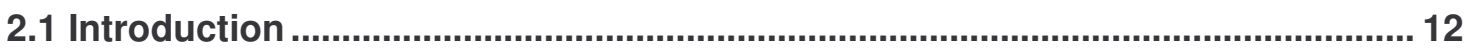

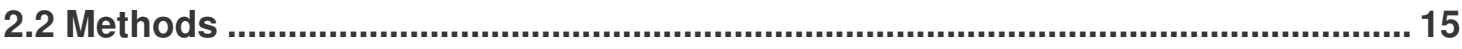

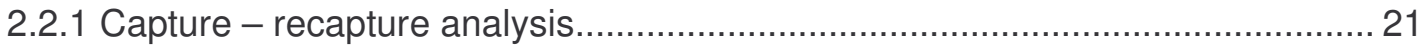

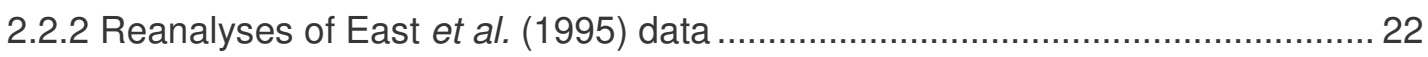

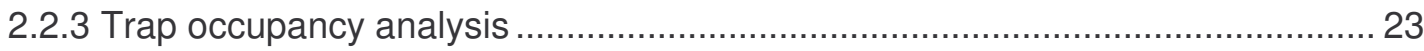

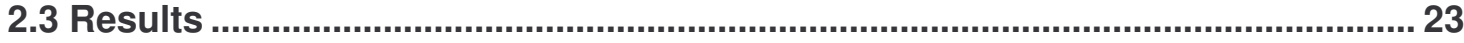

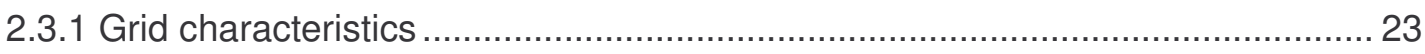

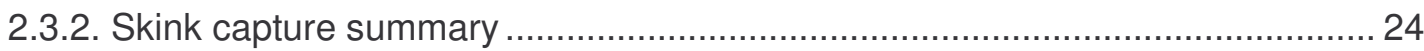

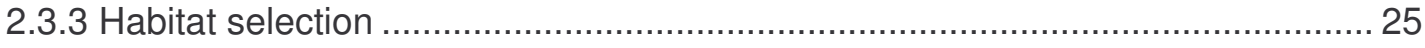

2.3.4 Density of $O$. lineoocellatum from the East et al. (1995) survey........................ 33

2.3.5 Comparison with the East et al. (1995) survey ............................................... 35

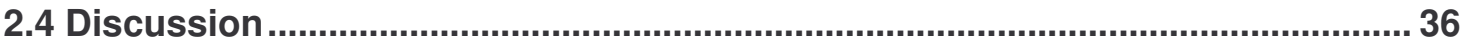




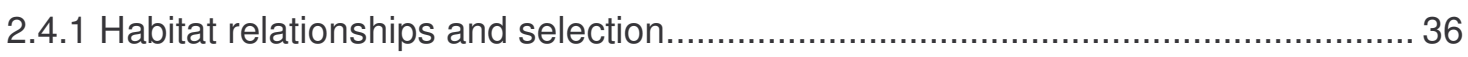

2.4.2 Comparison with the East et al. (1995) survey ............................................... 39

2.4.3 Predictions and recommendations ................................................................ 40

Chapter 3: Skink body condition and tail loss in different habitats ......................... 41

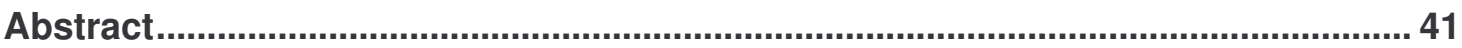

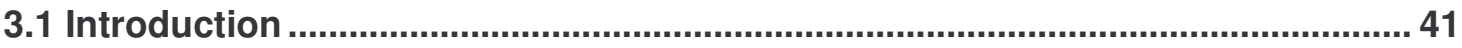

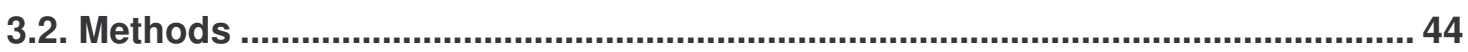

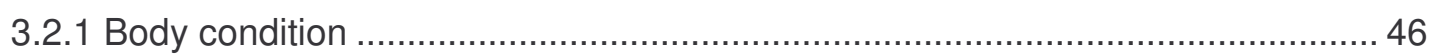

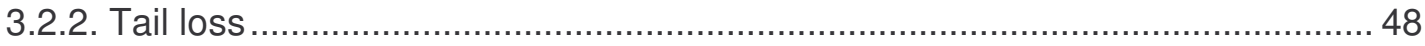

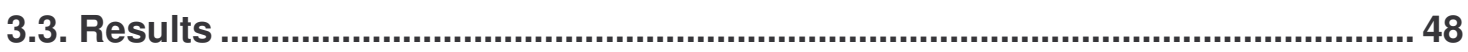

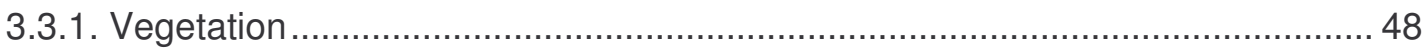

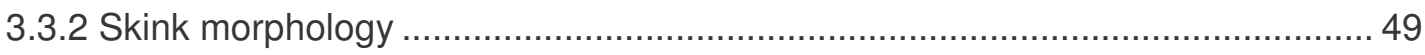

3.3.3. Body condition of skinks in different habitats ............................................ 51

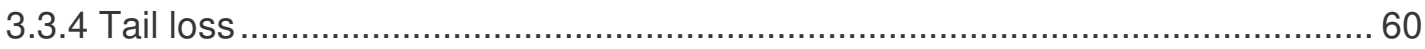

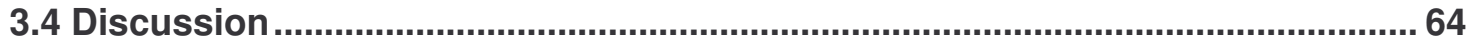

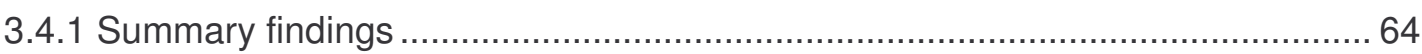

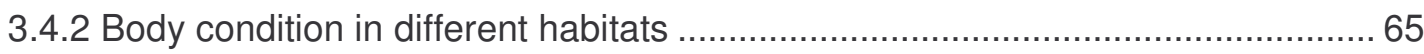

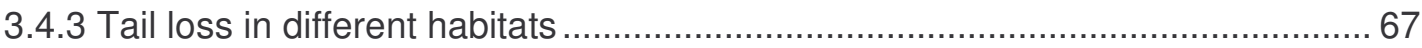

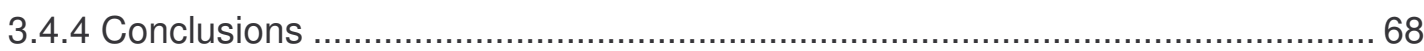

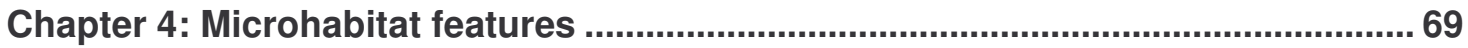

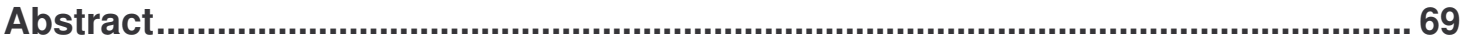

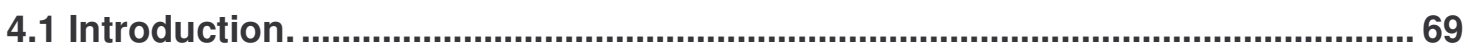

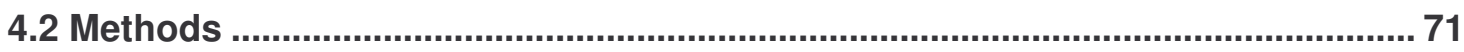

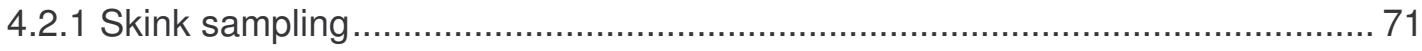

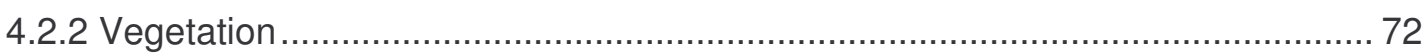

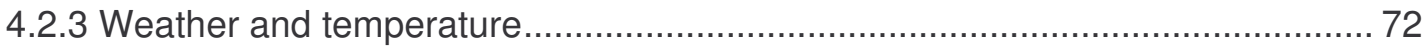

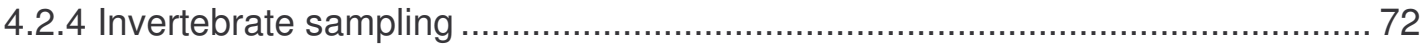

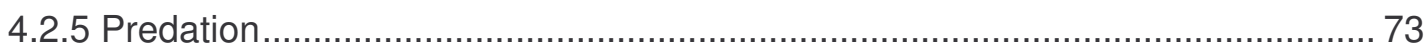

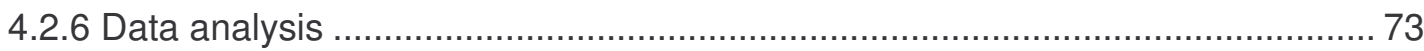

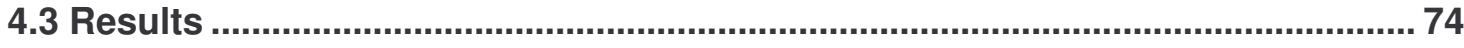

4.3.1 Vegetation: Cover and height .............................................................. 74

5.3.2 Trap occupancy of skink in different habitats .................................................. 76

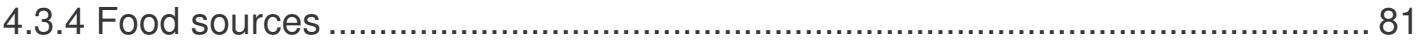

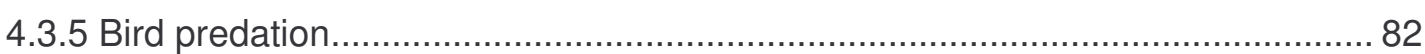

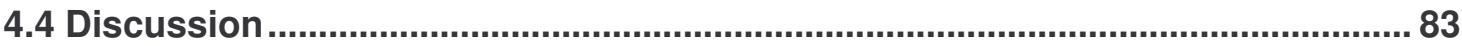




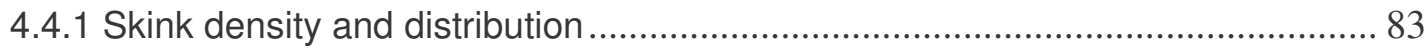

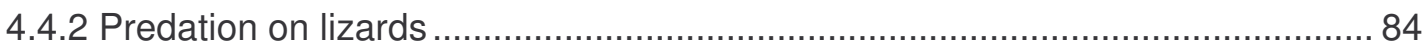

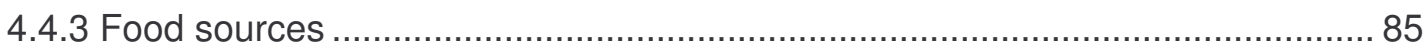

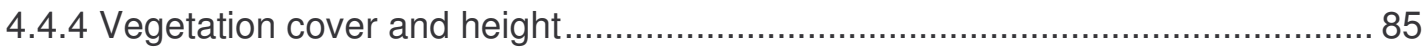

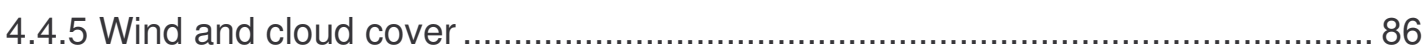

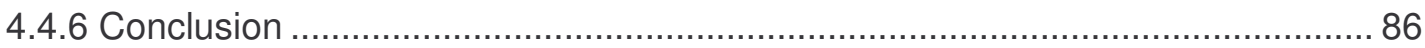

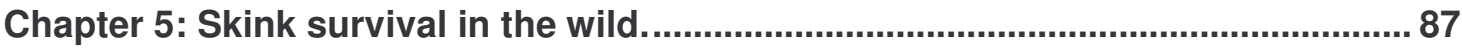

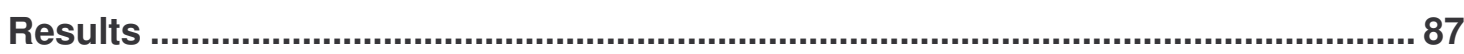

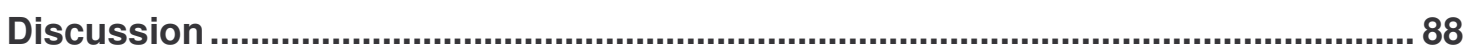

Chapter 6. Summary of results and discussion......................................................... 89

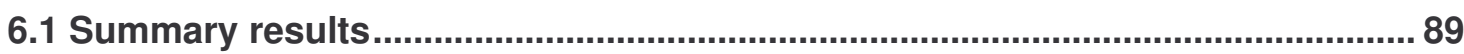

6.1.1 Abundance, density and distribution of skinks .............................................90

6.1.2 Change over time: The impact of revegetation ............................................. 91

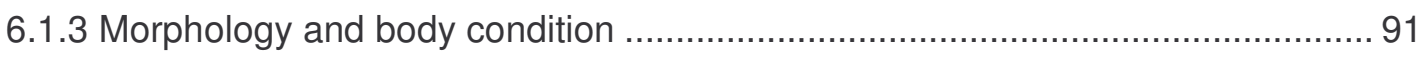

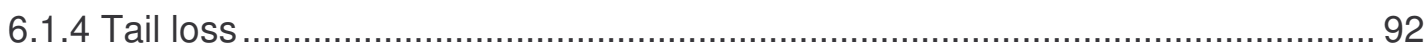

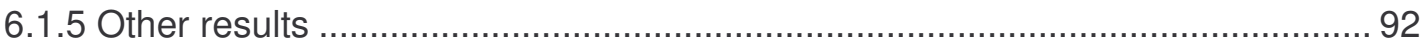

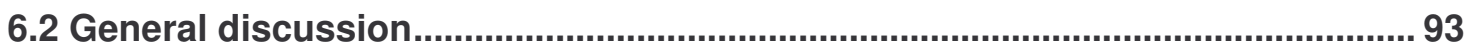

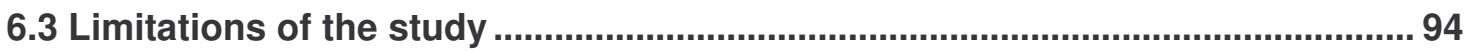

6.4 Predictions and conservation implications............................................................95

References:

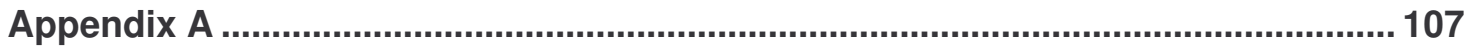

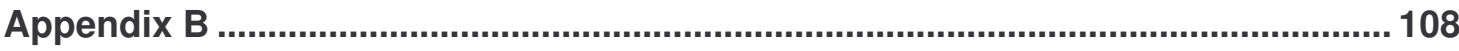




\section{Chapter 1}

Figure list

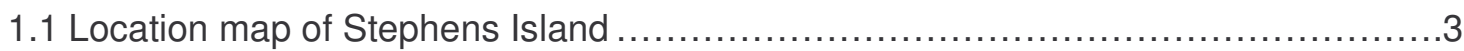

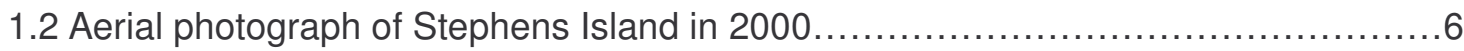

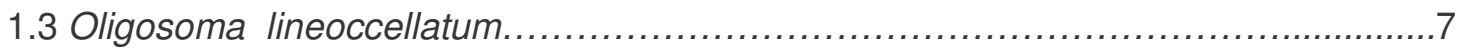

1.4 Oligosoma infrapunctatum..........................................................

1.5 Oligsoma nigriplantare polychroma.............................................

1.6 Oligosoma zelandicum............................................................. 10

\section{Chapter 2}

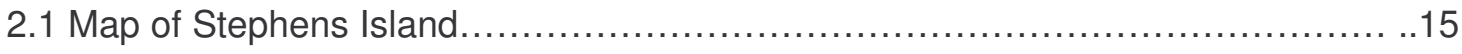

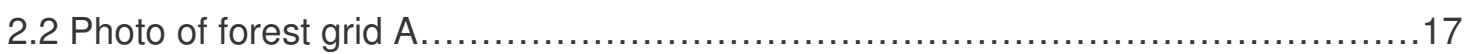

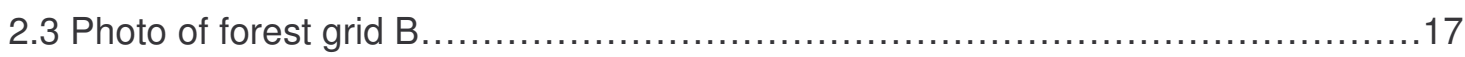

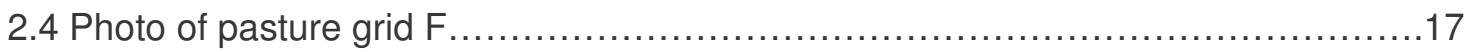

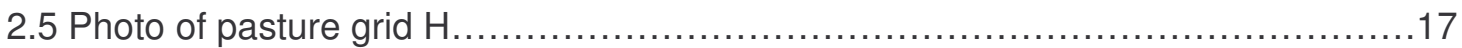

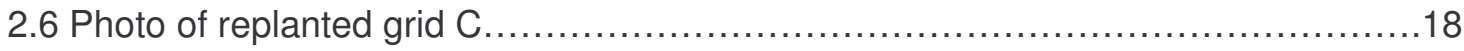

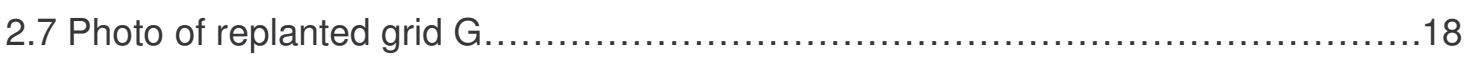

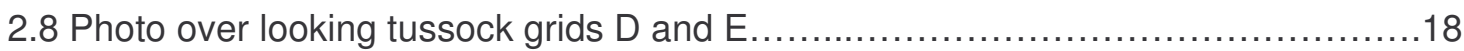

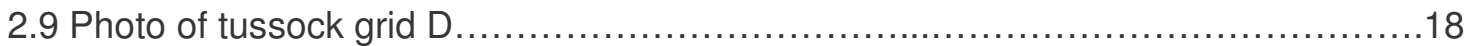

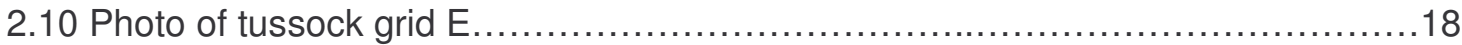

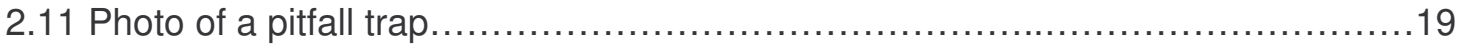

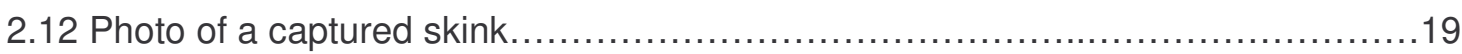

2.13 Trap occupancy rates of the four skink species in different habitats................27

2.14 Density of $O$. lineoocellatum from model $\{p(t \times h a b), N(h a b)\}$ in December ...........32

2.15 Density of $O$. lineoocellatum from model $\{\mathrm{p}(\mathrm{t} \times \mathrm{hab}), \mathrm{N}(\mathrm{hab})\}$ in March...............33

\section{Chapter 3}

3.1 SVL range of skinks caught during the December trip.............................50

3.2: Body condition of male, female and juvenile O. lineoocellatum

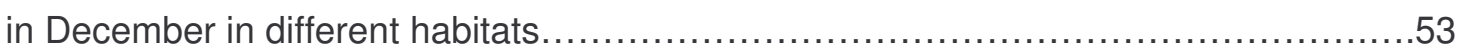


3.3. Body condition of male, female and juvenile O. lineoocellatum in

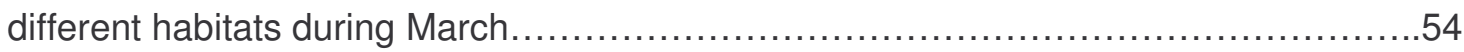

3.4. Body condition (lgwgtsvl) of O. nigriplantare polychroma in

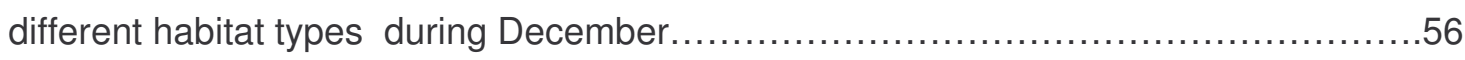

3.5. Body condition (lgwgtsvl) of $O$. nigriplantare polychroma

in different habitat types during March

3.6: Body condition index (lgwgtsvl) of $O$. infrapunctatum in

December in different habitats.

3.7: Body condition index (lgwgtsvl) of $O$. infrapunctatum in March

in the different habitats.

3.8. The $95 \%$ confidence level of the proportion of tail loss by sex/size

class during both December and March....

\section{Chapter 4}

4.1. Total skink captures per trap compared with the cover of the vegetation over each pitfall trap. .76

4.2. Capture rates of the four skink species in different habitats

on Stephens Island.

4.3. Comparison of skink capture rate with the maximum temperature in December.....78

4.4. Comparison of skink capture rate with maximum temperature March.

4.5. Maximum, minimum and average temperature for all grids

on Stephens Island between 19/09/03 - 22/11/03.

4.6. Combined capture rate of skink species on Stephens Island in relation

to the strength of the wind.

4.7. Combined capture rate of skink species on Stephens Island in relation to the level of cloud cover 80

4.8. The proportion of fruiting species in each of the grids and different habitat types on Stephens Island.

4.9. The number of invertebrates in each habitat type on Stephens Island (Markwell 1999).... 


\section{Table list}

\section{Chapter 2}

2.1 Total number of skink individuals caught (percentage of total).

2.2 Number of skinks caught per trap/day for the four species over the two trapping periods.

2.3 Trap occupancy AIC, values determining which factors influence the numbers of skinks per trap.

2.4 Table of Bonferroni comparison of the skink capture rate between the different habitat types.

2.5. AIC values for MARK models to estimate $O$. lineoocellatum population.

2.6 MARK population estimates of $O$. lineoocellatum by habitat type from model $\{p(t \times h a b), N(h a b)\}$, habitat type (grid)

2.7 MARK population estimates of $O$. lineoocellatum by grid using model $\{p(t \times$ hab $), N(g)\}$

2.8 Location of $O$. lineoocellatum recaptures with respect to the original trap caught, percentage of total (number)

2.9 Adjusted habitat area in $\mathrm{m}^{2}$

2.10 Adjusted grid area in $\mathrm{m}^{2}$.

2.11 MARK estimates of the density of $O$. lineoocellatum per hectare in

December and March from model $\{p(t \times h a b), N(g)\}$

2.12 Relative AIC values for $O$. lineoocellatum to determine influences on

the survival rate and the probability of capture (East et al. 1995)....

2.13 Densities of $O$. lineoocellatum per hectare reanalysed from the

East et al. (1995) for grids one (pasture) and two (tussock) .35

2.14 Trap occupancy rates of skinks in different grids.... .36

2.15 Table of East et al. (1995) capture estimates.... 36 


\section{Chapter 3}

3.1 Mean skink SVL (s.e.) and weight (s.e.) and range in December and March 50

3.2. Model selection by AIC values indicating which parameters had the most effect on the data set .51

3.3. Multivariate analysis of the body condition (lgwgtsvl) of $O$. lineoocellatum .52

3.4. Tukey test of the body condition of $O$. lineoocellatum the showing the statistical differences the habitat types...

3.5. Multivariate analysis of the body condition (lgwgtsvl) of

O. nigriplantare polychroma

3.6. Tukey tests indicating the statistical difference in the body condition index (lgwgtsvl) of $O$. nigriplantare polychroma in different habitat types.

3.7: Multivariate analysis of the body condition (lgwgtsvl) of

O. infrapunctatum in December and March....

3.8. Tukey tests indicating the statistical difference in the body condition (lgwgtsvl) of $O$. infrapunctatum in different habitats.

3.9. The percentage of the proportion of the population exhibiting some degree of tail loss in the four skink species on Stephens Island

3.10. Mean tail loss for $O$. lineoocellatum in different grids.

3.11. Mean tail loss for $O$. nigriplantare polychroma in different grids. 63

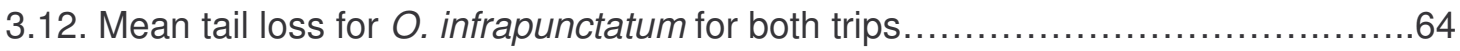

3.13. Mean tail loss of $O$. zelandicum for both trips. 64

\section{Chapter 4}

4.1. ANOVA table of captures (total and by species) and their relationship

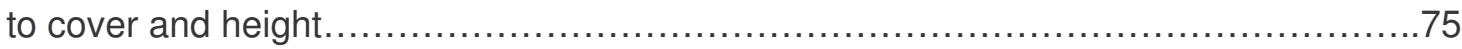

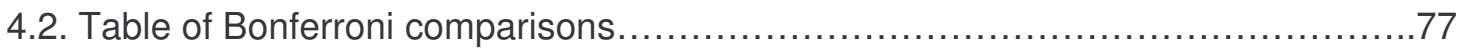

4.3. Comparison of the average temperature on Stephens Island, between different habitat types. 


\section{Chapter 1}

\section{Introduction}

\subsection{The research question}

Offshore islands contain a disproportionately large amount of New Zealand's biological wealth. They contain species that may never have occurred on the mainland as well as those that are now restricted to offshore islands, such as the tuatara (Daugherty et al. 1990). Due to geographic distance and the need to cross water, islands are comparatively difficult for introduced predators, the biggest threat to native biota, to reach (Towns and Daugherty 1994). Although the human alterations of islands have often been as devastating as those on the mainland, some species have found refuge on them (Craig 1990). Of New Zealand's extant reptile species, $41 \%$ (27 out of 65 species) survive entirely on rat free offshore islands (Towns and Daugherty 1994).

Ecological restoration is considered an important part of conservation, but extensive or indiscriminate revegetation may endanger the existing fauna (Simberloff 1990a). Changes in habitat can have severe consequences for some species (Towns and Elliot 1996). In areas with a diverse range of fauna, such as Stephens Island, it is important to protect a wide range of habitat types (Bury and Pearl 1999).

In 1992, East et al. (1995) studied the spatial distributions and relative densities of the four skinks species: Oligosoma infrapunctatum, O. lineoocellatum, O. nigriplantare polychroma, O. zelandicum on Stephens Island. They examined habitats that represented the probable sequences of succession from short grass to mature bush 
(East et al. 1995). The vegetation on the island has changed due to plant succession and replanting by the Department of Conservation. East et al. (1995) predicted only one, O. infrapunctatum, of the four species of skink would be enhanced from revegetation. This raises an important question, might vegetative restoration be negative?

This project re-examines the abundance and distribution of the skink species on Stephens Island, focusing on four habitat types (forest, tussock, pasture and replanted) including the East et al. (1995) sites. It has two aims; the first aim is to determine the effects of revegetation to the skinks of Stephens Island. The second aim is to determine the conservation implications of restoration for the management of reptile populations. To meet these aims I plan to answer the following questions:

- Can we determine the abundance and/or distribution of skink species in the four habitats (forest, tussock, pasture and replanted) on Stephens Island?

- Has replanting altered the distribution and/or abundance of skink species since the East et al. (1995) survey?

- Do the different habitat types have an impact on the body condition index and the rate of tail loss in skinks?

- Can we provide an estimate of skink survival in the wild by locating individual toe clips from East et al. (1995) survey?

The answers to these questions will determine whether the revegetation of Stephens Island is beneficial for skinks and other more endangered species of reptile. At the end of the project I make my own predictions for the future of skinks on Stephens Island. 
None of the skink species studied are endangered or rare (Towns et al. 2001). However, all except the common skink $O$. nigriplantare polychroma have limited distributions. This study may provide a useful indicator of how environmental change may affect reptile species. The knowledge of how plant succession affects reptiles is important for the future of conservation management not only for Stephens Island skinks, but also for reptile conservation management and translocations.

\subsection{Study site}

\subsubsection{Stephens Island}

Stephens Island (Takapourewa) is situated in western Cook Strait, Marlborough Sounds, New Zealand, three kilometres north of D'urville Island at $174^{\circ} 00^{\prime} \mathrm{E}$ and $40^{\circ} 40^{\prime} \mathrm{S}$ (Figure 1.1).

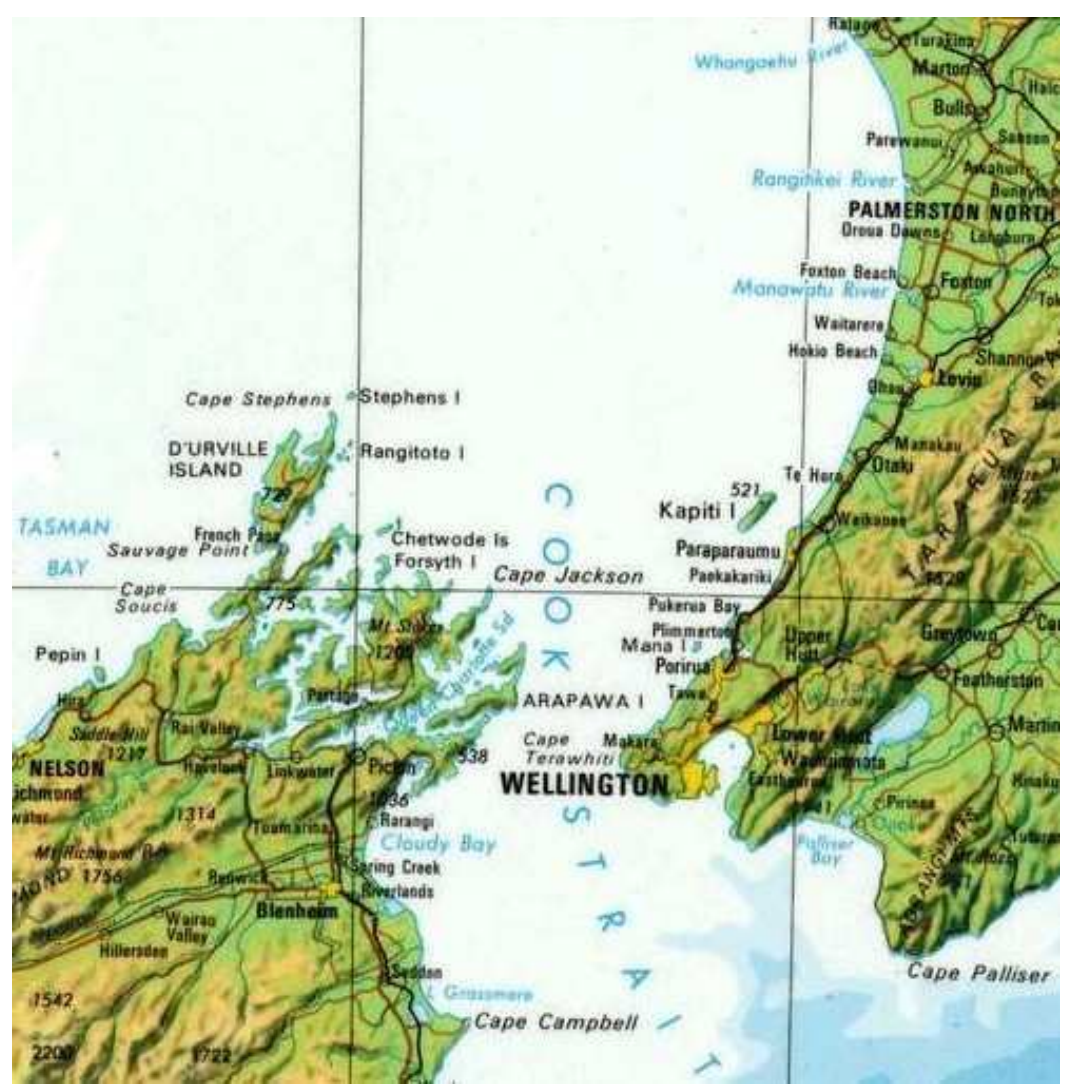

Figure 1.1 Location of Stephens Island (TopoMapNZ-2.0). 
The climate on Stephens Island is oceanic, with high winds (often salt laden), moderate rainfall and mild temperatures. The island is $2 \mathrm{~km}$ by $1 \mathrm{~km}$ (150 hectare) and reaches a maximum elevation of $283 \mathrm{~m}$. There are steep cliffs on the western side, and the eastern side is composed of hill slopes that are steep south of the summit. There are numerous small gullies, but no permanent fresh water (Walls 1988).

The island has a highly diverse reptile community, with the largest New Zealand population of tuatara, Sphenodon punctatus (East et al. 1995), one of three populations of the gecko, Hopodactylus stephensi, (Gill and Whitaker 2001), two other geckos (Naultinus manukanus, Hopodactylus maculatus) species and the four skink species. Rich soils, numerous invertebrates and the absence of mainland predators contribute to the abundance of reptiles (East et al. 1995, Markwell and Daugherty 2002). There is no evidence that rats have ever reached Stephens Island. Cats were introduced and are the probable cause for the extinction of the Stephens Island wren. The decision to remove the cats came in 1899. By 1910, 700 cats had been killed and all cats were removed by 1925 (Brown 2000).

Stephens Island was covered in forest until late last century. Following the establishment of a lighthouse station and farm in 1894 , burning and grazing destroyed $80 \%$ of the forest (Brown 2000). The island is now a mix of low forest, vineland, scrub, tall and short grass fields. Plants recorded from Stephens Island total 222 species, two thirds of which are native (Walls et al. 1988). A Department of Conservation officer lives permanently on the island to manage the restoration process, the sheep, island maintenance and protection. 


\subsubsection{Revegetation of Stephens Island}

The loss of forest on Stephens Island became an issue in the 1920's, but little was done to protect the remaining patches of bush from the livestock (Brown 2000). By 1949, the sheep numbers had risen to 400 , the Frogbank was described as a picture of desolation and stock had decimated Ruston Bush (Brown 2000). In 1951 a fence running along the edge of the forest remnants and the cliff edge was completed, protectingRuston Bush and the southern two thirds of the island from livestock (Brown 2000). By 1975 a fence along the cliff top of the northern end of the island, confined the livestock to the paddocks. The Wildlife Service under Brian Bell did limited amounts of restorative plantings from the 1950's onwards.

In 1989 the management of Stephens Island was transferred from the Ministry of Transport to the Department of Conservation. With conservation now the priority on Stephens Island, revegetation of the island became a primary objective (Brown 2000). Cattle were removed, but the sheep remained to retain areas of pasture for nesting tuatara and to keep the grass low to prevent the potential spread of fire.

Under the 1992 Stephens Island revegetation plan, the majority of pasture is to be retired and replanted over the next $10-15$ years (Brown 2000). The Frogbank (to protect the native frogs) and the corridor (linking the two surviving forests) are the first foci of revegetation (Brown 2000). It is aimed to plant about 10,000 seedlings on Stephens Island per year. Areas that are too heavily burrowed for assisted revegetation will be left. When the existing sheep die, they will not be replaced. All areas that are currently pasture will be replanted, with the possible exception of the tuatara nest areas. Figure 1.2 shows the vegetation distribution of Stephens Island in the year 2000. 


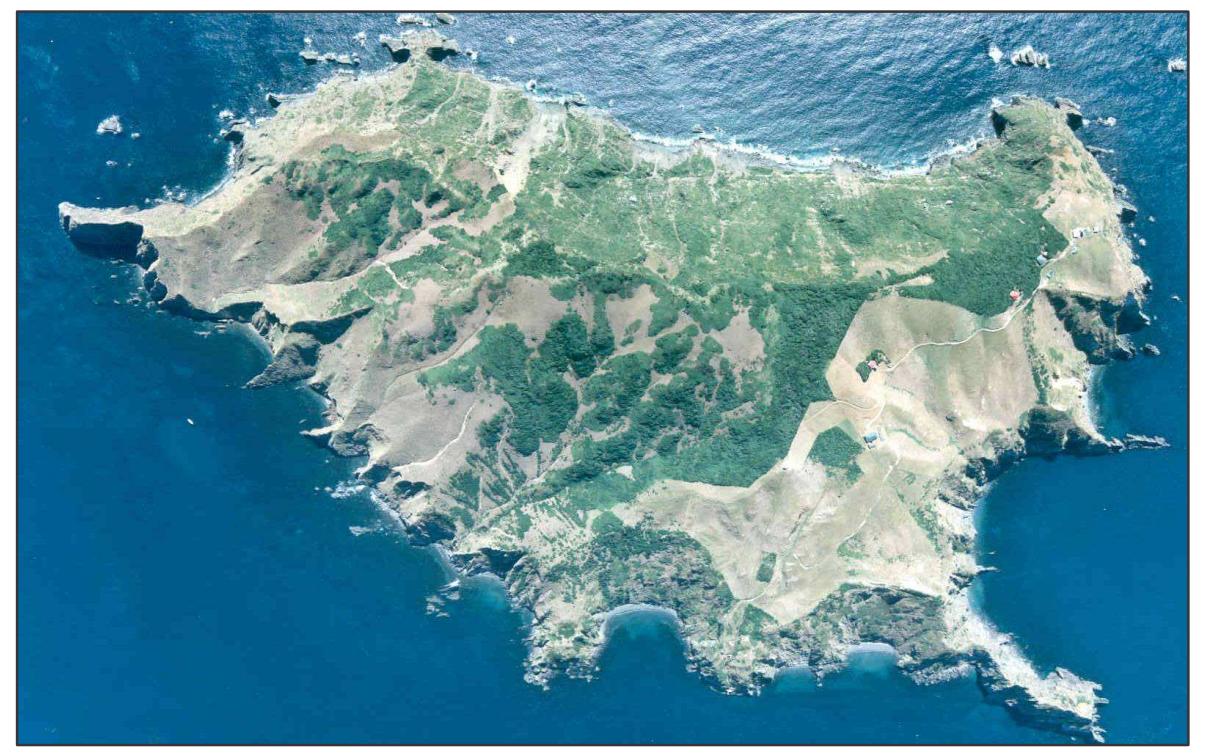

Figure 1.2 Stephens Island 2000.

\subsection{The skinks}

There are 34 extant species of endemic skink described in New Zealand. These skinks fall into two genera. The Oligosoma skinks, formerly in the genus Leiolopisma (Patterson and Daugherty 1995) have shallow pointed heads, bodies that are oval in cross section and long limbs and toes. They are more common in open habitats, active by day and sun bask. In comparison, the Cyclodina skinks have blunter heads, squarish bodies, short limbs and toes, prefer shaded habitats, and are nocturnal or crepuscular (Gill and Whitaker 2001). Of New Zealand's 34 skink species, 26 belong to Oligosoma and eight belong to Cyclodina (Gill and Whitaker 2001).

The New Zealand skinks are primarily carnivores, feeding on any arthropod that they can overpower (McCann 1956). Most species also eat soft fruits (Gill and Whitaker 2001). Stephens Island is home to four species of skink, Oligosoma lineoocellatum, $\mathrm{O}$. infrapunctatum, O. nigriplantare polychroma and O. zelandicum. 


\subsubsection{Oligosoma lineoocellatum.}

O. lineoocellatum has a brown, olive green or bright green back with distinctive pale green spots edged in black (Figure 1.3). The dorsolateral stripes are usually predominant and the belly can either be grey, pink or red and is unspotted. They can reach a size of $111 \mathrm{~mm}$ in snout vent length (SVL) (Gill and Whitaker 2001).

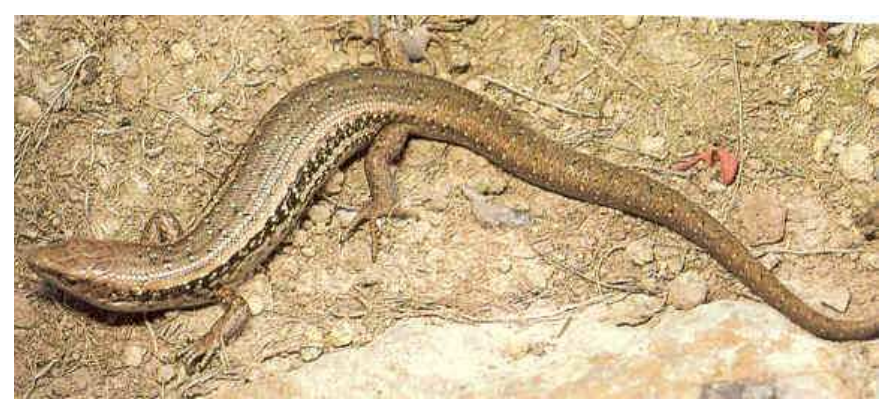

Figure 1.3 Oligosoma lineoocellatum. Picture from Gill and Whitaker (2001)

In the North Island O. lineoocellatum is restricted to eastern areas from Hawkes Bay to Wellington. In the South Island it is wide spread in eastern areas from Nelson, Marlborough Sounds to south Canterbury (Pickard and Towns 1988). Generally it is found in areas of open grass or scrubland areas from sea level to the subalpine zone (Gill and Whitaker, 2001). Its diet is mainly insectivorous, but includes other forms of ground dwelling animal life such as crustaceans. Oligosoma lineoocellatum young are born in late summer to early autumn (Robb 1986).

Some mainland populations seem to be in decline, for example in Wellington at Turakirae Head O. lineoocellatum was once common, but now is relatively rare (Whitaker 1982). Island populations have not shown similar declines, for example, the species is the most common reptile on Stephens Island (East et al. 1995) and is abundant on Matiu-Somes Island (Neil 1997). 


\subsubsection{Oligosoma infrapunctatum}

O. infrapunctatum is brown, striped and heavily speckled (Figure 1.4). The longitudinal stripes and bands have irregular speckled margins and undersurfaces are grey, yellowish or orange and heavily spotted (Gill and Whitaker 2001). The maximum reported SVL is 106mm (Gill and Whitaker 2001); however the individuals on Stephens Island are known to be larger, up to $240 \mathrm{~mm}$ total length (Robb 1986).

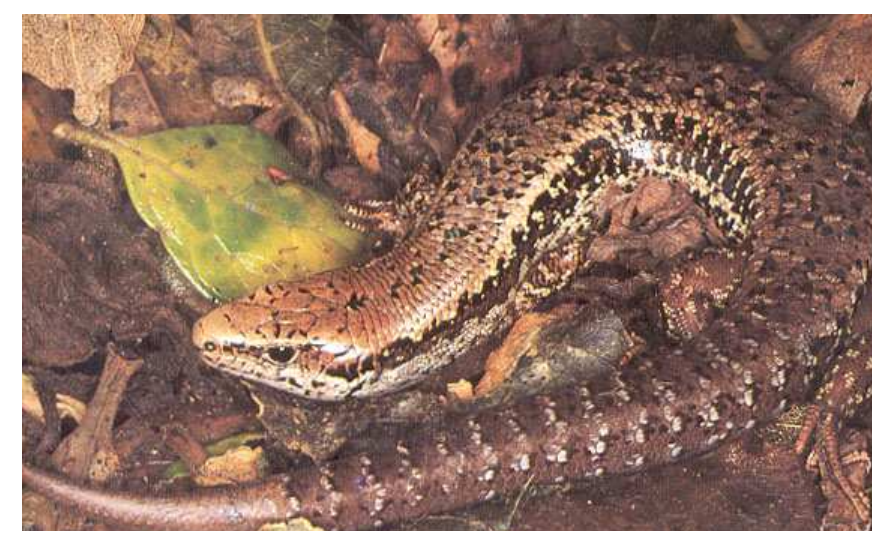

Figure 1.4 Oligosoma infrapunctatum. Picture from Gill and Whitaker (2001).

O. infrapunctatum has a widespread but patchy distribution. It is found on Whale Island, Bay of Plenty, Waikato, central North Island, Wairarapa, Stephens Island, Nelson, and northern Westland. O. infrapunctatum is generally found in open forest, scrubby areas, tussock country (Gill and Whitaker 2001) and in semi arid habitats (Neilson 2002). Of the four species of skink studied, $O$. infrapunctatum is the rarest.

\subsubsection{Oligosoma nigriplantare polychroma}

O. nigriplantare polychroma pattern varies in different regions. It is brown with prominent stripes and often speckled (Figure 1.5). The underside is grey or yellowish and usually unspotted. It reaches a maximum size of $77 \mathrm{~mm}$ SVL (Gill and Whitaker 2001). 


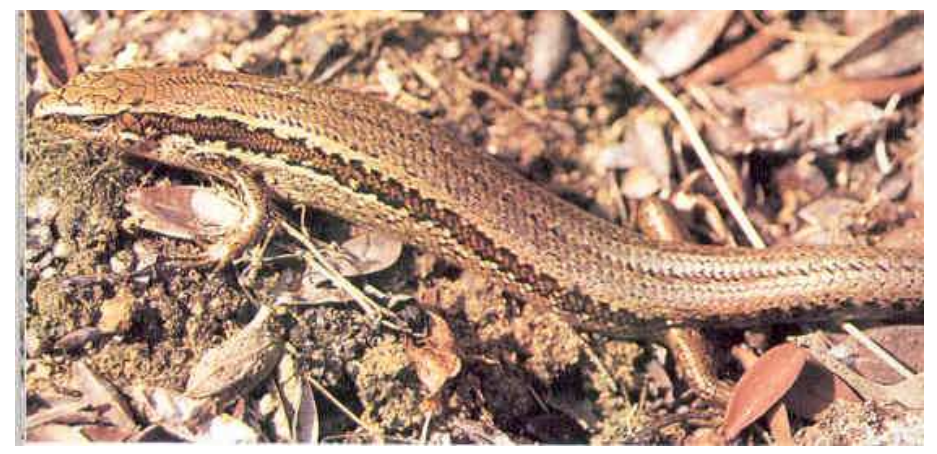

Figure 1.5. Oligosoma nigriplantare polychroma. Picture from Gill and Whitaker (2001).

It is found in Hawkes Bay, central to southern parts of the North Island, throughout the South Island and Stewart Island. It inhabits dry, open areas with low vegetation or debris such as logs or stones for cover. Oligosoma nigriplantare polychroma is common in coastal areas, shingle riverbeds, tussock grassland (Patterson 1992), farmland and urban areas, and may reach an altitude of 1700m (Gill and Whitaker 2001).

\subsubsection{Oligosoma zelandicum}

Oligosoma zelandicum has pale brown back and darker brown sides (Figure 1.6). Its belly is grey, straw coloured or suffused with red or orange and sometimes spotted (Gill and Whitaker 2001). It has a distinctive line down the foreleg (Hitchmough pers.comm, 2002), which distinguishes it from O. nigriplantare polychroma. It reaches a maximum SVL of 73mm (Gill and Whitaker 2001). 


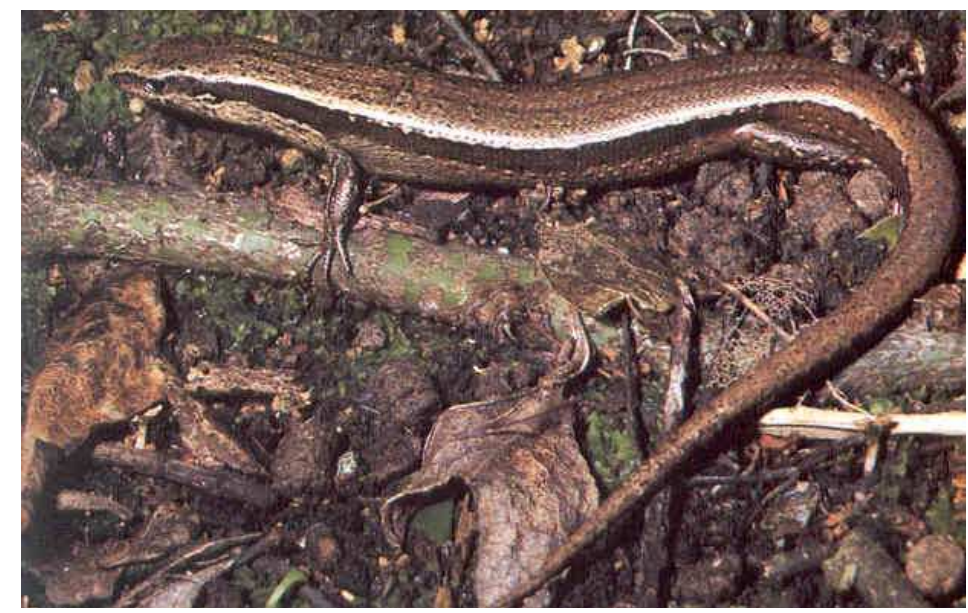

Figure 1.6. Oligosoma zelandicum. Pictures from Gill and Whitaker (2001).

In the North Island O. zelandicum is found west of the ranges from Taranaki to Wellington (Gill, 1976). In the South Island, it is found in the Marlborough Sounds, Nelson and north Westland. Its habitat is normally forest, shady and moist situations in farmland or gardens (Gill and Whitaker 2001). It is thought to be crepuscular (Rufaut and Clearwater 1998) or diurnal (Towns and Elliot 1996).

\subsection{Structure of thesis}

There are six chapters in this thesis. Chapter two focuses on capture rates and density estimates of skinks in the different habitat types and the effect of revegetation. Chapter three investigates the size, body condition and proportion of tail loss of skinks in the different habitat types. Both of these chapters are written for publication. The fourth chapter investigates the factors that may influence the distribution of skinks, including weather, predation and food abundances. Chapter five describes wild skink survival and is written as a short note for a journal. Following this is a general summary of thesis findings. 


\subsection{Permits}

All work in this thesis was done with the permission of the Department of Conservation (permit number LIZ2030) and the approval of the Victoria University of Wellington Animal Ethics Committee (permit number 2002R8). 


\title{
Chapter two
}

\section{Is Restoration Beneficial for the Skinks of Stephens Island / Takapourewa?}

\begin{abstract}
This research studies the impact that restoration has had on the distribution and/or abundance of skink species (Oligosoma lineoocellatum, O. nigriplantare polychroma, $O$. infrapunctatum and O. zelandicum) on Stephens Island. Oligosoma lineoocellatum dominated the capture rate $(74 \%$ of all individuals caught) in most habitats (replanted, tussock and pasture) except the forest. Results indicate that all species are abundant in the long grass and young trees of the replanted or tussock habitat. Forest areas are depauperate of skinks. Areas replanted 13 years ago from pasture, and are now scrub, support a greater diversity and higher abundance of skinks. This suggests that, for now, revegetation increases both the abundance and diversity of skinks. However, should revegetation create more forest habitat through plantations or plant growth, it is likely that the numbers of all four species of skink will decline.
\end{abstract}

\subsection{Introduction}

Approximately $37 \%$ of New Zealand reptile species survive only on offshore islands (Daugherty et al. 1994). Many mainland populations are becoming increasingly rare or endangered due to habitat destruction and predation by introduced mammals (Towns et al. 1990). Thus the protection and management of islands hosting indigenous species are a conservation priority (Daugherty et al. 1990). Management often involves ecological restoration of degraded or modified islands in order to restore indigenous biotic communities (Craig 1990). 
Restoration of a natural habitat is generally considered beneficial to native communities (Hobbs and Norton 1996). However, research predicts that the revegetation of Stephens Island could be detrimental to three of the four skink species, due to the selective loss of suitable open habitat (East et al. 1995). If correct, this prediction could have important implications for the future management of the island. This project aims to investigate the effect of 13 years of vegetative restoration on the abundance and distribution of skinks on Stephens Island, in light of this prediction.

Stephens Island is a Wildlife Sanctuary situated in the north-western Marlborough Sounds, administered by the New Zealand Department of Conservation and Ngati Koata (Figure 1.1). The island is known for its diverse and abundant reptile community (East et al. 1995), including the tuatara, Sphenodon punctatus, three species of gecko and the focus of this study, four skink species: Oligosoma infrapunctatum, $O$. lineoocellatum, $O$. nigriplantare polychroma, and O. zelandicum (East et al. 1995).

Prior to the mid $19^{\text {th }}$ century Stephens Island was covered in a podocarp/broadleaf forest (Walls 1988). Following the establishment of a lighthouse and farm on the island in 1894, approximately $80 \%$ of the original forest was converted into pasture (Brown 2000). In 1989, the control of Stephens Island was transferred from the Ministry of Transport to the Department of Conservation, and reforestation became a key conservation goal. Frequent high winds make natural restoration slow. Thus the planting of about 10,000 seedlings per year has assisted revegetation. By 1992, the island was a mixture of low forest, vineland, scrub, tall and short grass fields (East et al. 1995). Change in vegetation may, however, endanger the existing fauna (Simberloff 1990b). 
Lizards select microhabitats where they can optimise their thermoregulatory, antipredator and foraging requirements (Schlaepfer and Gavin 2001, Martin and Lopez 2002). Thus, each skink species may react differently to revegetation, due to differences in these requirements. The current distribution of vegetation on Stephens Island is patchy (Figure 1.2), and similar vegetation types are fragmented. Habitat fragmentation has been shown to negatively affect reptiles. Resulting impacts include decreased abundance and species richness (Sumner et al. 1999, Sarre 1998), genetic alterations (Stows et al. 2001, Cummingham and Moritz, 1998), fluctuating asymmetry (Sarre 1996), community compositional changes (Mac Nally and Brown 2001) and behavioural changes (Sarre 1998).

East et al. (1995) studied the relative distribution and abundance of the eight species of reptiles on Stephens Island in different successional stages of habitat. They predicted how revegetation would affect the four skink species based on these habitat preferences. This project will test the following predictions of East et al. (1995):

- The forest skink O. infrapunctatum will increase in numbers as forest area increases;

- The grassland species, O. lineoocellatum and O. nigriplantare polychroma will decline in numbers as the grasslands are revegetated;

- Abundance of O. zelandicum, found only in low numbers in the East et al. (1995) survey, will reduce in numbers if vineland converts to forest. 


\subsection{Methods}

Mark-recapture methods were used to estimate the distribution and abundance of the four species of skink over two data collections periods: $21^{\text {st }}$ November $-10^{\text {th }}$ December 2002 and $7^{\text {th }}-16^{\text {th }}$ March 2003. Trapping was done for a minimum of seven days as recommended by Moseby and Read (2001).

Pitfall traps were placed in eight grids. The grids were selected to include two of each habitat type; forest (grids A and B), tussock and vineland (grids D and E), pasture (grids F and $\mathrm{H}$ ) and replanted sites (grids $\mathrm{C}$ and $\mathrm{G}$ ) (Figure 2.1).

\section{Stephens Island/Takapourewa}

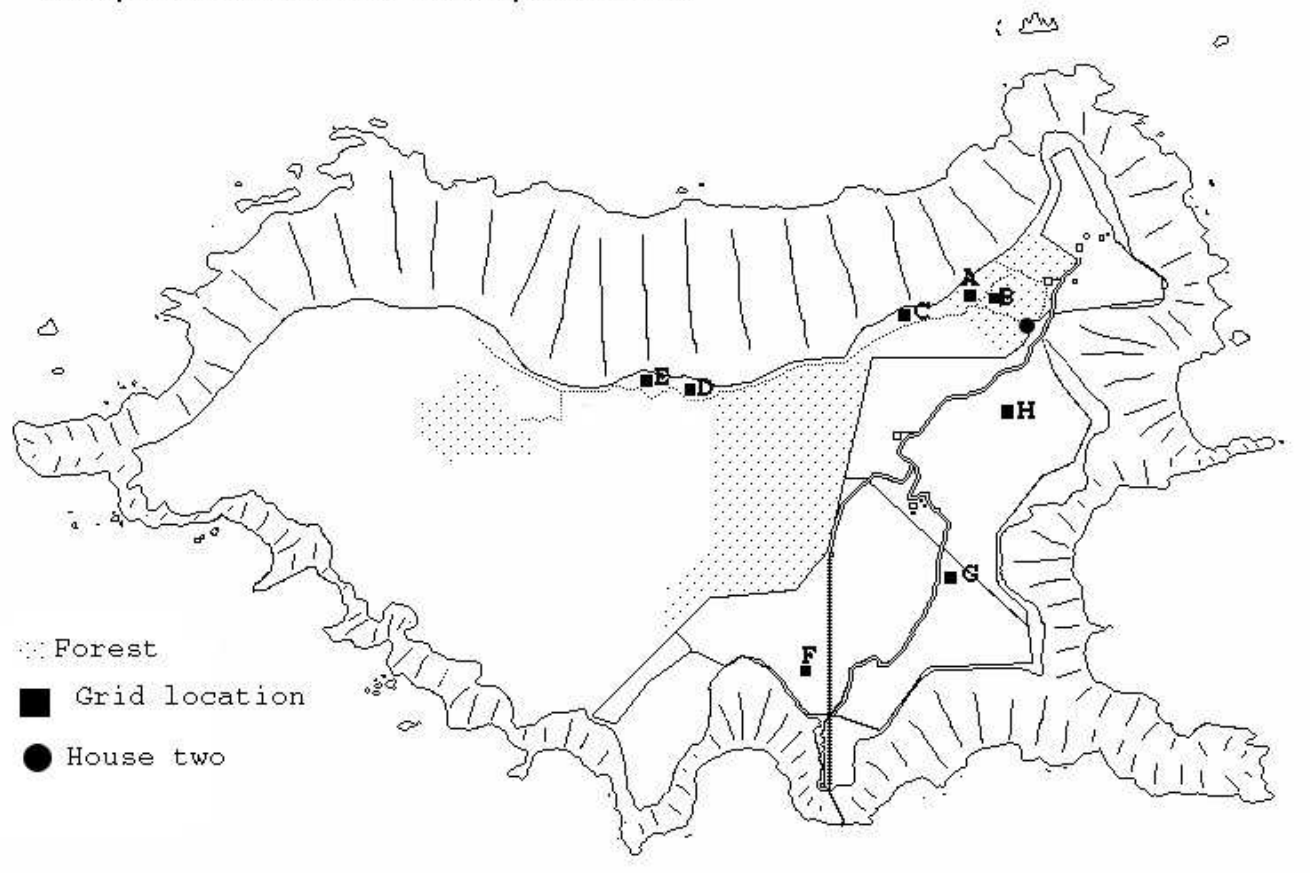

Figure 2.1: Location of grids in Stephens Island (Markwell 1997). 
Throughout the grids, similar aspect, bird activity and sheep disturbance were sought. Actual grid location was determined by a stratified design. Within strata each grid was selected randomly subject to a variety of influencing factors:

- Grids A (Figure 2.2), C (Figure 2.6), D (Figure 2.9), and E (Figure 2.10) were selected as they were the sites of the East et al. (1995) survey. Grid C has been planted three times, the first major plantation was in 1991, follow up plantings were done in 1998 and 2000.

- Grid B (Figure 2.3) was limited to Keepers Bush because of permit restrictions.

- Grids D and E (Figure 2.8) were situated closer to one another, as no other tussock sites were available. There was about $20 \mathrm{~m}$ between the two grids.

- Grid G (Figure 2.7) was selected because the plants were of similar size to those in grid C, affecting the level of sunlight and insect activity. Grid G was planted in 1997 (Knight pers.comm 2002).

- Grids F (Figure 2.4) and H (Figure 2.5) were located in pasture with similar aspect, and were fenced off from sheep. 


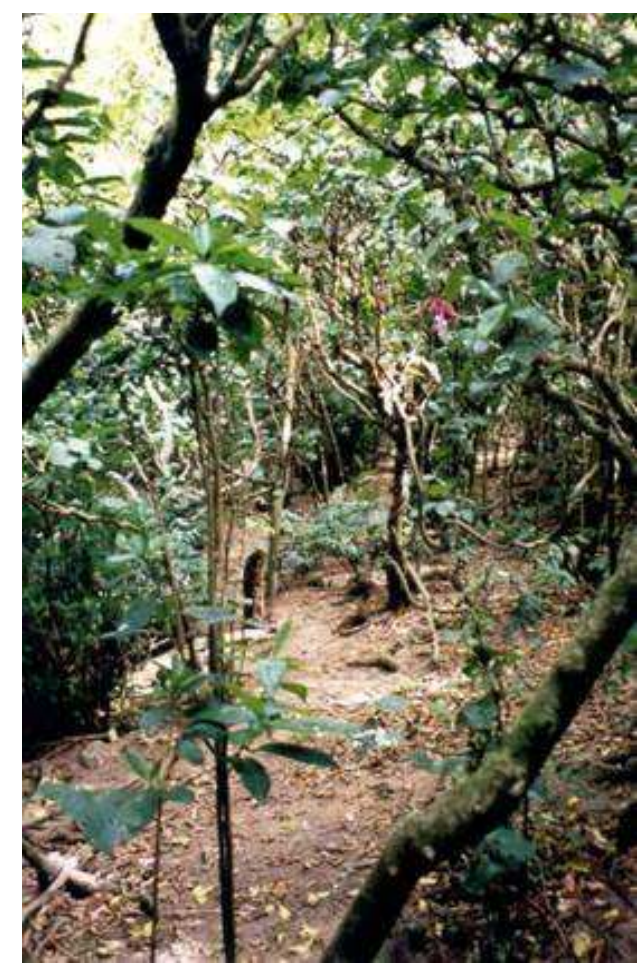

2.2 Forest Grid A

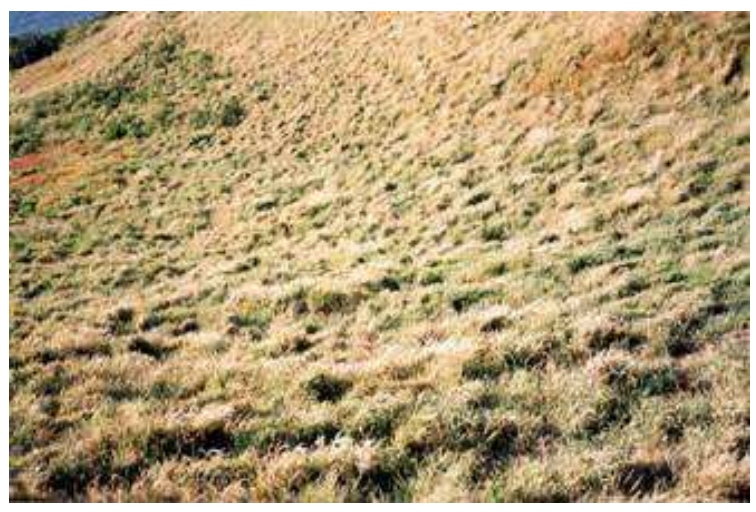

2.4 Pasture Grid F

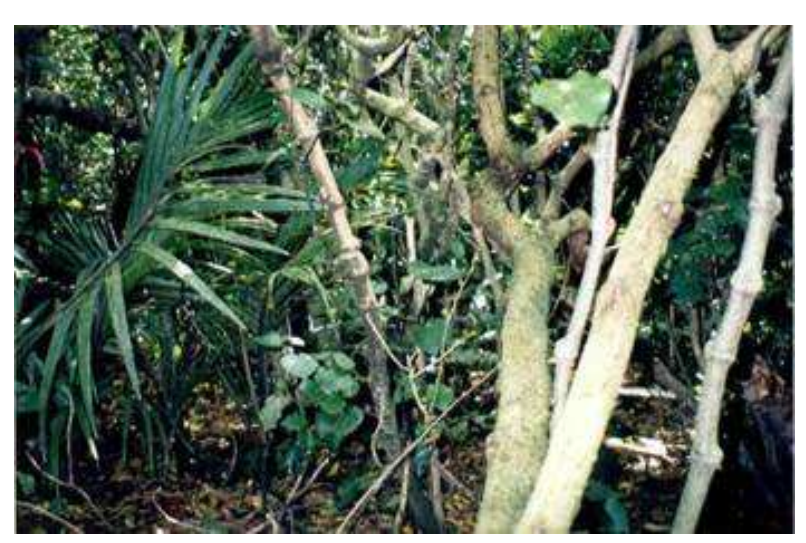

2.3 Forest Grid B

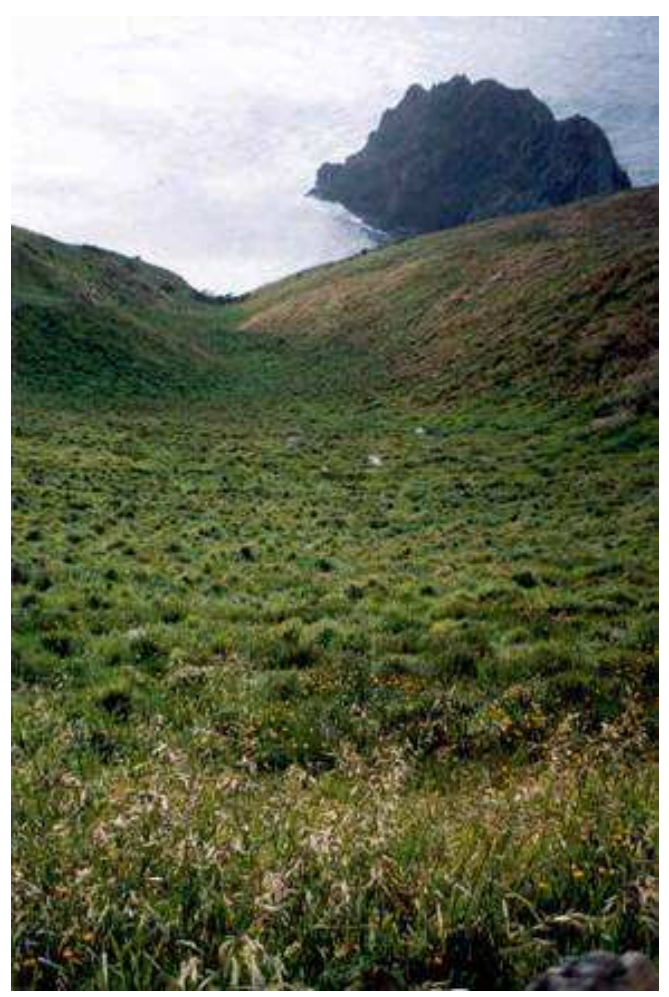

2.5 Pasture Grid H 


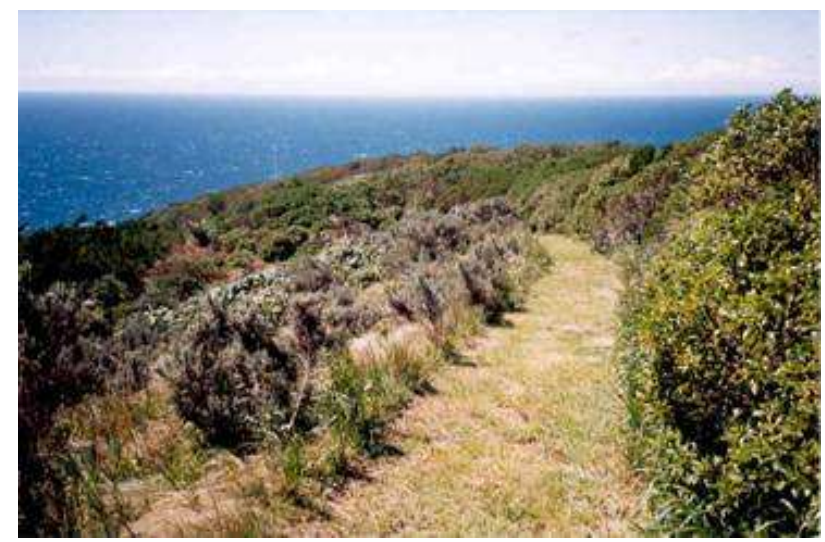

\subsection{Replanted Grid C}

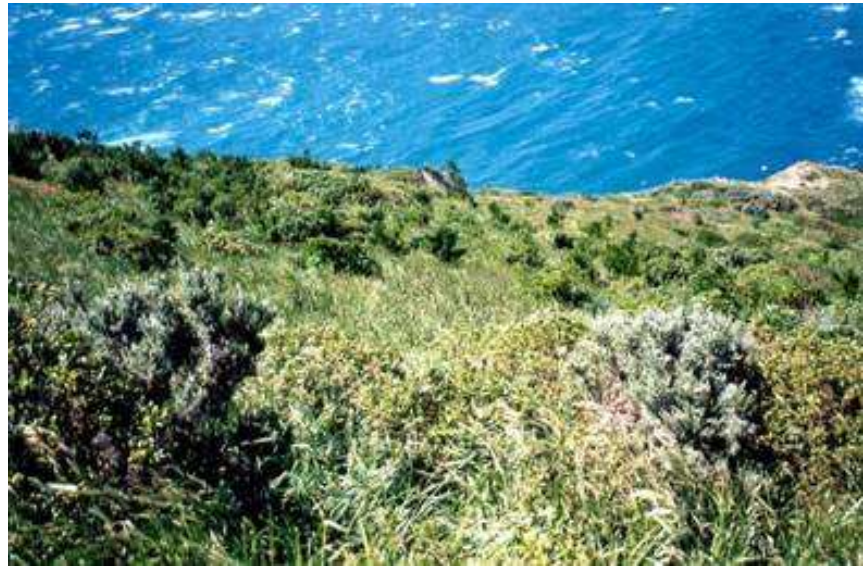

2.7 Replanted Grid G
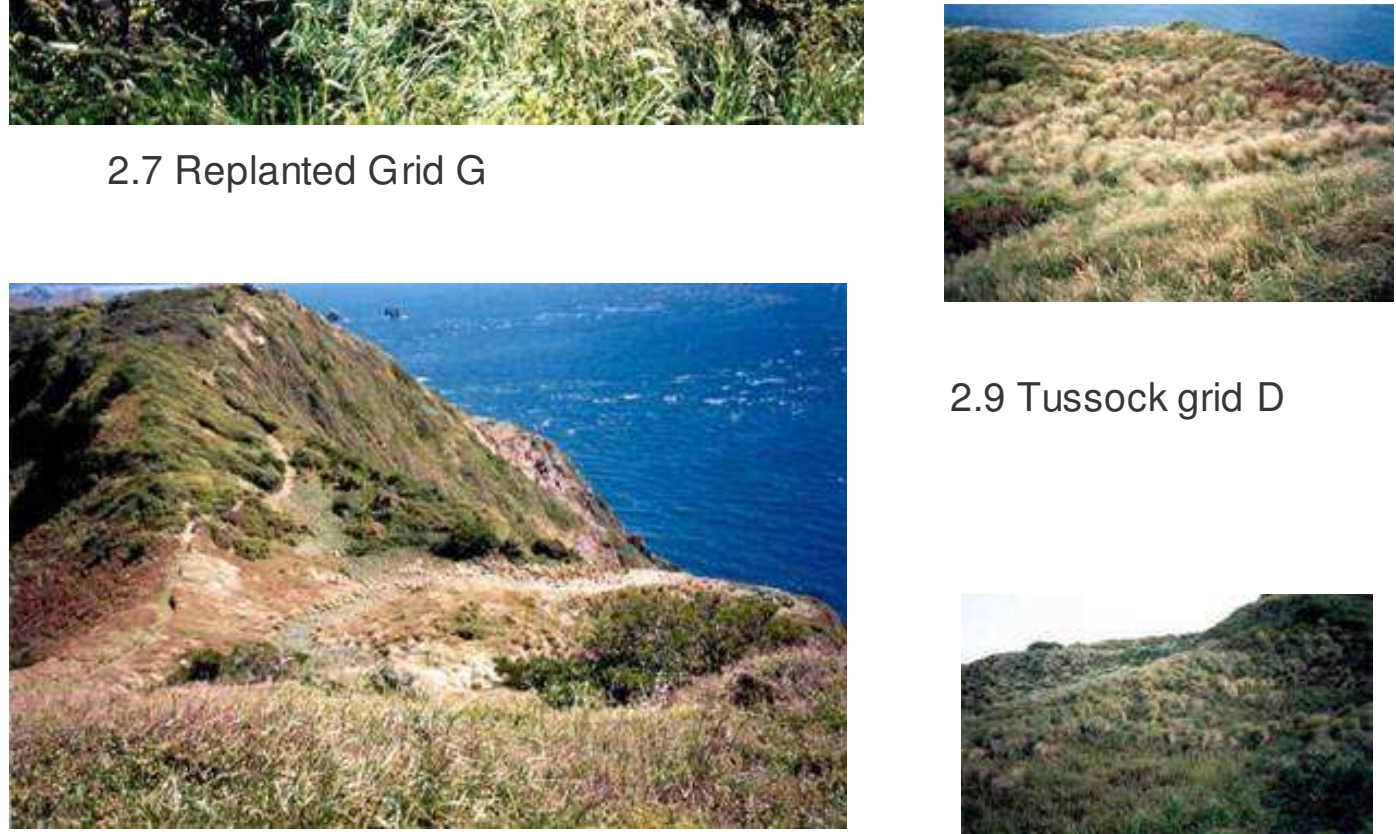

2.9 Tussock grid D

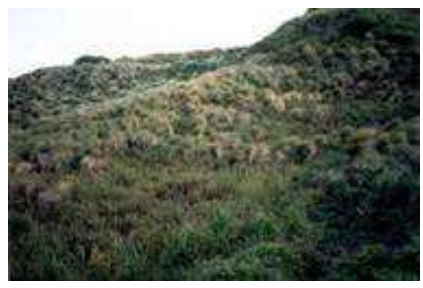

2.8. Over looking tussock grids $\mathrm{D}$ and $\mathrm{E}$

2.10 Tussock Grid E 


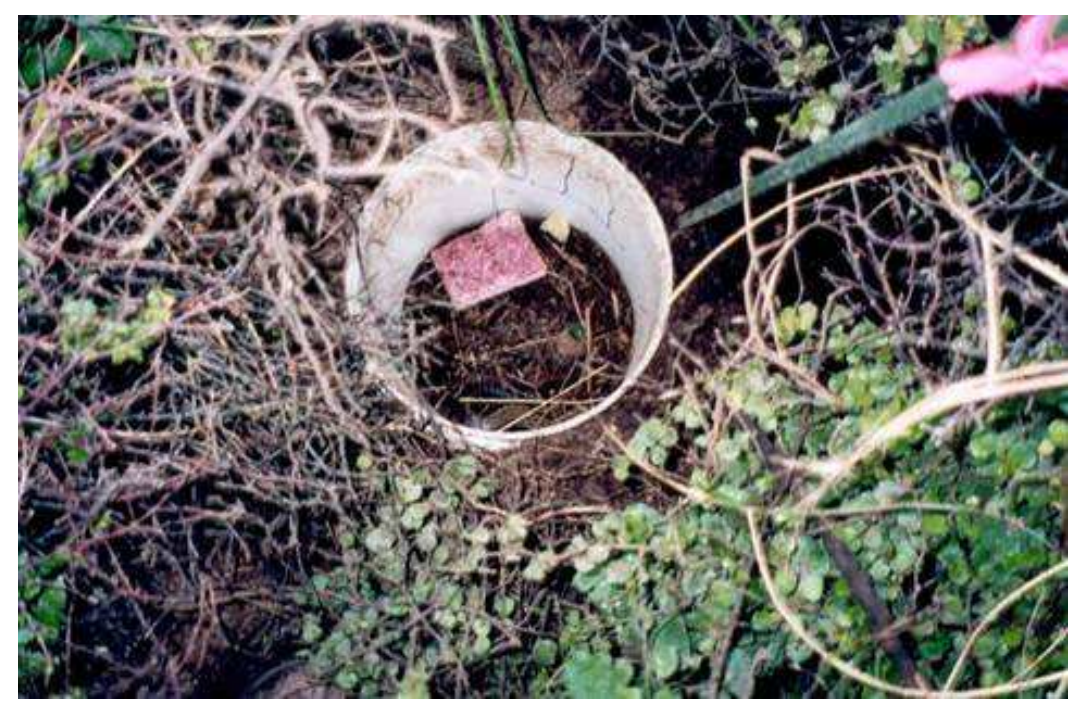

2.11 Pitfall trap

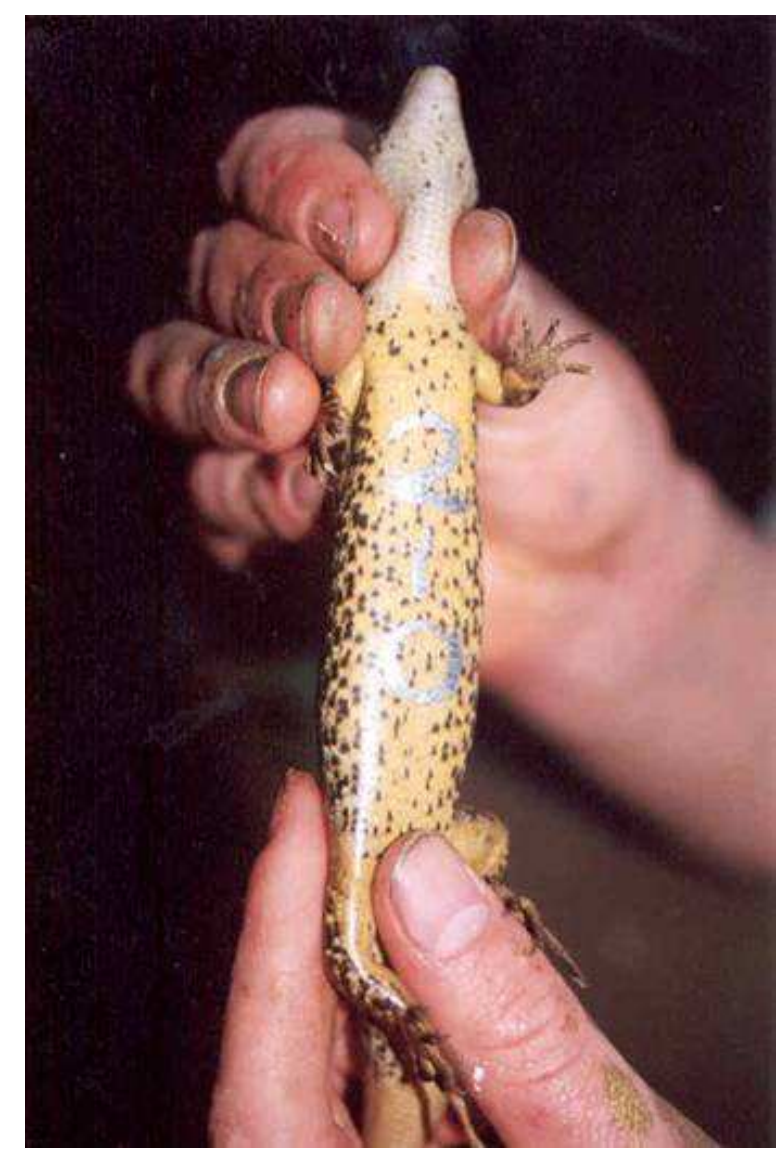

2.12. A marked skink O. infapunctatum 
Each grid consisted of 16 pitfalls in a four by four design, five metres apart (a total of 128 traps). Pitfalls were four litre plastic paint buckets, with four drainage holes approximately $6 \mathrm{~mm}$ in diameter, set flush to the ground surface similar to Phillpot (2000), Markwell and Daugherty (2002). The traps contained damp sponges (about $60 \times 40 \mathrm{~mm}$ ) that were watered daily, and a layer of dirt, grass or leaf litter about $3 \mathrm{~cm}$ high to prevent captured skinks from dehydrating and to provide cover from predators (Enge 2001) (Figure 2.11). On hot, dry days traps were watered again at midday. Traps did not have a shade cover as covers can reduce capture rates (Hobbs and James 1999). Each trap was baited with a $1 \mathrm{~cm}^{3}$ piece of tinned pear (Whitaker 1967). The traps were open from 0630 to $1400 \mathrm{hrs}$. Skinks were cleared from traps in a Latin square design, to balance the time difference between the closing of the first trap and last trap. For example, on day one, clearing started on grid $A$, following a circuit through to $\mathrm{H}$. On day two, clearing started at $\mathrm{B}$, and continued round the circuit to $\mathrm{H}$ with $\mathrm{A}$ cleared last and so on.

On first capture, each skink was given an individual number, written on its ventral surface using a silver metallic marker (Artline ${ }^{R}$ 990XF) (Figure 2.12). These marks stay on skinks for up to three weeks (Stephens unpubl. data). Snout-vent length (SVL), vent-tail length (to an accuracy of $1 \mathrm{~mm}$ ) and weight (with a $30 \mathrm{~g}$ Pesola balance accurate to $0.5 \mathrm{~g}$ ) were recorded before skinks were released outside the trap. Recaptured skinks were recorded.

The vegetation species composition, height and cover in the $0.89 \mathrm{~m}^{2}$ area around each pitfall trap were recorded. The number of bird burrows, slope and the aspect of each grid were also recorded. Weather details were recorded at the Stephens Island weather station and a data logger positioned outside House \#2 (Figure 2.1), as weather and temperature are known to influence the capture rate of skinks (Read and Moseby 2001). 


\subsubsection{Capture - recapture analysis}

Closed population models in MARK v2.1 (White 2001) were used to determine the population size of $O$. lineoocellatum. The capture rate of the other three species was too low for calculation. These models allow for different probabilities of capture with respect to location, time and behaviour (different heterogeneity and response to capture). The parameters used were capture probability $(p)$, recapture probability $(c)$ and population estimate $(M)$. The MARK package provides a population estimate with standard errors and $95 \%$ confidence intervals.

The validity of all models relies on the following set of assumptions (White et al. 1982):

1. The population is closed. As the data collection was done over a relatively short period of time, it limited any potential gains or losses to an insignificant amount.

2. No identifying marks are lost.

3. Marking does not change the catchability of the animal.

4. Marks are not misread on subsequent captures.

5. For any given location and trapping occasion, each individual has an equal probability of first capture $(p)$ or recapture $(c)$.

The starting model allows four types of variation:

1. Time $\left(\mathrm{M}_{\mathrm{T}}\right)$. This model allows for changes in capture rates over time, such as those due to changes in weather conditions.

2. Behaviour $\left(\mathrm{M}_{\mathrm{B}}\right)$. This model accounts for the animals' response to capture, for example, if an animal was trap happy or shy, the capture rate would alter through the duration of the experiment.

3. Location ( $\mathrm{M}_{\mathrm{G}}$ or $\left.\mathrm{M}_{\mathrm{Hab}}\right)$. This model allowed for variation in capture probability due to grid location or habitat type. 
4. Number $\left(\mathrm{M}_{\mathrm{N}}\right)$. Number (or population) is used as a surrogate of density and can be used to determine where the capture probability is influenced by habitat type.

The most appropriate model for the data was selected using Akaike Information Criteria (AIC) (Burnham and Anderson 1998, Burnham et al. 1995). AIC selects the most parsimonious model (fewest parameters) by determining those parameters that have the largest impact on the data. It examines the variation explained by each model compared with the variation in the data set trading off bias and precision (Burnham and Anderson 1998). Relative AIC values are used to rank models, and the model with the lowest AIC is used to provide population estimates for each grid or habitat type.

$\mathrm{AIC}$ is defined as

$A I C=$ residual deviance $(R D)+2 \times$ number of parameters.

Density estimates for $O$. lineoocellatum were determined using population estimates from the MARK analyses. The area of the grids was calculated by adding to the outside of the grid a boundary strip equal to half the average distance that skinks moved within the grids. Perimeter traps were assumed to be the centre of the skinks' home range; therefore half the average distance was added as the boundary strip on all four sides of the grid (Phillpot 2000).

\subsubsection{Reanalyses of East et al. (1995) data}

The grids where O. lineoocellatum were captured in the East et al. (1995) study were reanalysed using the Jolly Seber open population model. The skinks in this study were permanently marked. This has the same assumptions as closed capture models but also incorporates birth, death and migration of skinks. This model assumes that animals have 
identical survival rates. Chi squared tests and AIC statistics were used to select the model used for analysis.

\subsubsection{Trap occupancy analysis}

For trap occupancy analysis, captures of all species were pooled per trap. The programme R (R Development Core Team 2003) was used to determine if the number of captures per trap per day differed significantly in each habitat type for each skink species. Generalized linear models with Poisson distribution were used to determine the influences on the capture rate, such as species of skink, habitat or grid, weather, day or trap. Where multiple testing was done, a Bonferroni adjustment was made. This adjusts the individual false positive error rate to allow for a fixed experiment-wise error rate (probability of at least one individual error). For an overall 0.05 significance level, the $p$ value for an individual test must be less than $0.05 / \mathrm{k}$, where $\mathrm{k}$ equals the number of tests. This analysis assumes equal capture probability among species, an assumption that may be incorrect.

Weather was divided into three arbitrary types:

1. Days when it was fine, with little wind or cloud cover.

2. Days when there was a strong or constant south-easterly wind blowing.

3. Days when it was wet, due to constant rain throughout the day or fog.

\subsection{Results}

\subsubsection{Grid characteristics}

Forest grid A is dominated by mahoe (Melicytus ramiflorus), taupata (Coprosma repens), ngaio (Myoporum laetum) and kawakawa (Macropiper excelum). Forest grid B is 
dominated by mahoe. Silver tussock (Poa cita) is the dominant plant in both tussock grids D and E, Muehlenbeckia australis borders the two grids and there are areas of grass inside the grids. Fairy prions (Pachyptila turtur) burrow these grids. There are two grass species in the paddocks. The dominant grass is Festuca arundinacea $70 \%$ in grid $\mathrm{F}$ and $65 \%$ in grid $\mathrm{H})$. The other grass is Loilum perenne, a perennial ryegrass. Long grass and the major replanted species of taupata, tauhinau (Cassinia leptophylla) and ngaio dominate grid $\mathrm{C}$ and $\mathrm{G}$ (Appendix $\mathrm{A})$.

\subsubsection{Skink capture summary}

In December, over the ten days sampled, 651 individual skinks were captured (1248 total including recaptures). During March, over the seven-day period sampled, 715 individual skinks were captured, (1472 total captures) (Table 2.1).

Table 2.1: Total number of skink individuals caught (percentage of total)

\begin{tabular}{llllll}
\hline Trip & O. lineoocellatum & O. infrapunctatum & $\begin{array}{l}\text { O. nigriplantare } \\
\text { polychroma }\end{array}$ & O. zelandicum & Total \\
\hline December & $501(77 \%)$ & $40(6 \%)$ & $96(15 \%)$ & $14(2 \%)$ & 651 \\
March & $499(70 \%)$ & $33(5 \%)$ & $164(23 \%)$ & $18(2 \%)$ & 714 \\
Totals & 1000 & 73 & 260 & 32 & 1365 \\
\hline
\end{tabular}

Oligosoma lineoocellatum was caught approximately three times more often than the other species combined, at a rate of almost one skink per trap each day (Table 2.2). Oligosoma nigriplantare polychroma had the second highest capture rate, followed by $O$. infrapunctatum. Capture rate of $O$. zelandicum was lowest of the four species, with only two skinks caught per day over the 128 traps (Table 2.2). More skinks were caught in 
March, with an average of 0.407 animals per trap per day (s.e. 1.049), than in December, with an average of 0.244 (s.e. 1.029).

Table 2.2 Number of skinks caught per trap/day for the four species over the two trapping periods.

\begin{tabular}{lll}
\hline Skink species & Average per trap/day & Standard error (s.e.) \\
\hline O. lineoocellatum & 0.95 & 1.13 \\
O. nigriplantare polychroma & 0.22 & 1.14 \\
O. infrapunctatum & 0.06 & 1.09 \\
O. zelandicum & 0.02 & 1.24 \\
\hline
\end{tabular}

\subsubsection{Habitat selection}

\section{Trap occupancy}

AIC modelling indicated that species, trap and day were the most influential factors on the numbers in each trap. The individual trap influenced the occupancy rate more than the grids or habitat type. Trip (December or March), weather and habitat had a minor effect on trap occupancy (Table 2.3). Comparisons of skink capture rate among individual traps could not be calculated, due to the large number of parameters.

Fine days had the highest mean trap occupancy rate with 0.379 skinks per trap (s.e. 1.02), followed by windy days with 0.167 (s.e. 1.087). Wet days had the lowest numbers of animal captures with an average of 0.005 (s.e. 1.52). 
Table 2.3 Trap occupancy AIC values determining which factors influence the numbers of skinks per trap (models in bold are those used in analyses).

\begin{tabular}{llll}
\hline Model & AIC value & Relative AIC & Parameters \\
\hline Null Model & 14352.0 & 7135.4 & 0 \\
Trip & 14177.6 & 6961.0 & 2 \\
Day & 13457.0 & 6240.4 & 17 \\
Weather & 13600.0 & 6383.4 & 3 \\
Habitat & 11992.0 & 4775.4 & 4 \\
Grid & 11882.1 & 4665.5 & 8 \\
Trap & 11675.7 & 4459.1 & 128 \\
Species & 10698.0 & 3481.4 & 4 \\
Species + habitat & $\mathbf{8 3 3 8 . 2}$ & $\mathbf{1 1 2 1 . 7}$ & $\mathbf{8}$ \\
Species + grid & $\mathbf{8 2 2 8 . 3}$ & $\mathbf{1 0 1 1 . 7}$ & $\mathbf{1 2}$ \\
Species + trap & 8021.6 & 985.0 & 136 \\
Species + trap +day & 7216.6 & 0 & 153 \\
\hline
\end{tabular}

Significantly more $O$. infrapunctatum were caught in the replanted grids than in the tussock and they were the only skinks caught in the forest. Trap occupancy of $O$. lineoocellatum was also significantly higher in the replanted habitat than the tussock and pasture habitats. Moreover its capture rate was higher than the other skinks in all habitat types except forest. Oligosoma nigriplantare polychroma, although significantly more prevalent in the tussock grids, was also found in the replanted grids and to a lesser extent, the pasture grids (with fewer individuals in pasture grid F during March). Oligosoma zelandicum was almost solely found in the tussock grids, in very low numbers. However, the capture rate was significantly higher in the tussock than the replanted habitat where only three individuals were caught (Figure 2.13 and Table 2.4). 


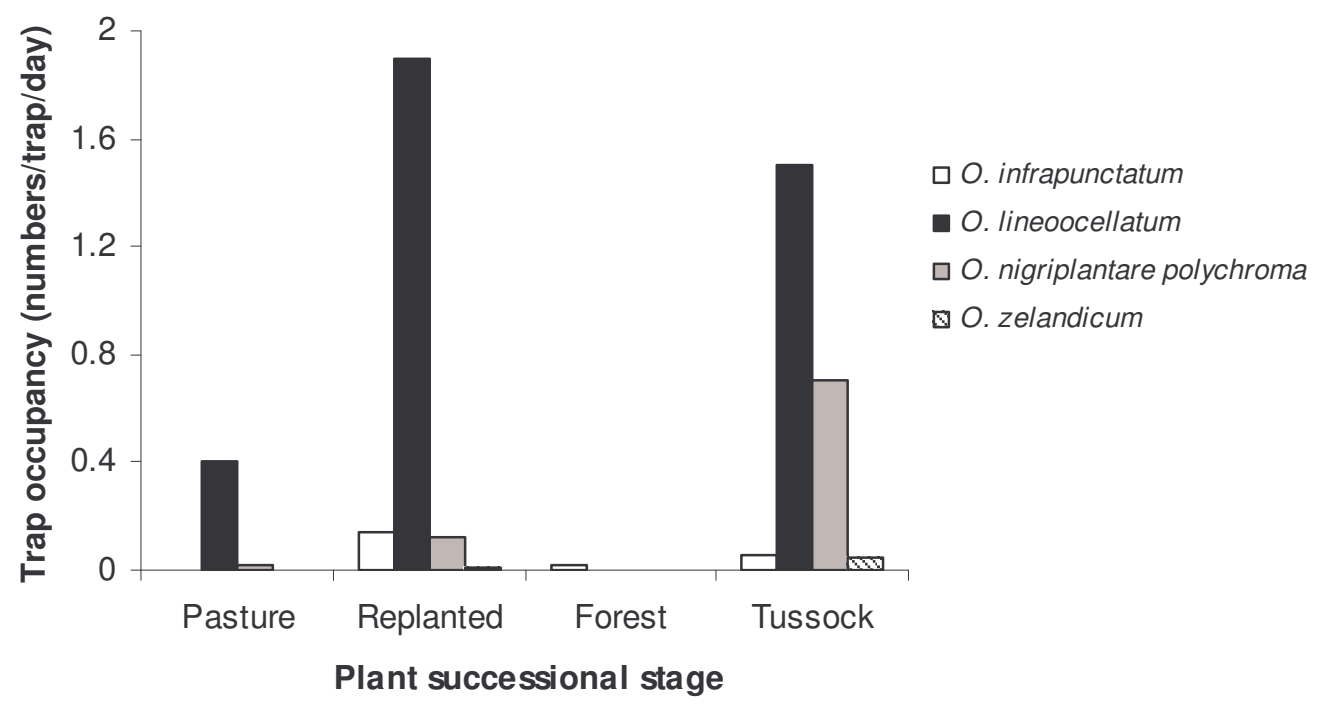

Figure 2.13 Trap occupancy rates of the four skink species in different habitats

Table 2.4 Comparison of capture rates of skinks in different habitats

Bon is the Bonferroni adjustment (the $p$ value has to be under this value to be significant), $R$ represents replanted, $\mathrm{P}=$ pasture, $\mathrm{T}=$ tussock and $\mathrm{F}=$ forest habitat, "significance difference in capture rates.

\begin{tabular}{llllllll}
\hline Species & $\mathrm{F}-\mathrm{P}$ & $\mathrm{F}-\mathrm{R}$ & $\mathrm{F}-\mathrm{T}$ & $\mathrm{P}-\mathrm{R}$ & $\mathrm{P}-\mathrm{T}$ & $\mathrm{R}-\mathrm{T}$ & $\mathrm{Bon}$ \\
\hline O. infrapunctatum & 0.491 & $0^{*}$ & 0.017 & 0.194 & 0.448 & $0^{*}$ & 0.008 \\
O. lineoocellatum & 0.159 & 0.015 & 0.017 & $0^{*}$ & $0^{*}$ & $0^{*}$ & 0.008 \\
O.n. polychroma & 0.508 & 0.196 & 0.027 & $0^{*}$ & $0^{*}$ & $0^{*}$ & 0.01 \\
O. zelandicum & $\mathrm{NA}$ & 0.561 & 0.443 & 0.561 & 0.443 & $0^{*}$ & 0.017 \\
\hline
\end{tabular}

\section{Population and density estimates for 0 . lineoocellatum from MARK.}

Capture and recapture numbers were too low to estimate the density of $O$.

infrapunctatum, O. nigriplantare polychroma and O. zelandicum. Forest grids A and B have not been included in the population estimates as no $O$. lineoocellatum were caught in these grids. Two models best represent the data. In March the best model $\{p(t \times$ hab), $\mathrm{N}(\mathrm{g})$ \} includes time and habitat as factors influencing the probability of capture and 
abundance by grid. For the December collection period, a second model $\{p(t \times$ hab), $\mathrm{N}($ hab) $\}$ allows for abundance to vary by habitat type. In December, AIC results indicate that habitat type and time are much stronger influences on the probability of capture than the behaviour of skinks. Behaviour is not identified as a significant factor describing the data in December. In March, behaviour influenced the capture probability, but MARK was unable to fit the model (Table 2.5).

Table 2.5 AIC values for models to estimate $O$. lineoocellatum population The model may include, $t=$ time, $g=$ the six grids, hab = three habitat types, $b=$ behaviour of the skinks, and $\mathrm{N}=$ the number in the grid, $\mathrm{x}=$ interaction between factors. $\mathrm{N}(1)$ indicates a constant abundance over all six grids. For example $\{p(t \times h a b), N(h a b)\}$ indicates the probability of capture is influenced by time and habitat, and the number is influenced by habitat. Models in bold indicate those used in analyses.

\begin{tabular}{|c|c|c|c|c|}
\hline & December & & March & \\
\hline Model & Relative AIC & Parameters & Relative AIC & Parameters \\
\hline$\{p(t \times$ hab), $N(h a b)\}$ & 0 & 27 & 3.04 & 24 \\
\hline$\{p(t \times h a b), N(g)\}$ & 1 & 30 & 0 & 27 \\
\hline$\{p(t \times g), N(g)\}$ & 12.57 & 54 & 2.09 & 48 \\
\hline$\{p(t+b) \times g), N(g)\}$ & 15.79 & 90 & NA & NA \\
\hline$\{p(t \times$ hab $), N(1)\}$ & 16.03 & 25 & 18.20 & 22 \\
\hline$\{p(t), N(g)\}$ & 75.41 & 14 & 101.07 & 12 \\
\hline$\{p(h a b), N(g)\}$ & 145.79 & 9 & 60.67 & 9 \\
\hline$\{p(g), N(g)\}$ & 46.7 & 15 & 60.60 & 12 \\
\hline
\end{tabular}

The population of $O$. lineoocellatum in both December and March was highest in the replanted habitat, followed by the tussock and lowest in the pasture grids. The low capture and recapture rates in the pasture grid result in large standard errors. In March, 
only two skinks were recaptured in the pasture, and approximately ten recaptures are needed to make an accurate population estimate (Table 2.6). The population of $O$. lineoocellatum in both the December and March trips $\{\mathrm{p}(\mathrm{t} x \mathrm{hab}), \mathrm{N}(\mathrm{g})\}$ was highest in the pasture grid $\mathrm{H}$ and lowest in pasture grid $\mathrm{F}$, although this difference was not significant (Table 2.7).

In both December and March, the majority of recaptured animals ( $70 \%)$ were recaught in the same trap they were originally caught in. Some made it to a neighbouring trap. Very few skinks found traps 10 to $14 \mathrm{~m}$ away (Table 2.8). More animals were caught in traps other than the ones in which they were originally caught in March than in December.

Table 2.6 MARK population estimates of $O$. lineoocellatum by habitat type from model $\{p(t x$ hab), $\mathrm{N}($ hab)\}, habitat type (grids)

\begin{tabular}{lllll}
\hline & December & & March \\
& Estimate & Std error & Estimate & Std error \\
Replanted (CG) & 127 & 2.35 & 169 & 2.50 \\
Tussock (DE) & 115 & 3.54 & 113 & 2.72 \\
Pasture (FH) & 83 & 11.12 & 95 & 34.59 \\
\hline
\end{tabular}


Table 2.7 MARK population estimates of $O$. lineoocellatum by grid using model $\{p(t) x$ hab), $\mathrm{N}(\mathrm{g})\}$.

\begin{tabular}{lrrrr}
\hline & December & \multicolumn{3}{c}{ March } \\
\hline & Estimate & Std error & Estimate & Std error \\
Replanted C & 128 & 3.50 & 172 & 3.94 \\
Replanted G & 85 & 2.78 & 97 & 2.85 \\
Tussock D & 115 & 4.73 & 114 & 3.83 \\
Tussock E & 101 & 4.35 & 89 & 3.31 \\
Pasture F & 72 & 10.48 & 74 & 28.17 \\
Pasture H & 132 & 16.57 & 173 & 59.79 \\
\hline
\end{tabular}

Table 2.8 Location of 0 . lineoocellatum recaptures with respect to the original trap caught, percentage of total (number)

\begin{tabular}{lllll}
\hline & Original trap & $5-7 \mathrm{~m}$ & $10-14 \mathrm{~m}$ & $15-20 \mathrm{~m}$ \\
\hline December & $73.9 \%(181)$ & $21.2 \%(52)$ & $4.1 \%(10)$ & $0.8 \%(2)$ \\
March & $66.4 \%(160)$ & $30.7 \%(74)$ & $2.1 \%(5)$ & $0.8 \%(2)$ \\
\hline
\end{tabular}

In December, movement between traps in the pasture was on average $6.7 \mathrm{~m}$ (grid $\mathrm{F} 8.5 \mathrm{~m}$ and $\mathrm{H} 6.2 \mathrm{~m}$ ) which was significantly higher than the $5.5 \mathrm{~m}$ in the tussock grids ( $T$ test, $\mathrm{p}=$ 0.05 ) (grid D 5.3m and E 5.9m) and the 5.5m in the replanted grids (grid C 5.2m and grid G 5.9m) (T test $p=0.03)$. There was no significant difference between the replanted and the tussock girds ( $T$ test $p=0.7$ ). In March there was an average movement of $6 \mathrm{~m}$ in the tussock grids (5.9m in grid $D$ and $6 \mathrm{~m}$ in grid $E), 6.2 \mathrm{~m}$ in the replanted areas $(6.1 \mathrm{~m}$ in grid $\mathrm{C}$ and $6.3 \mathrm{~m}$ in grid $\mathrm{G}$ ) and $7 \mathrm{~m}$ in the pasture (5.8m in grid $\mathrm{F}$ and $8.2 \mathrm{~m}$ in grid $\mathrm{H}$ ). 
The adjusted grid area includes animals moving into the grid from outside the grid perimeter. It was greater in March than December (Table 2.9 and 2.10). The replanted grids had the lowest adjusted area, followed by the tussock and the pasture grids (Table 2.9).

Table 2.9 Adjusted habitat area in $\mathrm{m}^{2}$

\begin{tabular}{llll}
\hline & Replanted & Tussock & Pasture \\
\hline December & 420 & 424 & 471 \\
March & 449 & 441 & 484 \\
\hline
\end{tabular}

Table 2.10 Adjusted grid area in $\mathrm{m}^{2}$

\begin{tabular}{lllllll}
\hline & Replant C & Replant G & Tussock D & Tussock E & Pasture F & Pasture H \\
\hline December & 408 & 437 & 412 & 437 & 552 & 449 \\
March & 445 & 454 & 437 & 441 & 433 & 538 \\
\hline
\end{tabular}

The densities (numbers per hectare) of $O$. lineoocellatum were different in similar habitat types (with the exception of the tussock grids). The densities were higher in replanted grid $\mathrm{C}$ than $\mathrm{G}$ and pasture grid $\mathrm{H}$ compared to $\mathrm{F}$ (Table 2.11). By habitat, the density of $O$. lineoocellatum was higher in the replanted (density of 3020/ha in December and 3769/ha in March) areas when compare to the tussock (2690/ha and 2560/ha) or pasture (1740/ha and 1963/ha) habitats (Figure 2.14 and 2.15). Densities in the pasture habitat had very wide confidence intervals (particularly in March), due to low numbers of captures and recaptures (Figures 2.14 and 2.15). 
Table 2.11 MARK estimates of the density of $O$. lineoocellatum per hectare in December and March from model $\{\mathrm{p}(\mathrm{t} \times \mathrm{hab}), \mathrm{N}(\mathrm{g})\}$ (probability of capture influenced by time and habitat, density by grid).

\begin{tabular}{lllll}
\hline & December & \multicolumn{3}{l}{ March } \\
& Density & $95 \% \mathrm{Cl}$ & Density & $95 \% \mathrm{Cl}$ \\
& $(\# /$ /hectare $)$ & & $(\# /$ hectare $)$ & \\
Replanted C & 3160 & $3046-3401$ & 3865 & $3752-4112$ \\
Replanted G & 1964 & $1885-2155$ & 2240 & $2170-2425$ \\
Tussock D & 2804 & $2640-3108$ & 2511 & $2401-2731$ \\
Tussock E & 2303 & $2164-2571$ & 2036 & $1945-2243$ \\
Pasture F & 1314 & $1043-1815$ & 1678 & $907-3628$ \\
Pasture H & 2956 & $2406-3893$ & 3125 & $1840-6500$ \\
\hline
\end{tabular}

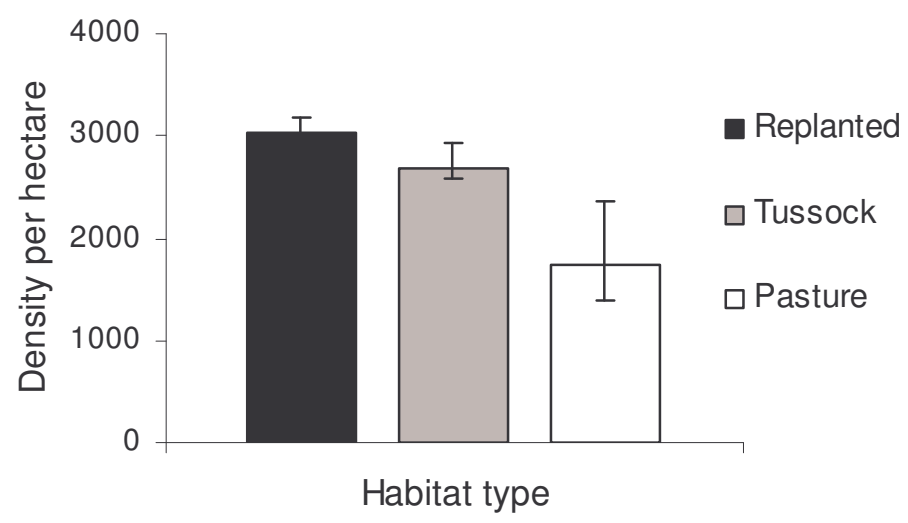

Figure 2.14 Density of $O$. lineoocellatum from model $\{p(t x$ hab), $N(h a b)\}$ (probability of capture influenced by time and habitat, density by habitat) in December. 


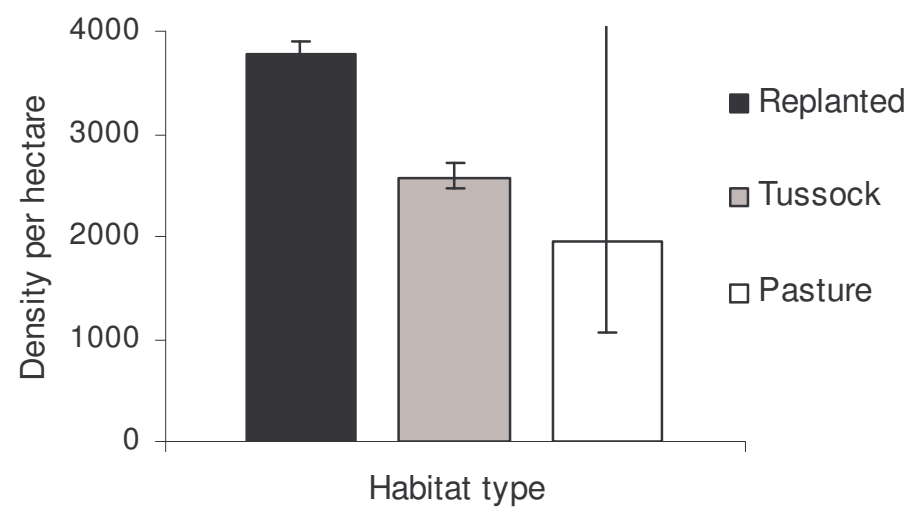

Figure 2.15 Density of $O$. lineoocellatum from model $\{p(t \times h a b), N(h a b)\} \quad$ (probability of capture influenced by time and habitat, density habitat) in March.

\subsubsection{Density of $O$. lineoocellatum from the East et al. (1995) survey}

In the pasture grid (now replanted grid C), the East et al. (1995) survey caught 76 different skinks (103 total captures) while in the tussock grid (now grids D and E) they caught 284 individual skinks with 654 captures. The reanalysis of their data found that the two main parameters were survivorship and probability of capture influenced by time and grid. AIC statistics indicate capture rates varied both through time and between the two habitats (Table 2.12).

Chi square test comparing models $\{\mathrm{phi}(\mathrm{hab}), \mathrm{p}(\mathrm{t} \times \mathrm{hab})\}$ (survivorship by habitat and probability of capture by time and habitat) and $\{$ phi(.) $p(t \times$ hab)\} (survivorship constant and probability of capture by time and habitat), indicated that there was a significant difference between the models $($ Chi $s q=3.89, d f=1, p=0.0486)$. Burnham and Anderson (1998) state that if the AIC difference is less than 2 (as it is in this case) the difference is insignificant. Therefore habitat had little influence on survivorship. 
Table 2.12. Relative AIC values for $O$. lineoocellatum to determine influences on the survival rate and the probability of capture. Model in bold used for analysis.

\begin{tabular}{lllll}
\hline Survival (phi) & \multicolumn{4}{l}{ Probability of Capture (p) } \\
\hline & Constant (.) & Habitat (hab) & Time (t) & $\begin{array}{l}\text { Time and habitat } \\
\text { (thab) }\end{array}$ \\
& & & & 1.8 \\
Constant (.) & 104.9 & 76.8 & 19.0 & 0 \\
Habitat (g) & 93.0 & 77.3 & 11.9 & 5.6 \\
Time (t) & 50.9 & 32.1 & 22.2 & 10.3 \\
Time and Habitat & 49.2 & 38.0 & 20.0 & \\
(thab) & & & & \\
\hline
\end{tabular}

East et al. (1995) surveyed in a $24 \times 24 \mathrm{~m}$ grid $\left(576 \mathrm{~m}^{2}\right)$. They found that their skinks moved an average of $7.9 \mathrm{~m}$. This gives a boundary strip of $3.95 \mathrm{~m}$ around the grid and an area of $781.2 \mathrm{~m}^{2}$.

From the East et al. (1995) survey, the density of $O$. lineoocellatum in the pasture had large confidence intervals, a result of the lower number of captures and recaptures. The density of $O$. lineoocellatum in the pasture was always substantially lower (varying between $124-1591$ fewer animals per hectare) than that of the tussock. The difference between the habitats was not significant due to the wide confidence intervals in the pasture. Tussock density estimates for November, January and February was constant at $2500 /$ ha. The density decreased for the last session (March). This decrease is a fairly common problem with Jolly Seber models at the end of surveys, resulting from lower probability of recapture due to fewer (or no) follow up trips (Table 2.13). 
Table 2.13. Densities of $O$. lineoocellatum per hectare reanalysed from the East et al. (1995) for the pasture and the tussock. $\mathrm{Cl}=95 \%$ confidence interval.

\begin{tabular}{lllll}
\hline & Pasture & \multicolumn{3}{l}{ Tussock } \\
\hline Month & Density & $\mathrm{Cl}$ & Density & $\mathrm{Cl}$ \\
\hline November & 953 & $485-3580$ & 2544 & $2259-3580$ \\
January & 2494 & $958-12826$ & 2618 & $2290-3322$ \\
February & 1190 & $224-17363$ & 2021 & $1448-3426$ \\
March & 736 & $176-10236$ & 1456 & $1077-2447$ \\
\hline
\end{tabular}

\subsubsection{Comparison with the East et al. (1995) survey}

The pasture grid has been replanted (grid $\mathrm{C}$ ) and density estimates of $O$. lineoocellatum now range between $3046-4112$ animals per hectare (Figures 2.14 and 2.15). Due to the wide confidence intervals from the East et al. (1995) survey, the pasture density estimates ranged from 176-17363/ha (Table 2.13), there was no statistical difference between the surveys. The East et al. (1995) tussock habitat (grids D and E) was still tussock and this survey found density estimates to vary from $1945-3108 /$ ha (Figures 2.14 and 2.15) at the $95 \%$ confidence level. This estimate was similar to the East et al. (1995) survey estimate of between 1077-3580/ha (Table 2.13).

The capture rates of this survey (Table 2.14), cannot be directly compared to those findings of the East et al. (1995) survey in 1992 (Table 2.15), due to the large number of variables that differed between the sampling sessions, for example, weather. East et al. (1995) pasture grid and replanted grid C, tussock grid and tussock grids D and $E$, and their forest grid and forest grid $\mathrm{A}$ are all at the same locations. In both surveys, the capture rate of $O$. lineoocellatum was higher than for the other skink species in all grids. Capture rates between surveys show similar numbers of animals caught in the same habitat type (Tables 2.14 and 2.15). 
Table 2.14. Trap occupancy rates of skinks in different grids (s.e. $=$ standard error)

\begin{tabular}{lllllllll}
\hline & \multicolumn{2}{l}{ O. infrapunctatum } & \multicolumn{2}{c}{ O. n. polychroma } & \multicolumn{2}{c}{ O. zelandicum } & \multicolumn{2}{c}{ O. lineoocellatum } \\
\hline & Mean & s.e. & Mean & s.e. & Mean & s.e. & Mean & s.e \\
Forest A & 0.03 & 0.01 & NA & NA & NA & NA & NA & NA \\
Forest B & 0.02 & 0.01 & NA & NA & NA & NA & NA & NA \\
Replanted C & 0.22 & 0.03 & 0.11 & 0.02 & 0.01 & 0.01 & 2.46 & 0.13 \\
Replanted G & 0.14 & 0.03 & 0.24 & 0.03 & NA & NA & 1.42 & 0.09 \\
Tussock D & 0.05 & 0.01 & 0.82 & 0.07 & 0.04 & 0.02 & 1.65 & 0.09 \\
Tussock E & 0.04 & 0.01 & 0.51 & 0.05 & 0.06 & 0.02 & 1.26 & 0.07 \\
Pasture F & NA & NA & 0.03 & 0.01 & NA & NA & 0.24 & 0.04 \\
Pasture H & NA & NA & NA & NA & NA & NA & 0.58 & 0.05 \\
\hline
\end{tabular}

Table 2.15. Table of East et al. (1995) capture estimates (s.d. = standard deviation).

\begin{tabular}{lllllllll}
\hline & \multicolumn{2}{l}{ O. infrapunctatum } & \multicolumn{2}{l}{ O. n. polychroma } & \multicolumn{2}{l}{ O. zelandicum } & \multicolumn{2}{l}{ O. lineoocellatum } \\
\hline \multirow{3}{*}{ Pasture } & Average & s.d. & Average & s.d. & Average & s.d & Average & s.d. \\
Tussock & 0.01 & 0.01 & 0.03 & 0.02 & NA & NA & 0.33 & 0.39 \\
Bush & 0.07 & 0.07 & 0.09 & 0.06 & 0.2 & 0.21 & 0.71 & 0.49 \\
\hline
\end{tabular}

\subsection{Discussion}

Oligosoma infrapunctatum appears to benefit from the revegetation of Stephens Island as predicted by the East et al. (1995) survey analyses. The prediction that the other three species will decline as a result of the revegetation is currently not supported by this study.

\subsubsection{Habitat relationships and selection}

All skink species on Stephens Island are more common in the long grass and young trees of the replanted or tussock habitats. Habitat type determines species composition and order of abundance. Oligosoma lineoocellatum was the dominant species in the 
replanted area, and accounted for about two thirds of the captures in the tussock. Oligosoma nigriplantare polychroma had the second highest capture rate in the tussock areas. Oligosoma infrapunctatum had a higher capture rate in the replanted areas than in the other habitat areas. Oligosoma zelandicum (with the exception of three individuals) was only found in the tussock habitat in small numbers. When it was caught, it was usually in one of a few traps surrounded by Muehlenbeckia vines. The forest areas are depauperate of skinks; only low numbers of $O$. infrapunctatum were caught in this habitat type.

Capture rates were influenced by individual traps more than by either habitat type or grid. This may reflect the numerous microhabitat types found within each grid. For example, in the replanted habitats, there were traps covered with bush (normally taupata), or surrounded by tall grass, flax or a mixture of plant species. Some traps in the tussock grids were surrounded by grass, others by dirt or Muehlenbeckia vines.

All skink species are predominantly found in one habitat, for example, O. nigriplantare polychroma in the tussock, O. zelandicum in the vineland and $O$. infrapunctatum in the replanted areas. This may indicate microhabitat specialisation, caused either by competition or local adaptation to a particular niche. This has been recorded elsewhere (e.g. Carrascal et al. 1989, Patterson 1992, Towns and Elliott 1996, Singh et al. 2002). Oligosoma lineoocellatum dominates all habitats except the forest, indicating that this species may be a generalist and a good patch or ecotone invader (Towns pers.comm). Generalist species are known to benefit in areas of disturbance or edge habitats (Sarre 1996, Sarre 1998, Mac Nally and Brown 2001). The vegetation distribution on Stephens Island is patchy and this situation may benefit $O$. lineoocellatum. 
Oligosoma lineoocellatum account for $74 \%$ of all individuals caught. It is the most aggressive of all the species (East et al. 1995). It is possible that it out-competes the other species. Fresh tail loss was noted on five $O$. infrapunctatum when caught in traps with a large number of $O$. lineoocellatum.

The numbers of $O$. nigriplantare polychroma were higher in March than December and its range expanded into the pasture areas. This increase in numbers caught may have been due to the hot dry summer. Oligosoma nigriplantare polychroma was found primarily in the tussock, possibly due to its yellow and striped appearance providing the best camouflage in this habitat. Colour patterns of the common skink in Central Otago often reflect their preferred microclimate, for example striped animals in the grass and speckled animals in rock habitats (Patterson 1985, Freeman 1997). This may also be the case on Stephens Island.

Oligosoma infrapunctatum was more common in shaded areas where it can burrow into dead leaves and is well camouflaged. It is the only skink species caught in the forest, but even there it was caught in low numbers. It was more abundant in the replanted areas. The forest has higher density of tuatara (potential skink predator), relative to the pasture (Carmichael et al. 1989).

Oligosoma zelandicum was found only in low numbers. A few individuals were found in replanted grid $\mathrm{C}$ during the survey, and in replanted grid $\mathrm{G}$ during the pilot study (Stephens unpubl. data), indicating it inhabits these areas but either in low numbers or was hard to catch. Rufaut and Clearwater (1998) indicated that O. zelandicum is crepuscular. If this is the case, there is a chance that sampling from $6.30 \mathrm{am}$ to between 2-6pm, may miss O. zelandicum. Oligosoma zelandicum is normally found in the forest, 
or in shady and moist situations in farmland or gardens (Gill and Whitaker 2001).

However, for O. zelandicum forest habitat may not be suitable on Stephens Island due to the large number of predatory tuatara.

\subsubsection{Comparison with the East et al. (1995) survey}

There has been little change in terms of abundance and diversity, between the East et al. (1995) survey and the current survey in areas where the vegetation has remained similar over time. There are still only $O$. lineoocellatum in the pasture (with the exception of a few $O$. nigriplantare polychroma found during March) and only $O$. infrapunctatum in the forest. Oligosoma zelandicum is still found in very low numbers in the vineland, and $O$. nigriplantare polychroma still has the highest density in the tussock habitat. Although the capture rates between the East et al. (1995) survey and these results cannot be statistically compared, they show similar numbers of animals caught in the same habitat.

In the replanted habitat the diversity and abundance of skinks have dramatically increased from the 1992 survey (East et al. 1995). Previously when this grid was pasture, only $O$. lineoocellatum was found. Now after 13 years of restoration, all four skink species can be captured in the more diverse habitat. Trap occupancy rates have increased for $O$. lineoocellatum from 0.33 (per trap, per day) to 2.46, for O. nigriplantare polychroma from 0.03 to 0.11 and for 0 . infrapunctatum from 0.01 to 0.22 . Oligosoma zelandicum, which had trap occupancy of zero in the pasture of the East et al. (1995) survey, increased to a trap occupancy rate of 0.01 .

There is no significant difference in the density of $O$. lineoocellatum in the replanted habitat between this survey and the East et al. (1995) survey. The East et al. (1995) survey has a wide estimate from 224-17363 animals per hectare at the 95\% confidence 
level. However, this project gave $95 \%$ density estimates ranging from $2930-4111 /$ ha. The East et al. (1995) survey found very few skinks, which resulted in wide confidence limits.

\subsubsection{Predictions and recommendations}

Skink abundance and diversity in replanted areas suggests that the current level of revegetation benefits skink populations. Intermediate levels of disturbance such as revegetation can maximise biodiversity (Krebs 1994). The mosaic vegetation on Stephens Island means that it is probably at the peak of the 'intermediate disturbance curve'. A fully forested island is likely to decrease biodiversity. Should revegetation, through plantations or plant growth, create more forest habitat (depauperate of skinks) as is planned, it is likely that the population of all four species will decline. It can be argued that skink populations may currently be higher than they were in pre-European times, due to an increase of the proportion of suitable habitats on the island, and that Stephens Island should be returned to its natural balance. The population of each skink species could potentially be managed by adjusting the proportion of habitat types, such as increasing vineland for $O$. zelandicum. A mosaic of vegetation types is recommended, where some areas are replanted and others such as the tussock are left as they are. 


\title{
Chapter 3
}

\section{Habitat differences on Stephens Island/ Takapourewa do not influence skink body condition index or tail loss}

\begin{abstract}
The body condition (log weight / log snout-vent length) and tail loss of four skink species (Oligosoma lineoocellatum, O. infrapunctatum, O. nigriplantare polychroma and $O$. zelandicum) were compared in different habitats (forest, pasture, replanted and tussock) on Stephens Island. Changing vegetation does not seem to negatively affect skink body condition. Despite the numerous differences between the habitats, the body condition and the proportion of skinks with missing tails were similar among the different habitats. This may be attributed to numerous factors such as predation or competition that influence body condition or cause tail loss. Juvenile skinks had a significantly lower body condition and a lower proportion of tail loss than adult skinks.
\end{abstract}

\subsection{Introduction}

The morphology of an animal is influenced by both environmental and genetic factors (Harvey and Pagel 1991). Morphological comparison of two conspecific populations can indicate variation in environmental conditions (Sinclair 1998). For example, the body condition index of skinks could vary across habitat types due to the differing environmental conditions in each habitat. Stephens Island is currently a mosaic of vegetation types, including forest, scrub, tussock, vineland, pasture, and revegetating areas. At least one of the four skink species is found in each of these habitats (East et al. 1995). 
There are two aims in this project. The first aim is to investigate the effect of different vegetation types (pasture, tussock, and forest) on body condition and tail loss for the skink species; Oligosoma lineoocellatum, O. infrapunctatum, O. nigriplantare polychroma and O. zelandicum on Stephens Island. The second aim is to investigate the effect that change in vegetation has had on body condition and tail loss on the four skink species.

Body condition is an indirect measure of an animal's fitness. The log weight / log SVL (snout-vent length) of an animal aims to account for body size and for body weight (the heavier the animal for its length, the better the body condition). Body condition can be influenced by both biotic and abiotic factors. For example the biomass of arthropods has been found to influence the body condition index in the female lizard Tropidurus itambere (Van Sluys 1998).

Skinks are assumed to select microhabitats where they can optimise their thermoregulatory, antipredator, and foraging requirements (Martin and Lopez 2002). For example, microhabitat structure affects the density of five lizard species in the Mediterranean dehesa (Martin 2002). Skinks may be forced to live in sub-optimal habitats due to factors such as inter or intra specific competition and predation. This may lower the body condition of the animal. Body length and growth rate in the lizard Lacerta vivipara have been shown to be negatively influenced by density (Massot et al. 1992).

With a change in vegetation structure, there are also changes in other biotic and abiotic variables (Majer 1990). Plant species differ and invertebrate abundance and/or diversity may change in response to the plants, leading to higher trophic level changes. Shade increases and wind exposure decreases with taller plant structures. When combined, these influences may determine whether skinks can survive and reproduce in each 
habitat. For example, Carrascal et al. (1989) found a significant correlation between the presence of two lizard species, Psammodromus hispanicus and $P$. algirus, and tree cover. Environmental variation can induce life history variation, for example, thermal regimes have been found to influence food availability, which affects the growth rates of Sceloporus merriami (Grant and Dunham 1988). Food availability is known to influence individual growth rate, survivorship, reproduction, and therefore the fitness of lizards (Andrews 1976, Dunham 1978, Ballinger and Congdon 1980, Parker 1994, Smith and Ballinger 1994).

A changing environment has the potential to cause stress on an animal. Habitat fragmentation has been shown to negatively affect reptiles. The resulting impacts include decreased abundance and species richness (Sumner et al. 1999, Sarre 1998), genetic alterations (Stows et al. 2001), fluctuating asymmetry (Sarre 1996), community compositional changes (Mac Nally and Brown 2001) and behavioural changes (Sarre 1998). The negative impacts from a changing environment may mean that revegetation on Stephens Island may not benefit all skink species and this may be reflected in the body condition of skinks.

Tail loss is another factor that influences the body condition of reptiles and complicates analysis. Tuatara, Sphenodon punctatus, with long tails have significantly higher body condition than those with average or short tail lengths (Hoare 2002). Tail loss in reptiles is known to lower or reduce growth and survival (Wilson 1992, Althoff and Thompson 1994, Parker 1994), reproductive output (Martin and Salvador 1993), locomotor abilities (Brown et al. 1995) and lipid resources (Vitt et al. 1974). The shedding of tails is believed to be a defence tactic (Arnold 1984a). This distracts predators, giving the lizard time to escape (Dial and Fitzpatrick 1981, Arnold 1984a). If levels of predation are higher in 
some habitats than in others, the level of tail loss in these habitats may also be higher. Phillpot (2000) suggested that a high frequency of tail loss on both Stephens Island and North Brother Island (New Zealand) may be due to competition, so levels of tail loss may be higher in habitats with greater skink density.

Stephens Island provides an appropriate location to study the relationship between body condition and habitats, as it has a variety of habitat types and four species of skink. Revegetated habitat provides an opportunity to determine what effect vegetation change may have on skink body condition. Each habitat differs in skink composition, skink density (chapter 2), food availability and predation risk (chapter 4). This may alter the body condition and the level of tail loss. I hypothesis that the body condition index of skinks is higher in optimal habitats.

\subsection{Methods}

Stephens Island is a Wildlife Sanctuary situated in the northern Marlborough Sounds, administered by the Department of Conservation, New Zealand (Figure 1.1). Since the 1990s vegetative restoration of Stephens Island has aimed to eventually return the island to its original forested state (Brown 2000).

Eight grids were selected on Stephens Island, including replicates of four habitat types: forest $(A$ and $B)$, tussock/vineland $(D$ and $E)$, pasture $(F$ and $H)$ and replanted $(C$ and $G)$. Grid locations were determined by a stratified random design, constrained by other variables such as aspect, bird activity, plant size, and sheep disturbance (Figure 2.1). 
- Grids A (Figure 2.2), C (Figure 2.6), D (Figure 2.9) and E (Figure 2.10) were the sites of a previous survey (East et al. 1995). Grid C has been planted three times, the first major planting was in 1991, with follow-up plantings in 1998 and 2000.

- Grid B (Figure 2.3) was located in Keepers Bush.

- Grid G (Figure 2.7) was planted in 1997 (Knight pers.comm 2002).

- Grid F (Figure 2.4) and H (Figure 2.5) both had sheep excluded, but were still pasture grass.

Within each grid 16 pitfall traps were set out in a four by four design (five metres apart). In total, 128 pitfall traps were operated during two surveys in December 2002 and March 2003. The plant species present, vegetation height, and vegetation cover were recorded in the $0.89 \mathrm{~m}^{2}$ square area around each pitfall trap. The number of bird burrows, slope terrain (four vertical and four horizontal measurements) and aspect were also recorded.

Each trap was a four litre white plastic paint bucket, with four drainage holes $(6 \mathrm{~mm}$ in diameter), set flush to the ground surface. A damp sponge and a layer of soil or leaf litter were laid in each trap to prevent dehydration and provide cover for skinks. Traps were baited with $1 \mathrm{~cm}^{3}$ piece of Watties ${ }^{\mathrm{TM}}$ tinned pears and open from 0630 to 1400 daily. The traps were cleared in a Latin square design, to account for the time difference between the closing of the first trap and the last trap. For example, day 1 clearing started on grid A, following a circuit through to $\mathrm{H}$. On day 2 clearing started on $\mathrm{B}$, onwards on the circuit to $\mathrm{H}$ with $\mathrm{A}$ last and so on.

Captured skinks were weighed using a Pesola ${ }^{\mathrm{TM}}$ spring balance $(30 \mathrm{~g}$ or $50 \mathrm{~g}$, accurate to $0.5 \mathrm{~g}$ ). Snout to vent length (SVL), length of tail from the vent (VT) and tail 
regeneration were all measured using a $150 \mathrm{~mm}$ plastic ruler accurate to $1 \mathrm{~mm}$. Sex was determined by applying pressure to either side of the vent area. This action everted two hemipenes in males (Arnold 1984b, Harlow 1996). If no hemipenes were found, then to ensure accuracy the animal was examined for other signs of femaleness such as a rounder tail and the extended abdomen of a gravid female. Species and trap number were recorded. Each skink was given a individual number written on the ventral surface of the skink using a silver metallic marker - Artline ${ }^{\circledR}$ 990XF, known to stay on skinks for up to three weeks (Stephens unpubl.). Recaptured animals were recorded.

It is difficult to determine if a skink is a juvenile / subadult or an adult without dissecting it. Following Spencer et al. (1998) individuals with a SVL of less than $40 \mathrm{~mm}$ for $O$. nigriplantare polychroma and $60 \mathrm{~mm}$ for 0 . lineoocellatum were assumed to be juvenile/sub-adults skinks. Oligosoma zelandicum are a similar size to $O$. nigriplantare polychroma, so juveniles were judged to be individuals less than $40 \mathrm{~mm}$. Juvenile $O$. infrapunctatum were estimated on size, as there is no literature base to determine size of maturity.

\subsubsection{Body condition}

Five body condition measurements were examined. The measurements were: weight (wgt) of the animal, SVL (snout-vent length), VT (vent to tail), log (wgt) divided by log (SVL) (lgwgtsvl) and weight divided by SVL ${ }^{3}$. Normal Q-Q plots and Residuals vs. Fitted graphs (program R - R Development Core Team 2003) were used to test normality, variance and to determine which body condition index was the most suitable to use.

Model selection was based on the Akaike Information Criterion (AIC) value (Burnham and Anderson 1998) to determine whether the data were best sorted by habitat or grid. 
AIC is a form of model comparison, which selects the most parsimonious model by determining which parameters have the largest impact on the data. It looks at the variation explained by each model compared with the variation in the dataset, trading off bias and precision (Burnham and Anderson 1998). The AIC model favours a low residual deviation but penalises if there are too many parameters (Pledger pers. comm. 2003). The AIC value itself does not matter as it is relative to the AIC values of other models. The lower the AIC value compared to that of other models, the better the model is suited to the data set and so AIC determines what parameters most influence the data set.

AIC is defined as:

$\mathrm{AIC}=$ residual deviation $(\mathrm{RD})+2 \times$ number of parameters.

Multivariate analysis of variance was employed (SPSS 11.0), to determine whether skink body condition differed among habitats, grids or sex/size class. Hypothesis testing was based on the null hypothesis $L B M=0$, (no difference in body condition among habitats, sex/size or species). A univariate test using F statistics and the Bonferroni-type simultaneous confidence intervals based on Student's t distribution was used to contrast differences across all dependent variables. A Wilk's Lamba test was used to indicate if there was a significant difference in the data set and Roy's Largest Root was used to test if this variation was the result of one variable. The trips were analyzed separately as the skinks were not permanently marked.

Once it was determined that differences existed amongst the means, post hoc range tests and pairwise multiple comparisons identified which means differed statistically. The Tukey HSD test made pairwise comparisons between groups and set the experiment wise error rate to the error rate for the collection of all pairwise comparisons. 
Graphing was done in Microsoft Excel XP or SPSS version 11.0. All graphs are +/- one standard error unless otherwise stated.

\subsubsection{Tail loss}

Tail loss is defined as any degree of tail loss, whether total or partial tail loss, recent or regenerated. Tail loss frequency was divided into two groups, those with some degree of tail loss (1) and those with complete tails (0) (Phillpot 2000). The data were categorised by trip (December or March), sex/size (male, female or juvenile), grid and habitat type.

As the data were non-parametric, chi squared tests $\left(X^{2}\right)$ were used to investigate whether rates of tail loss differed among the species, sex/sizes, habitat types and grids at the $95 \%$ confidence level. If there was a statistical difference then multiple comparison tests were used identify to where this difference lay (Zar 1999).

\subsection{Results}

\subsubsection{Vegetation}

Forest grid $\mathrm{A}$ is dominated by mahoe (Melicytus ramiflorus), taupata (Coprosma repens), ngaio (Myoporum laetum) and kawakawa (Macropiper excelum). Forest grid B is dominated by mahoe. Silver tussock (Poa cita) is the dominant plant in both tussock grids D and E, Muehlenbeckia australis edges the two grids, and there are areas of grass inside the grids. Fairy prions (Pachyptila turtur) heavily burrow these grids. There are two grass species in the paddocks. The dominant grass is Festuca arundinacea ( $70 \%$ cover in grid $\mathrm{F}$ and $65 \%$ in grid $\mathrm{H}$ ), and the other grass was a perennial ryegrass (Loium 
perenne). Long grass and the major replanted species of taupata, tauhinau (Cassinia leptophylla) and ngaio dominate grid C and G (Appendix A).

\subsubsection{Skink morphology}

Overall, $O$. infrapunctatum was the largest skink species $(S V L$ mean $=97 \mathrm{~mm})$, followed by 0 . lineoocellatum $(69 \mathrm{~mm})$, O. nigriplantare polychroma $(58 \mathrm{~mm})$ and $O$. zelandicum (55 mm) (Figure 3.1 and Table 3.1). Oligosoma infrapunctatum had the largest mass of the four species with O. nigriplantare polychroma being the lightest (Table 3.1).

The four species differ significantly in SVL $(F=132.9, p<0.0005$ for December and $F=$ 220.2, $p<0.0005$ for March). There was also a difference among the weights (December, $F=114.5$, and $p<0.0005$, March, $F=93.2, p<0.0005$ ) of the skink species.

There was no statistical difference in SVL between the trips $(F=1.847, p=0.174))$. The skinks were significantly heavier in the December trip than in the March trip $(F=11.62, p$ $=0.01)$. 


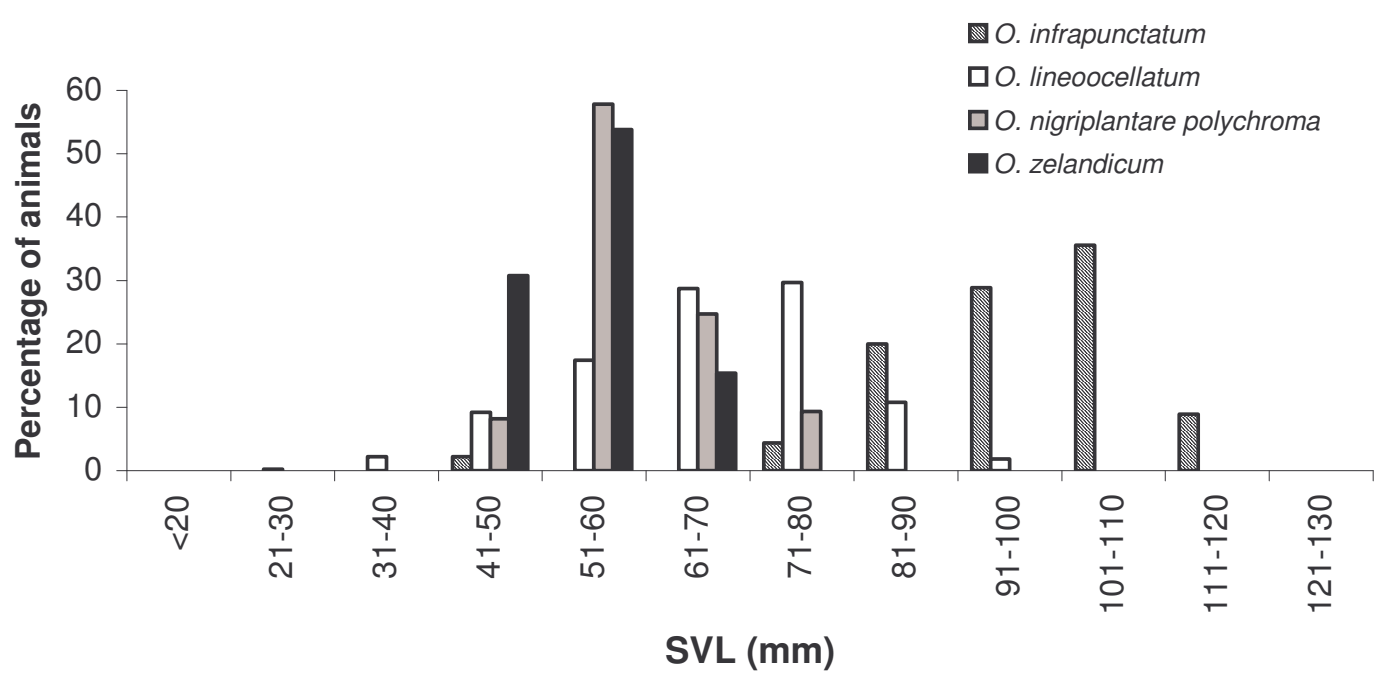

Figure 3.1 SVL range of skinks caught during the December trip (March shows the same range).

Table 3.1 Size of skink species on Stephens Island in both December and March.

Numbers in brackets are 1 s.e. SVL = snout vent length, weight is in grams

\begin{tabular}{lllllllll}
\hline & \multicolumn{2}{l}{ O. infrapunctatum } & \multicolumn{2}{l}{ O. lineoocellatum } & \multicolumn{2}{l}{ O. n. polychroma } & \multicolumn{2}{l}{ O. zelandicum } \\
\hline & Dec & March & Dec & March & Dec & March & Dec & March \\
\cline { 2 - 9 } $\begin{array}{l}\text { Mean SVL } \\
\text { (mm) }\end{array}$ & 96.7 & $87.4(1.8)$ & 67.6 & $60.8(0.9)$ & $57.8(0.7)$ & $51.3(2.2)$ & 54.5 & 54.4 \\
SVL & $(2.0)$ & & $(0.6)$ & & & & $(2.0)$ & $(2.2)$ \\
Range & $43-133$ & $31-115$ & $22-96$ & $33-101$ & $41-79$ & $34-71$ & $44-68$ & $45-65$ \\
Mean & 21.6 & $16.3(0.5)$ & 7.3 & $5.4(0.3)$ & $3.7(0.1)$ & $2.6(0.5)$ & 3.9 & 3.3 \\
weight (g) & $(1.2)$ & & $(0.4)$ & & & & $(0.4)$ & $(0.7)$ \\
Weight & $1.5-$ & $1-26$ & $0.5-18$ & $0.5-18$ & $0.5-7.5$ & $0.5-6$ & $1.5-6$ & $2-5$ \\
range & 35.5 & & & & & & & \\
Number & 40 & 33 & 501 & 499 & 96 & 164 & 14 & 18 \\
\hline
\end{tabular}




\subsubsection{Body condition of skinks in different habitats}

Based on visual examination of Normal Q-Q plots and residuals vs fitted graphs, the log weight divided by the log SVL (lgwgtsvl) was used for all skink species to measure body condition (Appendix B). Data were normally distributed and had equal variance, so parametric Tukey tests were used. Despite there being no statistical difference in body condition between of the two trips $(F=3.22, d f=1, p=0.073)$, the two trips were analyzed separately due to the lack of independence between the trips, as the skinks were not permanently marked.

AIC modelling indicated that sex or size class (sex/size), followed by habitat and species, were the important factors that best described the data set (Table 3.2). In this analysis habitat, sex/size and interactions among habitat and sex/size (habitat*sex) were investigated.

Table 3.2. Model selection by AIC values indicating which parameters had the most influence on skink body condition, * interaction between factors.

\begin{tabular}{lcc}
\hline Model & Number of parameters & Relative A.I.C value \\
\hline Species & 4 & 4 \\
Habitat & 4 & 4 \\
Grid & 8 & 12 \\
Sex/Size & 2 & 0 \\
Sex*habitat & 8 & 10 \\
Habitat*species & 14 & 22 \\
Species*Sex*habitat & 19 & 22 \\
Habitat + species & 7 & 6 \\
\hline
\end{tabular}




\section{Oligosoma lineoocellatum}

The multivariate analysis for $O$. lineoocellatum indicated that there was a significant difference in body condition index among the different sex/size classes during both trips (Table 3.3). There was no significant difference among the different habitat types in March, but there was during December (Table 3.3).

Table 3.3 Multivariate analysis of the body condition (lgwgtsvl) of $O$. lineoocellatum

\begin{tabular}{llcccccc}
\hline Effect & \multicolumn{5}{c}{ December } & \multicolumn{5}{c}{ March } \\
\hline \multirow{3}{*}{ Habitat } & Wilks' Lambda & 3.18 & 976 & 0.01 & 1.48 & 978 & 0.21 \\
& Roy's Largest & 6.4 & 489 & 0.00 & 2.56 & 489 & 0.08 \\
& Root & & & & & & \\
Sex/Size & Wilks' Lambda & 56.78 & 976 & 0.00 & 42.19 & 1341 & 0.00 \\
& Roy's Largest & 133.64 & 489 & 0.00 & 181.84 & 476 & 0.00 \\
& Root & & & & & & \\
Habitat * Sex & Wilks' Lambda & 1.12 & 976 & 0.35 & 22.49 & 974 & 0.00 \\
& Roy's Largest & 2.07 & 489 & 0.08 & 52.64 & 489 & 0.00 \\
& Root & & & & & & \\
\hline
\end{tabular}

Oligosoma lineoocellatum body condition significantly differs among the different sex and size classes (December, $F=159.4, \mathrm{df}=2, \mathrm{p}<0.0005$, March, $\mathrm{F}=144.8, \mathrm{df}=2, \mathrm{p}<$ 0.0005) (Figure 3.2 and 3.3). Tukey tests indicate juvenile skinks have a lower body condition than both the adult males (December, $p<0.0005$, s.e. $=0.015$ and March, $p<$ 0.0005 , s.e. $=0.017)$ and the adult females (December, p<0.0005, s.e. $=0.015$ and March $p<0.0005$, s.e. $=0.038)$. Body condition did not differ between male and female skinks (December, $p=0.092$, s.e. $=0.011$, March, $p=0.226$, s.e. $=0.01$ ) (Figures 3.2 and 3.3)

The average body condition of $O$. lineoocellatum in the replanted grids was significantly higher than in the tussock grids during both the December and March trips (Table 3.4). 
Table 3.4 Average differences in the body condition of $O$. lineoocellatum in different habitats and whether this difference is statistically significant. Mean difference is the average difference between the body conditions of the two habitat types.

\begin{tabular}{llcllclc}
\hline & \multicolumn{5}{c}{ December } & \multicolumn{7}{c}{ March } \\
\hline Habitat 1 & Habitat 2 & Mean difference & S.e. & P & Mean difference & S.e. & P \\
Replanted & Tussock & 0.56 & 0.01 & 0.00 & 0.03 & 0.01 & 0.02 \\
Replanted & Pasture & 0.06 & 0.01 & 0.91 & 0.04 & 0.02 & 0.11 \\
Pasture & Tussock & 0.06 & 0.01 & 0.06 & 0.02 & 0.02 & 0.59 \\
\hline
\end{tabular}

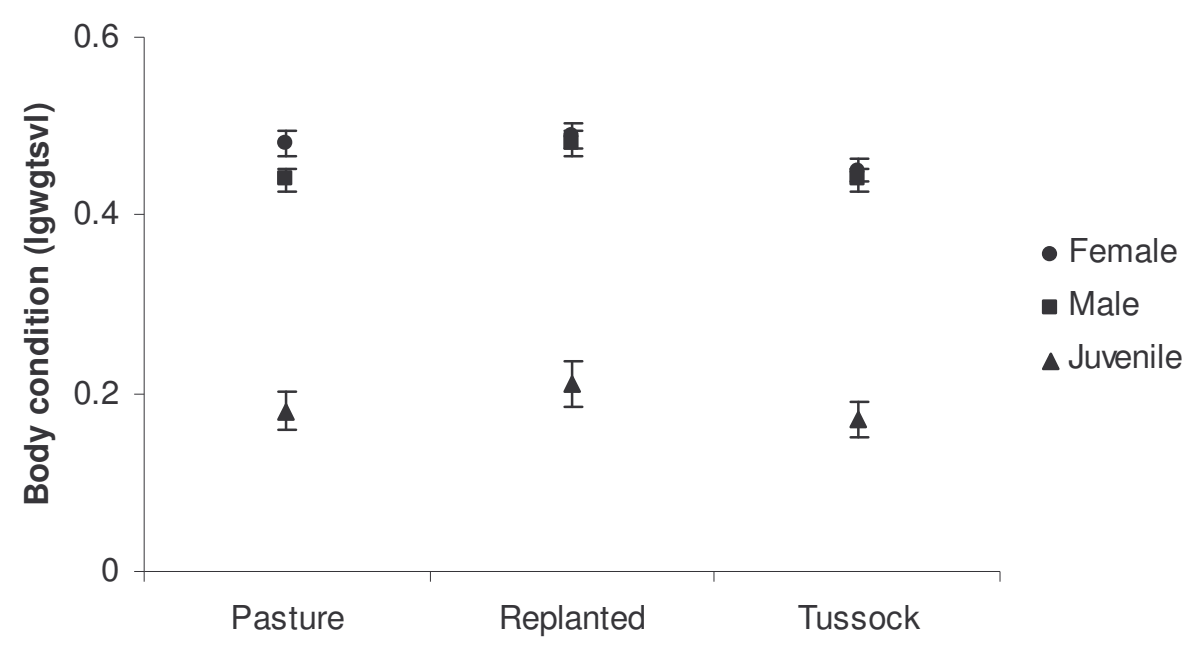

Figure 3.2: Body condition of male, female and juvenile O. lineoocellatum in December in different habitats. 


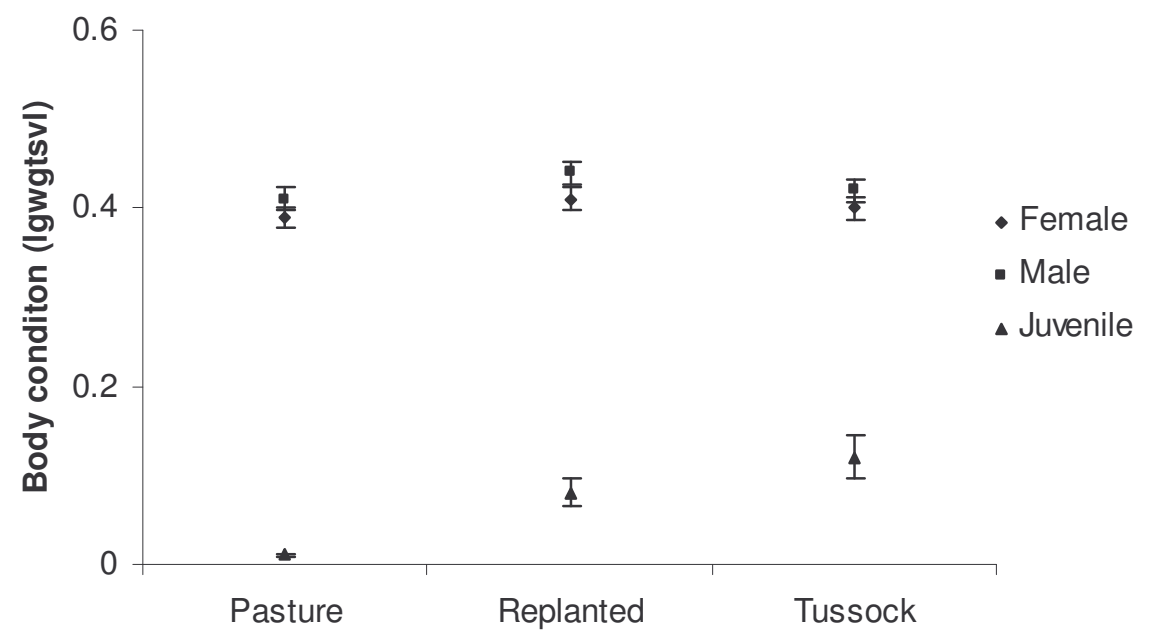

Figure 3.3 Body condition of male, female and juvenile O. lineoocellatum in different habitats during March

\section{Oligosoma nigriplantare polychroma}

The multivariate analysis for 0 . nigriplantare polychroma indicated that there was significant difference in body condition among the habitats, sex/size class and a difference in the interaction between habitat and sex/size (habitat*sex) for both December and March (Table 3.5).

For $O$. nigriplantare polychroma there is a significant difference among the body condition of the different sex/size class (December, $F=22.32, \mathrm{df}=2, \mathrm{p}<0.0005$, March $\mathrm{F}=54.196, \mathrm{df}=$ $2, p<0.0005)$. The body condition of the juveniles is lower than that of the adult male skinks (December, s.e. $=0.02321 p<0.0005$, March s.e $=2.168, p<0.0005)$ and the adult female skinks (December, s.e. $=0.024, p<0.0005$, March, s.e. $=2.172, p<0.0005)$. Body condition did not differ between the adult male and female skinks (December, s.e. $=0.015, p=0.346$, March, s.e. $=0.668, p=0.788)$ (Figures 3.4 and 3.5). 
Table 3.5 Multivariate analysis of the body condition (lgwgtsvl) of $O$. nigriplantare polychroma

\begin{tabular}{llcccccc}
\hline & \multicolumn{5}{c}{ December } & \multicolumn{5}{c}{ March } \\
\hline Effect & Habitat & F & Error df & P & F & Error df & P \\
& Wilk's Lambda & 6.19 & 68 & 0.00 & 4.79 & 312 & 0.00 \\
& Roy's Largest & 15 & 35 & 0.00 & 6.11 & 156 & 0.00 \\
& Root & & & & & & \\
Sex/Size & Wilks' Lambda & 5.77 & 154 & 0.00 & 47.19 & 514 & 0.00 \\
& Roy's Largest & 11.7 & 78 & 0.00 & 64.8 & 150 & 0.00 \\
& Root & & & & & & \\
Habitat * Sex & Wilks' Lambda & 7.88 & 70 & 0.00 & 12.42 & 312 & 0.00 \\
& Roy's Largest & 21.32 & 35 & 0.00 & 24.99 & 156 & 0.00 \\
& Root & & & & & & \\
\hline
\end{tabular}

Body condition did not vary among different habitats for either trip (December, $F=2.474$, $\mathrm{df}=3, \mathrm{p}=0.067$ and March $\mathrm{F}=2.42, \mathrm{df}=4, \mathrm{p}=0.051$ ). Although, Tukey tests indicate that in March the replanted grids had a statistically higher body condition than the tussock grids (Table 3.6, Figures 3.4 and 3.5). No skinks were found in the pasture during December. 
Table 3.6 Tukey tests indicating the statistical difference in the mean body condition index (lgwgtsvl) of $O$. nigriplantare polychroma in different habitat types. Mean difference is the average difference between the body conditions of the two habitat types.

\begin{tabular}{llllllll}
\hline & \multicolumn{7}{c}{ December } \\
& & & & March \\
\hline Habitat 1 & Habitat 2 & Mean difference & s.e. & P & Mean difference & s.e. & P \\
Replanted Tussock & 0.08 & 0.03 & 0.09 & 0.04 & 0.01 & 0.03 \\
Replanted Pasture & NA & NA & NA & 0.05 & 0.03 & 0.09 \\
Pasture & Tussock & NA & NA & NA & -0.01 & 0.02 & 0.83 \\
\hline
\end{tabular}

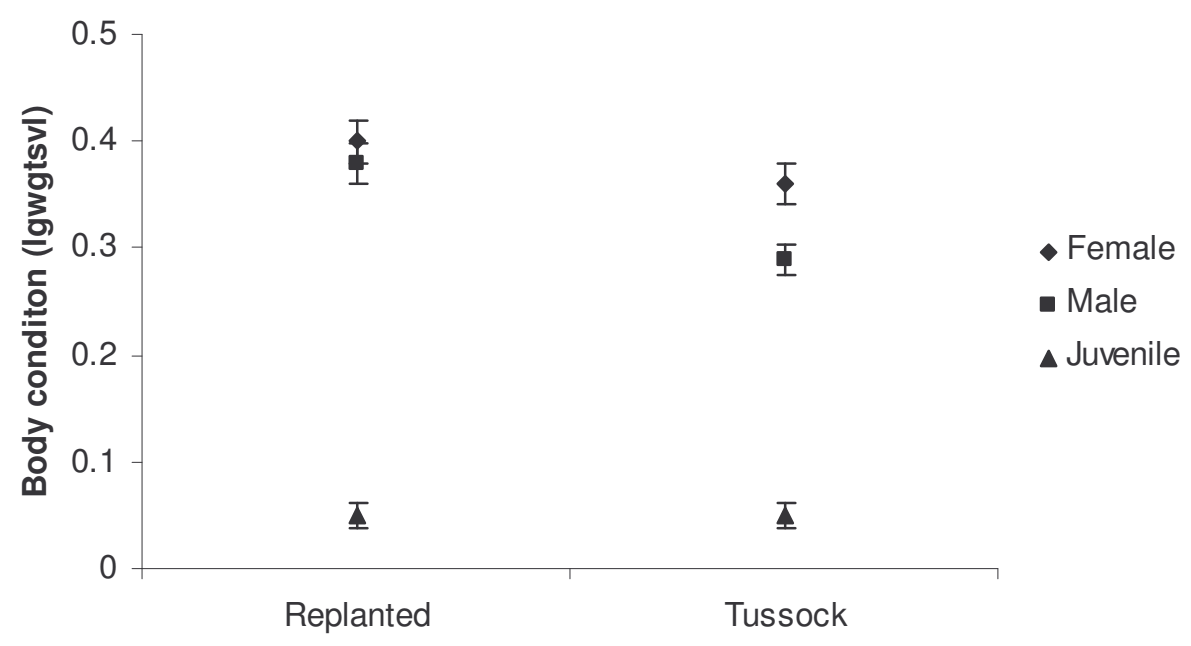

Figure 3.4 Body condition (lgwgtsvl) of $O$. nigriplantare polychroma in different habitat types during December. 


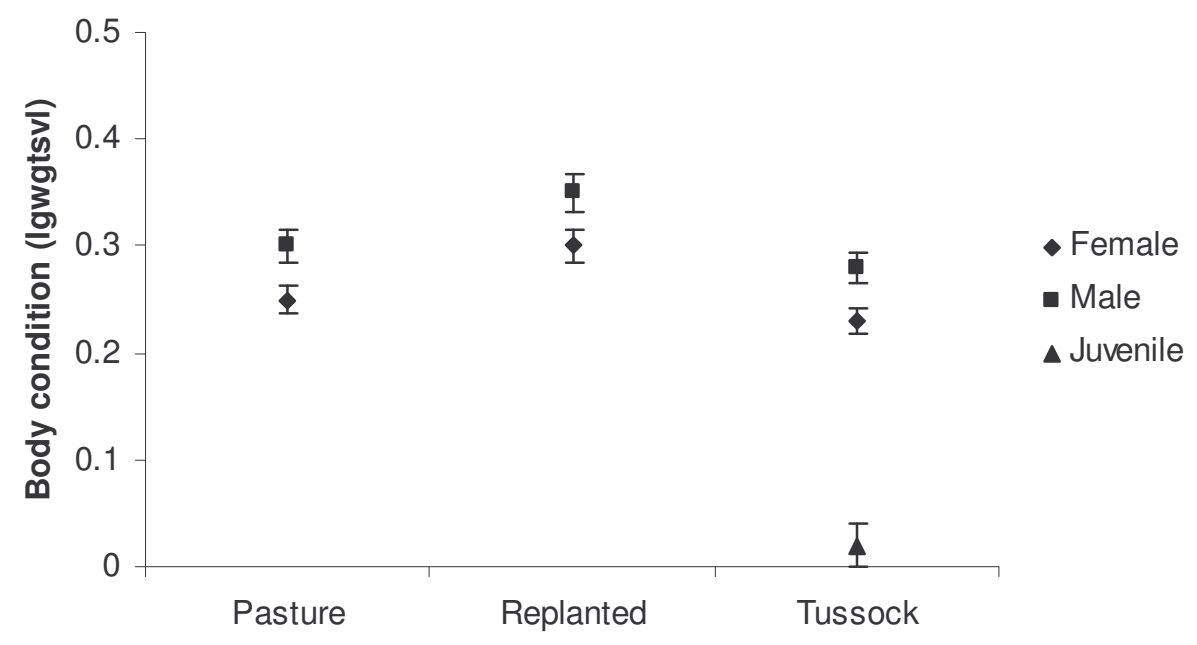

Figure 3.5 Body condition (lgwgtsvl) of $O$. nigriplantare polychroma in different habitat types during March.

\section{Oligosoma infrapunctatum}

In December, the multivariate analysis for $O$. infrapunctatum indicated there were significant differences among the habitats, sex/size and the interaction between habitat and sex (habitat*sex). In March, there was no statistical difference among the habitats (Table 3.7).

There was a difference in body condition between sex/size for $O$. infrapunctatum (December, $F=35.016, d f=2, p<0.0005$, March, $F=3.116, d f=2, p<0.0005$ ) (Figures 3.6 and 3.7). In March body condition was lower in the juveniles than the adult males (s.e. $=0.042, p<0.0005)$ and adult females (s.e. $=0.04, p<0.0005)$ (Figure 3.6 and 3.7). In March, there were no statistical differences between the adult male and female skinks (s.e. $=0.03, p=0.982$ ). Post hoc tests in December were not performed, as only one juvenile was caught. 
Table 3.7: Multivariate analysis of the body condition (lgwgtsvl) of $O$. infrapunctatum in December and March

\begin{tabular}{llcccccc}
\hline & \multicolumn{3}{c}{ December } & & March & \\
\hline Effect & Habitat & F & Error df & P & F & Error df & P \\
& Wilks' Lambda & 6.19 & 68 & 0.00 & 1.64 & 50 & 0.18 \\
& Roy's Largest & 15 & 35 & 0.00 & 2.19 & 26 & 0.13 \\
Sex & Root & & & & & & \\
& Wilks' Lambda & 48 & 48 & 0.00 & 23.45 & 34 & 0.00 \\
& Roy's Largest & 418.61 & 25 & 0.00 & 27.07 & 18 & 0.00 \\
Habitat * Sex & Root & & & & & & \\
& Wilks' Lambda & 7.88 & 70 & 0.00 & 4.51 & 50 & 0.00 \\
& Roy's Largest & 21.32 & 35 & 0.00 & 9.71 & 26 & 0.00 \\
& Root & & & & & & \\
\hline
\end{tabular}

In December there were no significant differences among the different grids $(F=0.608$, $d f=5, p=0.695)$. In March there was a difference at the $5 \%$ level of significance $(F=$ 2.703, $d f=5, p=0.047)$. Body condition did not significantly differ among the habitats in either December or March (Table 3.8).

Table 3.8 Tukey tests indicating the statistical difference in the mean body condition (lgwgtsvl) of $O$. infrapunctatum in different habitats. Mean difference is the average difference between the body conditions of the two habitat types.

\begin{tabular}{llcllcccc}
\hline & \multicolumn{3}{c}{ December } & \multicolumn{7}{c}{ March } \\
\hline Habitat 1 & Habitat 2 & Mean difference & s.e. & P & Mean difference & s.e. & P \\
Replanted & Tussock & 0.05 & 0.02 & 0.08 & 0.01 & 0.04 & 0.98 \\
Replanted & Forest & 0.03 & 0.34 & 0.98 & 0.1 & 0.04 & 0.05 \\
Forest & Tussock & 0.05 & 0.04 & 0.45 & -0.13 & 0.05 & 0.09 \\
\hline
\end{tabular}




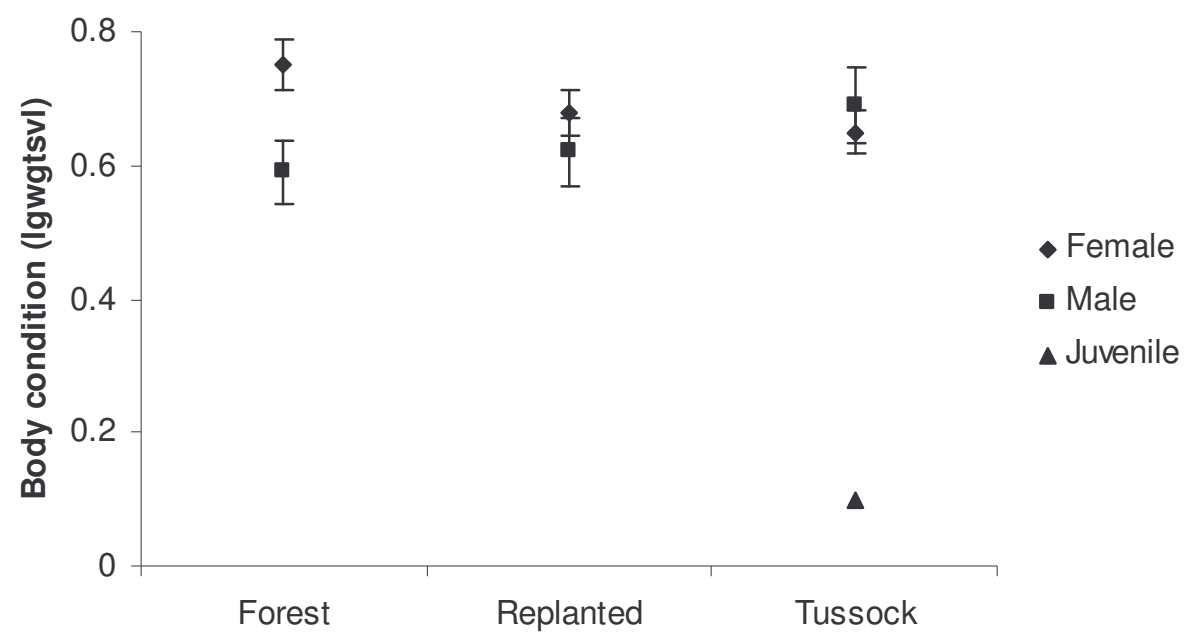

Figure 3.6: Body condition index (lgwgtsvl) of $O$. infrapunctatum in December in different habitats.

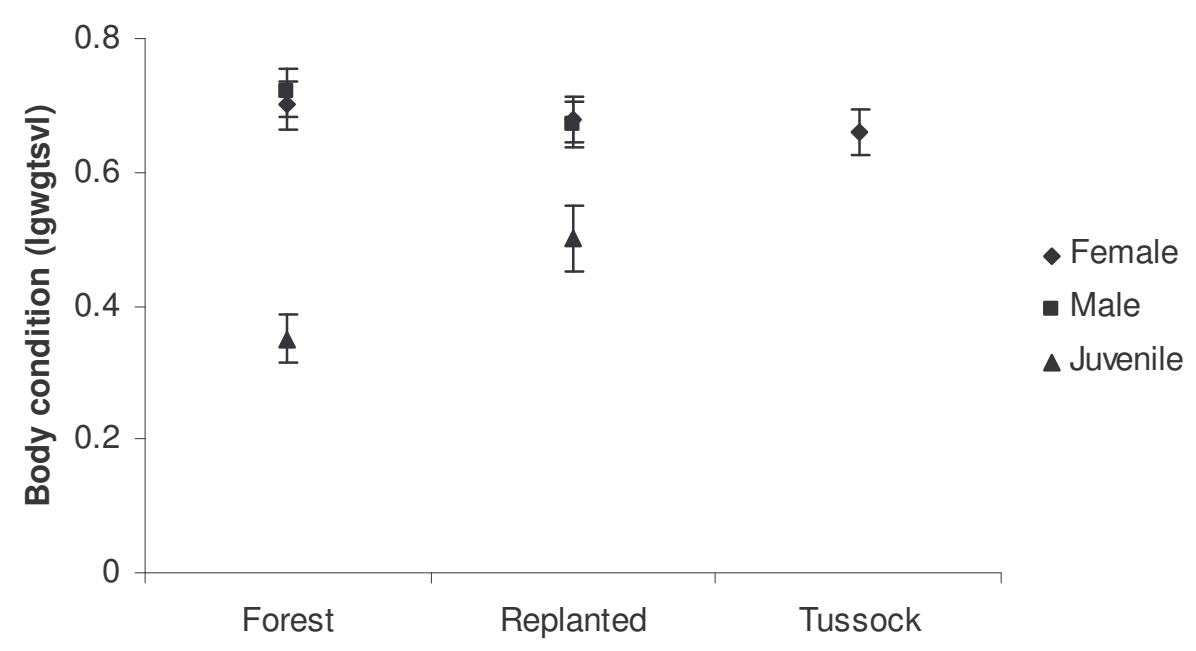

Figure 3.7: Body condition index (lgwgtsvl) of $O$. infrapunctatum in March in the different habitats

\section{Oligosoma zelandicum}

Only 11 O. zelandicum were caught in December and 18 in March. This makes data analysis difficult and less reliable. There was no statistical difference between the grids (December, $F=1.343, d f=2, p=0.33$, March $, F=0.558, d f=2, p=0.585$ ). Oligosoma 
zelandicum was only found in three grids, two of them tussock. There were also no significant differences between the sexes (December, $F=1.668$, df $=2, p=0.265$, March $F=2.786, d f=1, p=0.119)$.

\subsubsection{Tail loss}

All four species of skink on Stephens Island exhibited high levels of tail loss ( 82\% for all species). The difference between the two trips was not significant $\left(X^{2}=0.421, v=1,0.5\right.$ $<\mathrm{p}<0.75$ ). For all species except $O$. zelandicum, the skinks caught exhibited higher tail loss in March (82\%, s.e. 0.014) than it was in December (75\%, s.e. 0.017) (Table 3.9). There was no difference between tail loss in males $(82 \%$, s.e. 0.016$)$ and females $(83 \%$ s.e. 0.015$)$ over both trips. The tail loss of juvenile skinks, however, was much lower, with $48 \%$ (s.e. 0.043 ) of skinks having lost tails (Figure 3.8). By species, O. infrapunctatum had the highest percentage of tail loss and O. lineoocellatum had the lowest (Table 3.9). This difference between the species was not significant, $\left(X^{2}=4.151, v=3,0.25<p<\right.$ 0.5 for December or March, $X^{2}=6.27, v=3,0.05<p<0.1$ ). 
Table 3.9 The percentage of the sampled skinks exhibiting some degree of tail loss in the four skink species on Stephens Island over two trips.

\begin{tabular}{llcl}
\hline Species & Trip & $\begin{array}{l}\text { Percentage of sampled skinks } \\
\text { with evidence of tail loss }\end{array}$ & s.e. \\
\hline O. infrapunctatum & December & 86 & 0.06 \\
& March & 97 & 0.03 \\
O. lineoocellatum & December & 73 & 0.02 \\
& March & 80 & 0.18 \\
O. n. polychroma & December & 77 & 0.04 \\
& March & 88 & 0.03 \\
O. zelandicum & December & 85 & 0.10 \\
& March & 71 & 0.08 \\
\hline
\end{tabular}

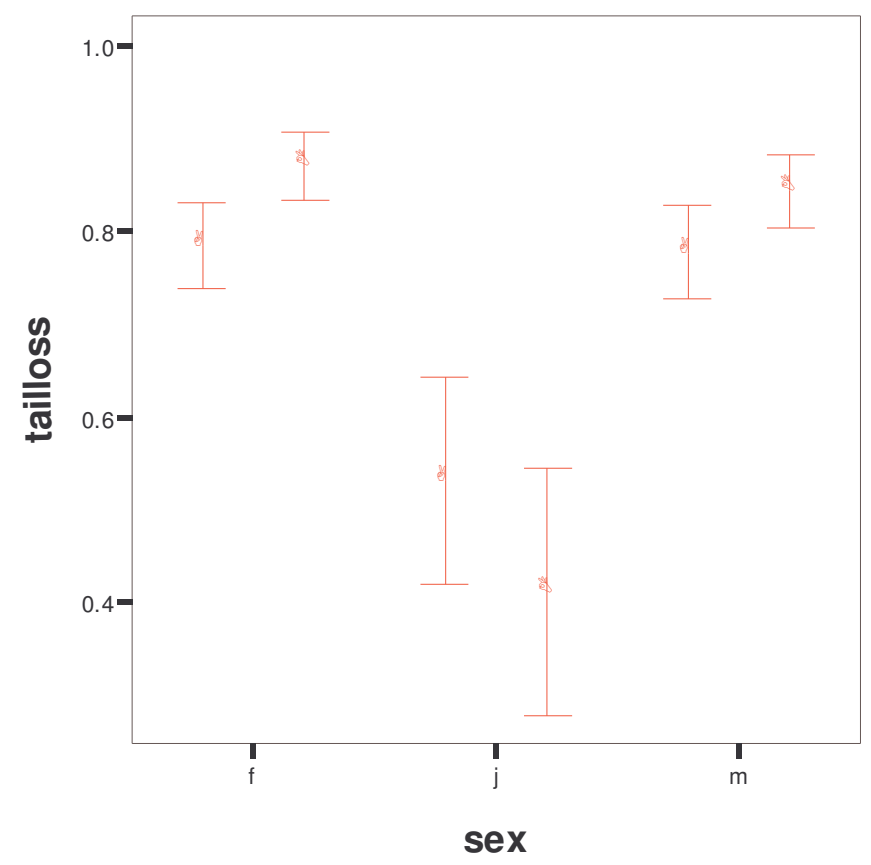

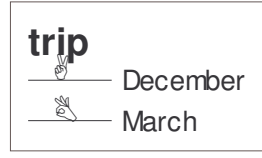

Error Bars show $95.0 \% \mathrm{Cl}$ of Mean

Figure 3.8 The $95 \%$ confidence level of the proportion of tail loss by sex/size class during both December and March. 


\section{Oligosoma lineoocellatum}

The proportion of individuals caught with missing tails did not differ among the different habitat types in either December $\left(X^{2}=5.819, v=2,0.05<p<0.1\right)$ or March $\left(X^{2}=0.7, v\right.$ $=2,0.1<p<0.95)$. However, tail loss was higher in the pasture grids in December and in the replanted grids in March compared with the other grids during the same period (Table 3.10).

Tail loss did significantly differ between the grids for both December $\left(X^{2}=14.15, v=5\right.$, $0.01<p<0.025)$ and March $\left(X^{2}=20.69, v=5, p<0.001\right)$. Skinks in the replanted grid $G$ had lower tail loss than most other grids. In December, there were statistical differences between the replanted grids $C$ and $G\left(X^{2}=5.45, v=1\right)$, replanted $C$ and pasture $H\left(X^{2}=\right.$ $10.05, v=1)$, tussock $E$ and replanted $G\left(X^{2}=5.09, v=1\right)$ and replanted $G$ and pasture $H\left(X^{2}=5.25 v=1\right)$. In March there was a statistical difference between replanted $C$ and tussock $D\left(X^{2}=4.87, v=1\right)$, replanted $C$ and $G\left(X^{2}=16.43, v=1\right)$ and tussock $E$ and replanted $\mathrm{G}\left(\mathrm{X}^{2}=7.26, \mathrm{v}=1\right)$.

Table 3.10 Mean tail loss for $O$. lineoocellatum in different habitats.

\begin{tabular}{llccc}
\hline \multicolumn{1}{c}{ Grid } & \multicolumn{1}{c}{ Trip } & $\begin{array}{c}\text { Number of } \\
\text { skinks }\end{array}$ & $\begin{array}{c}\text { Percentage } \\
\text { with tail loss }\end{array}$ & s.e. \\
\hline Replanted & December & 201 & 73 & 0.24 \\
Replanted & March & 253 & 80 & 0.34 \\
Tussock & December & 187 & 73 & 0.05 \\
Tussock & March & 185 & 81 & 0.04 \\
Pasture & December & 103 & 83 & 0.06 \\
Pasture & March & 63 & 76 & 0.08 \\
\hline
\end{tabular}




\section{Oligosoma nigriplantare polychroma}

O. nigriplantare polychroma tail loss was higher in March than it is in December (Table

3.11). Neither the difference among habitat types (December $X^{2}=0.674, v=1,0.1<p<$ 0.95, March $X^{2}=0.67, v=2,0.1<p<0.95$ ) nor grids (December $X^{2}=0.954, v=3,0.75$ $<\mathrm{p}<0.9$, March $\left.\mathrm{X}^{2}=3.872, \mathrm{v}=4,0.25<\mathrm{p}<0.5\right)$ were significant.

Table 3.11. Mean tail loss for O. nigriplantare polychroma in different habitats

\begin{tabular}{lllll}
\hline Grid & Trip & $\begin{array}{l}\text { Number of } \\
\text { skinks }\end{array}$ & $\begin{array}{l}\text { Percentage } \\
\text { with tail loss }\end{array}$ & s.e. \\
\hline Replanted & December & 27 & 78 & 0.12 \\
Replanted & March & 15 & 85 & 0.07 \\
Tussock & December & 41 & 77 & 0.08 \\
Tussock & March & 72 & 89 & 0.04 \\
Pasture & March & 8 & 88 & 0.13 \\
\hline
\end{tabular}

\section{Oligosoma infrapunctatum}

Tail loss was highest for $O$. infrapunctatum in the forest grids, with all individuals found there exhibiting some degree of tail loss. The percentage of individuals missing tails was high in all habitats (Table 3.12). There was no significant difference among the habitats (December $\mathrm{X}^{2}=2.9, \mathrm{v}=2,0.1<\mathrm{p}<0.95$ or March $\mathrm{X}^{2}=2.16, \mathrm{v}=2,0.1<\mathrm{p}<0.95$ ) or among the grids (December $X^{2}=6.221, v=5,0.25<p<0.5$ or $\operatorname{March}\left(X^{2}=7.46, v=5\right.$, $0.1<\mathrm{p}<0.25)$. 
Table 3.12. Mean tail loss for $O$. infrapunctatum in different for both trips

\begin{tabular}{lllll}
\hline Grid & Trip & $\begin{array}{l}\text { Number of } \\
\text { skinks }\end{array}$ & $\begin{array}{l}\text { Percentage } \\
\text { with tail loss }\end{array}$ & s.e. \\
\hline Forest & December & 4 & 100 & 0 \\
Forest & March & 7 & 100 & 0 \\
Replanted & December & 28 & 89 & 0.09 \\
Replanted & March & 20 & 85 & 0.13 \\
Tussock & December & 10 & 70 & 0.24 \\
Tussock & March & 6 & 100 & 0 \\
\hline
\end{tabular}

\section{Oligosoma zelandicum}

Few O. zelandicum were caught (14 in December and 18 in March). Tail loss was around 75-80\% (Table 3.13). Habitat could not be tested but there was no significant difference among the grids in either December $\left(X^{2}=0.636, v=2,0.5<p<0.75\right)$ or March $\left(X^{2}=\right.$ $3.59, v=2,0.1<p<0.25)$.

Table 3.13. Mean tail loss of $O$. zelandicum in different habitats for both trips.

\begin{tabular}{lllll}
\hline Grid & Trip & $\begin{array}{l}\text { Number of } \\
\text { skinks }\end{array}$ & $\begin{array}{l}\text { Percentage } \\
\text { with tail loss }\end{array}$ & s.e. \\
\hline Replanted & December & 2 & 100 & 0 \\
Replanted & March & 1 & 0 & 0 \\
Tussock & December & 12 & 75 & 0.19 \\
Tussock & March & 16 & 82 & 0.15 \\
\hline
\end{tabular}

\subsection{Discussion}

\subsubsection{Summary findings}

In general, body condition of skinks did not differ among the different habitat types.

Exceptions include a statistical difference indicating body condition was higher in the replanted habitat compared with the tussock grids for $O$. lineoocellatum and $O$. 
nigriplantare polychroma in March. Aside from the above, there were no differences between body condition in the replanted habitat and other habitats for any of the skink species. Nor were there any differences in the proportion of tail loss among the different habitat types. This indicates that the changing vegetation has little influence on body condition. Juvenile skinks had significantly lower body condition and a lower percentage of tail loss than adult skinks. For $O$. lineoocellatum tail loss was statistically lower in replanted grid $\mathrm{G}$ compared to the other seven grids.

\subsubsection{Body condition in different habitats}

The primary factors which are considered to affect the growth of reptiles include food, water, temperature, tail loss and genetic factors (Avery 1994). Vegetation structure affects foraging (Karasov and Anderson 1984), thermoregulation (Christian et al. 1983) and predator avoidance (Stamps et al. 1983). These are known to influence the morphology of an animal (Harvey and Pagel 1991). But in habitats that are optimal for skinks, there may be high skink density and high levels of competition. Differing rates of food/cover/predation and competition are reasons for or against selecting a potential habitat type (Krebs 1994). The reason there is little difference in body condition among the habitats may be a result of the trade off involved with this choice.

The habitat types on Stephens Island have different food assemblages in both fruit and invertebrate fauna (refer to chapter 4). On Stephens Island skink density has been found to be higher in the replanted and tussock habitats (chapter 2). These areas also appear to have a wider range of food sources (chapter 4), but they may also have high levels of competition. Trap occupancy rate (reflecting skink density) is greater in the tussock than it is in replanted habitats (chapter 2), and this may be the reason why the body condition 
of $O$. lineoocellatum and $O$. nigriplantare polychroma are higher in the replanted areas than the tussock.

The body condition of juveniles was lower than that of adults, possibly due to other factors such as competition with adult skinks, inefficient feeding or energy spent on growth. In December, females had slightly higher body condition than males. Many of the females were gravid and this increased their body mass. The body condition of male and female reptiles can fluctuate, peaking at different times due to courtship or nesting (Dickinson and Fa 2000, Hailey 2000).

Oligosoma infrapunctatum was the largest of the four skink species in both SVL and weight, followed by $\mathrm{O}$. lineoocellatum. Oligosoma nigriplantare polychroma was the smallest (in SVL and weight) of the skinks. Morphological adaptation of lizards to their environment has been reported, but most studies investigate limb or tail length (Irschick et al. 2000, Melville and Swain 2000, Vanhooydonck et al. 2000, Herrel et al. 2001, Kohisdorf et al. 2001, Bickel and Losos 2002). Size of a lizard may affect the rate of heat exchange (Asplund 1974), with larger bulky lizards associated with cooler, more densely vegetated conditions (Asplund 1974, Scheibe 1987). Oligosoma infrapunctatum was the only skink found in the cooler forest habitat (chapter 4).

The effect of tail loss on body condition was examined. It is assumed that skinks missing tails have lower body condition due to the loss of tail mass. Given that there was no difference in the level of tail loss between habitats, this assumption is unlikely to have affected the results. 


\subsubsection{Tail loss in different habitats}

Tail loss and its subsequent regeneration are important survival mechanisms in many lizards (Ballinger and Tinkle 1979). For example, lizards Coleonyx variegates with tails are more likely to escape predation than C. variegates without tails (Congdon et al. 1974). The causes of tail loss are varied, but the primary factors are predation (Nemes 2002) and agonistic encounters (Gvozdik 2000). While competition or interspecific aggression may be the reason behind tail loss in some grids, it may be predation in others. For example, levels of tail loss are higher in the forest, where there are low numbers of skinks, but high numbers of tuatara (S. punctatus) (Carmichael et al. 1989). Levels of tail loss are also higher in the replanted grids and the tussock grids, where there are few tuatara (personal oberservation), but high numbers of skinks. Skinks are preyed upon by several of the bird species present on Stephens Island, including starlings (Thompson 2000), blackbirds (Bell 1996), moreporks, kingfishers, seagulls and harriers. Starlings were observed feeding in pasture, blackbirds in the forest, harriers over tussock and the redbilled gulls over Muehlenbeckia vines (chapter 4). The different causes of tail loss (such as predation or competition) may result in the lack of difference among the grids and habitat types. Phillpot (2000) also found no difference in tail loss between habitat types for $O$. lineoocellatum and $O$. nigriplantare polychroma on North Brother Island, New Zealand.

For O. lineoocellatum, the replanted grid G had lower levels of tail loss compared with the other grids. This grid has high levels of cover (from the long grass and shrubs) and comparatively few tuatara (personal observation). The density of the most aggressive skink O. lineoocellatum (East et al. 1995) was lower than in the other replanted grid. With lower levels of competition and predation, a higher proportion of skinks are able to keep their tails intact. Juveniles were more likely to have complete tails than adults. This may 
just be a function of age, the older you are, the more likely the chance of predation. Variation of differing tail loss at different ages has been found elsewhere (eg Ballinger and Tinkle 1979, Phillpot 2000).

\subsubsection{Conclusions}

Many factors influence the body condition of an animal. Despite the differences among the habitats, there was no effect on body condition or tail loss. The revegetation has not negatively affected the body condition of lizards; in fact $O$. nigriplantare polychroma and O. lineoocellatum appear to benefit from it. Vegetation on Stephens Island has been changing for the last 100 years (Brown 2000) and the skinks may have adapted to vegetation change. The skinks are able to exploit favourable habitat types. This means island restoration could be fast tracked, with no harmful effects to the body condition of skink. However, the lack of skinks in the forest indicates that a fully forested Stephens Island may decrease both skink abundance and biodiversity (chapter 2). The role of intra specific and inter specific competition, skink density and predation as a cause of tail loss needs to be further explored, possibly in a lab based experiment. This information would be very useful for the translocation of reptile species. 


\title{
Chapter 4
}

\section{The influence of microhabitat features on the distribution and abundance of skinks on Stephens Island / Takapourewa}

\begin{abstract}
I investigated the role of habitat structure, temperature, food distribution and predation on the distribution and abundance of skinks (Oligosoma lineoocellatum, O. infrapunctatum, O. nigriplantare polychroma and O. zelandicum) on Stephens Island (New Zealand). Four habitat types were studied: forest, pasture, replanted and tussock. All species were found in greater abundance in the long grass and young trees of replanted or tussock habitats. Key findings from this study indicate there are positive correlations between the density of skinks, their food sources, and the temperature of the environment and a negative correlation with the presence of predators. Thermal attributes of the environment and inter or intra-specific competition also play a role in skink distribution.
\end{abstract}

\subsection{Introduction}

Habitat selection is the collective orientational response of an animal to its environment (Heatwole 1977). Animals are not distributed randomly (Martin and Salvador 1995). Animals respond to certain environmental stimuli, both biotic and abiotic, and this can determine the distribution of the population (Krebs 1994).

Lizards respond to numerous stimuli, including substrate (Martin and Salvador 1995, Fair and Henke 1997), habitat structure (Heatwole 1977, Castilla and Bauwens 1992), threat of predation (Stamps 1983, Carrascal et al. 1989), thermoregulation (Christain et al. 1983, Singh et al. 2002), potential food sources (Karasov and Anderson 1984, Diaz and 
Carrascal 1991, Chase 1998) and evaporative water loss (Neilson 2002). Structural characteristics of the environment are primary in reptile habitat selection (Heatwole 1977, Martin and Lopez 1998).

In this study I investigated habitat characteristics in the four skinks species Oligosoma infrapunctatum, O. lineoocellatum, O. nigriplantare polychroma and O. zelandicum on Stephens Island (East et al. 1995). These skink species are omnivorous, eating both insects and fruit (McCann 1956). Oligosoma lineoocellatum and O. nigriplantare polychroma are more common in open grassy habitat (East et al. 1995), O. nigriplantare polychroma is also found in dry areas (Gill and Whitaker 2001). Oligosoma infrapunctatum is normally found in open forest, scrubby or tussock areas, and $O$. zelandicum is found in forest, shady or moist situations in farmland or gardens (Gill 1976, Gill and Whitaker 2001). These four species can occur sympatrically.

Stephens Island is a Wildlife Sanctuary in the north-western Marlborough Sounds (New Zealand) administered by the Department of Conservation (Figure 1.1). The island has experienced extensive vegetation changes; approximately $80 \%$ of the forest on Stephens Island has been removed (Brown 2000). Despite this, it has remained a refuge for many species including the tuatara, Sphenodon punctatus, Hamilton's frog Leioplema hamiltoni, three gecko species and the four skink species mentioned previously (Brown 2000). About 10,000 seedlings are planted each year on Stephens Island (Knight pers.comm) to enhance natural vegetation. There are a variety of habitats including, forest, scrub, tussock, vineland, rank grass, pasture grass and replanted areas (East et al. 1995). The skinks are distributed differently in these habitats (East et al. 1995, chapter 2), but little is known about what drives this distribution. 
I investigated the effects of habitat structure (cover and height of vegetation), temperature (maximum temperature, and the temperature range in each of the habitats), food sources (fruit and invertebrates) and threat of predation on skink abundance and/or distribution. The knowledge of what factors influence skink abundance and/or distribution is useful for species and conservation management and will help to determine any negative impacts of processes such as revegetation.

\subsection{Methods}

\subsubsection{Skink sampling}

Skinks were caught by pitfall trapping between the $26^{\text {th }}$ November $-5^{\text {th }}$ December 2002 and $8^{\text {th }}-14^{\text {th }}$ March 2003, following the recommendations of Moseby and Read (2001). There were eight grids, two for each habitat type: pasture, replanted, tussock and forest (Figure 2.1). Similar aspect, bird activity and sheep disturbance were sought throughout all grids. Actual grid location was determined by a stratified design. There were 16 pitfall traps (totalling 128 buckets) in each grid. The pitfall traps were four litre plastic buckets, with four $6 \mathrm{~mm}$ drainage holes (recommended by Philpot 2000, Markwell 2002). To prevent the skinks dehydrating, the pitfall traps had a layer of dirt and a damp sponge (moistened twice daily). The traps did not have shade covers as covers reduce the capture rate (Hobbs and James 1999). The traps were baited with a $1 \mathrm{~cm}^{3}$ piece of canned pear (Whitaker 1967). Each individual skink caught was weighed with a Pesola ${ }^{\text {TM }}$ balance, accurate to $0.5 \mathrm{~g}$, and measured with a ruler, accurate to $1 \mathrm{~mm}$, for snout-vent length (SVL), vent-tail tip, and tail regeneration. Each individual was marked with a silver metallic pen (Artline 990XF). 


\subsubsection{Vegetation}

The vegetation species composition, height and cover in the $0.89 \mathrm{~m}^{2}$ area around each pitfall trap were recorded. Species were categorised by whether they produced fruit or not. The numbers of bird burrows, slope and the aspect of each grid were also recorded.

\subsubsection{Weather and temperature}

Weather data was recorded using three methods.

1. The permanent weather station on the northern end of Stephens Island recorded the daily maximum and minimum temperatures, humidity, wind direction and speed, rainfall and atmospheric pressure.

2. From $19^{\text {th }}$ September $-22^{\text {nd }}$ November 2003 data loggers (Tidbit Stowaway Onset Computer Corp) were placed in each grid to record the temperature every two hours (Figure 2.1).

3. Cloud cover and wind strength were recorded on an arbitrary scale from 1 to 5 .

1. No cloud cover and / or no wind

2. Few clouds and / or light winds (breeze)

3. Moderate cloud cover, and / or moderate winds

4. Compete cloud cover over the sky, and / or strong winds

5. Fog, mist or rain and / or gale force winds.

\subsubsection{Invertebrate sampling}

Data collected by Tim Markwell in 1996 was used to estimate the distribution and abundance of invertebrates in different habitats (Markwell 1999). Markwell's forest, pasture and tussock grids (A, B, D and E, Figure 2.1), were the same as those used for this study. 
In addition, invertebrate were sampled in conjunction with Jennie Franke and Tim Markwell $17^{\text {th }}-21^{\text {st }}$ November 2003. Two grids were laid in three habitat types (forest, replanted and pasture). Grids were the same as those used for the skink research, forest ( $A$ and $B)$, replanted $(C$ and $G$ ) and pasture $(F$ and $H)$ (Figure 2.1). In each grid five insect pitfall traps were laid in a $1 \mathrm{~m}^{2}$ area. Pitfalls were small plastic vials with lids to prevent skinks, weta and litter from entering the pitfall trap. Inside the vials Goults solution was used to preserve the invertebrates. The biomass, diversity (at order level) and abundance were recorded.

\subsubsection{Predation}

The feeding behaviour of birds was observed during daylight hours, from the $16^{\text {th }}-23^{\text {rd }}$ November 2003. Birds were watched for two to three hours at a time. All feeding observations were recorded along with time intervals between each feeding session.

\subsubsection{Data analysis}

Data analysis was conducted using SPSS version 11.0. ANOVA with a bonferroni correction applied to the capture rate of skinks per trap per day (chapter 2.2.4) to determine if the trap occupancy rate differed for skink species between different habitat types. Levene's test was used to determine whether the data set followed a normal distribution. Linear regression was used to determine whether temperature, cloud cover or wind level had any effect on the capture rate of skinks. 


\subsection{Results}

\subsubsection{Vegetation: Cover and Height}

Both vegetation cover $(\sim 70 \%)$ and height $(\sim 3 \mathrm{~m})$ were greater in the forest, than the other habitat types (Appendix A). The pasture had little to no cover, and the grass had a maximum height of $0.25 \mathrm{~m}$. Cover in the tussock grids was nearly $30 \%$ while the height was $0.25 \mathrm{~m}$ (s.e. 0.12 ) on average. Cover differed in the two replanted habitats; grid C had $39 \%$ cover, while grid $G$ had $18 \%$. Height averaged 0.9 m (s.e. 0.37) (Appendix A).

Height of the vegetation was positively correlated with the percentage cover $(F=5.097, p$ $<0.0005$ ). Capture rate of the skinks (total and by species) was not significantly related to either vegetation height or cover (Table 4.1and Figure 4.1), except plant cover did negatively affect the capture rate of $O$. nigriplantare polychroma (Table 4.1). Oligosoma zelandicum is not included in analyses as there were too few captures. 
Table 4.1: ANOVA table of skink captures (total and by species) and their relationship to cover and height of the vegetation surrounding the pitfall traps

\begin{tabular}{|c|c|c|c|c|c|c|c|}
\hline & Source & & $\begin{array}{l}\text { Sum of } \\
\text { Squares }\end{array}$ & $\mathrm{df}$ & $\begin{array}{l}\text { Mean } \\
\text { Square }\end{array}$ & $\mathrm{F}$ & Sig \\
\hline \multirow[t]{4}{*}{ Total skink captures } & Cover & & 9826.72 & 38 & 258.6 & 1.14 & .41 \\
\hline & Height & & 10684.8 & 35 & 305.28 & 1.34 & .28 \\
\hline & Cover & * & 8047.57 & 36 & 223.54 & 0.98 & .54 \\
\hline & Height & & & & & & \\
\hline \multirow[t]{4}{*}{ O. infrapunctatum } & Cover & & 136.05 & 38 & 3.58 & .39 & .99 \\
\hline & Height & & 150.70 & 35 & 4.31 & .46 & .97 \\
\hline & Cover & * & 92.23 & 36 & 2.56 & .28 & 1.0 \\
\hline & Height & & & & & & \\
\hline \multirow[t]{4}{*}{ O. lineoocellatum } & Cover & & 10857.56 & 37 & 293.45 & 1.05 & .49 \\
\hline & Height & & 15853.10 & 34 & 466.27 & 1.67 & .16 \\
\hline & Cover & * & 5426.51 & 34 & 159.6 & 0.57 & .91 \\
\hline & Height & & & & & & \\
\hline \multirow[t]{4}{*}{ O. n. polychroma } & Cover & & 1632.85 & 38 & 42.97 & 3.31 & .01 \\
\hline & Height & & 612.45 & 35 & 17.5 & 1.35 & .28 \\
\hline & Cover & * & 572.32 & 36 & 15.9 & 1.22 & .35 \\
\hline & Height & & & & & & \\
\hline
\end{tabular}




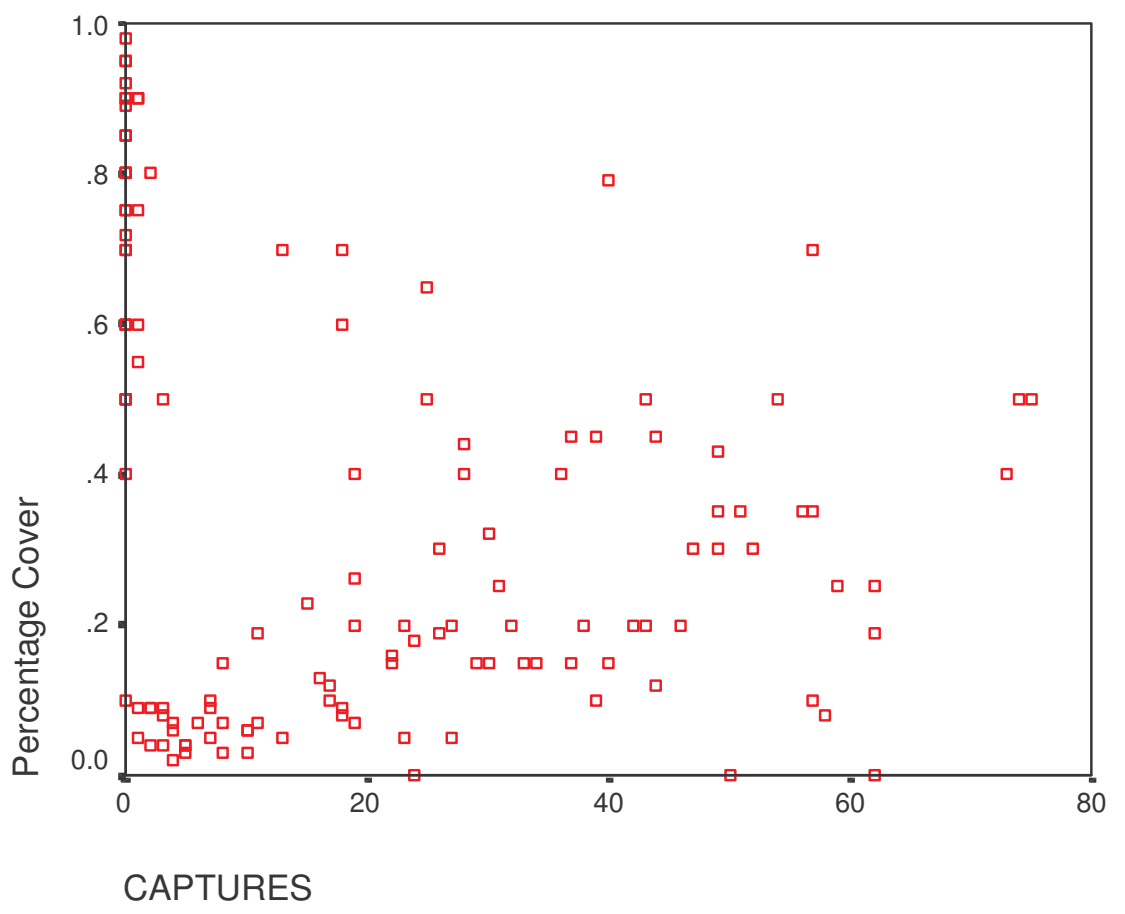

Figure 4.1 Total skink captures per trap compared with the cover of the vegetation over each pitfall trap. $P$ value is 0.413 .

\subsubsection{Trap occupancy of skinks in different habitats}

The trap occupancy of $O$. infrapunctatum in replanted habitat was significantly higher than in the forest or the tussock. Trap occupancy of $O$. lineoocellatum was also significantly higher in the replanted than in the tussock and pasture habitats, but more $O$. lineoocellatum were caught in the tussock than in the pasture. Trap occupancy for $O$. nigriplantare polychroma was significantly higher in the tussock than the replanted and pasture habitats, and higher in the replanted compared to the pasture. For Oligosoma zelandicum the only statistical difference in trap occupancy was between the replanted and the tussock (Figure 4.2, Table 4.2). 


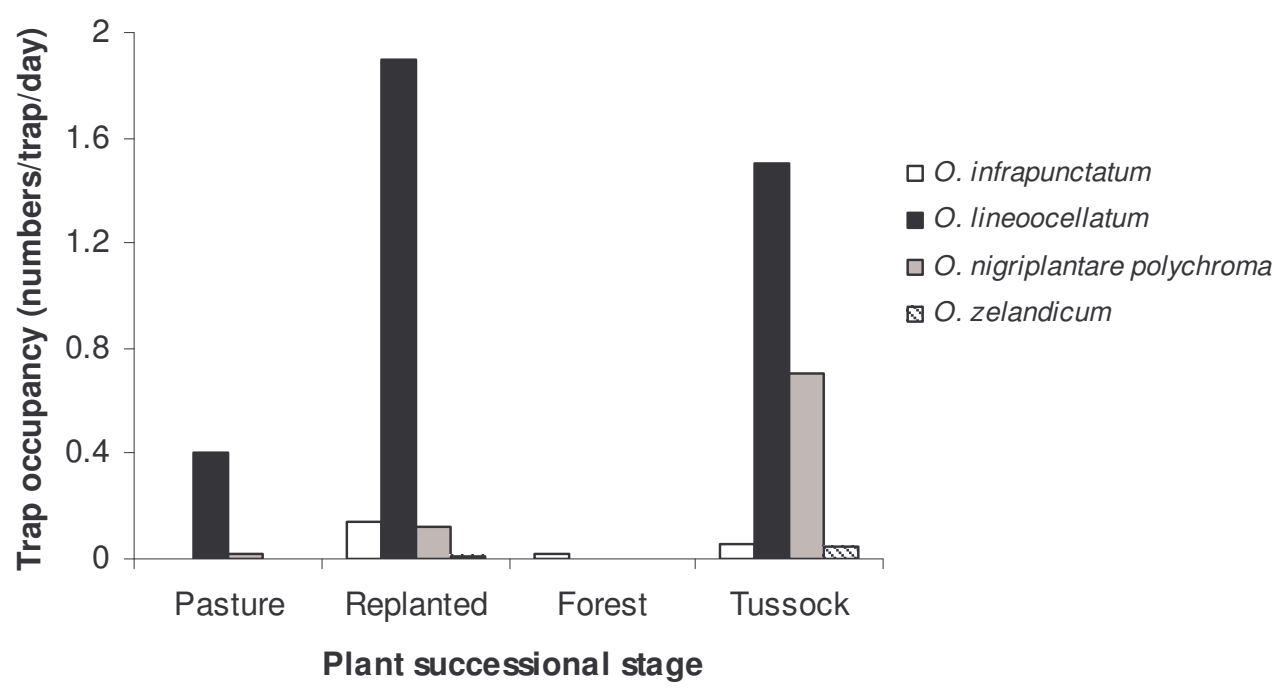

Figure 4.2 Capture rates of the four skink species in different habitats on Stephens

Island. Total capture rate was highest in the tussock grids compared to the other grids.

Table 4.2 Comparison of whether skink capture rate differs in different habitats.

Bon is the bonferroni adjustment (the $P$ value has to be under this value to be significant), $r$ represents replanted, $p=$ pasture, $t=$ tussock and $f=$ forest habitat, *significant differences

\begin{tabular}{llllllll}
\hline Species & $F p$ & $F r$ & $F t$ & $P r$ & $P t$ & $R t$ & Bon \\
\hline O. infrapunctatum & 0.49 & $0^{*}$ & 0.02 & 0.19 & 0.45 & $0^{*}$ & 0.008 \\
O. lineoocellatum & 0.16 & 0.02 & 0.02 & $0^{*}$ & $0^{*}$ & $0^{*}$ & 0.008 \\
O.n. polychroma & 0.51 & 0.20 & 0.03 & $0^{*}$ & $0^{*}$ & $0^{*}$ & 0.01 \\
O. zelandicum & NA & 0.56 & 0.44 & 0.56 & 0.44 & $0^{*}$ & 0.017 \\
\hline
\end{tabular}

\subsubsection{Weather and temperature}

\section{Temperature and the capture rate}

The total capture rate of skinks was positively affected by the maximum temperature $(F=$ 63.31, $\mathrm{p}<0.005$ ) (Figure 4.3 and 4.4 ) for both trips. 


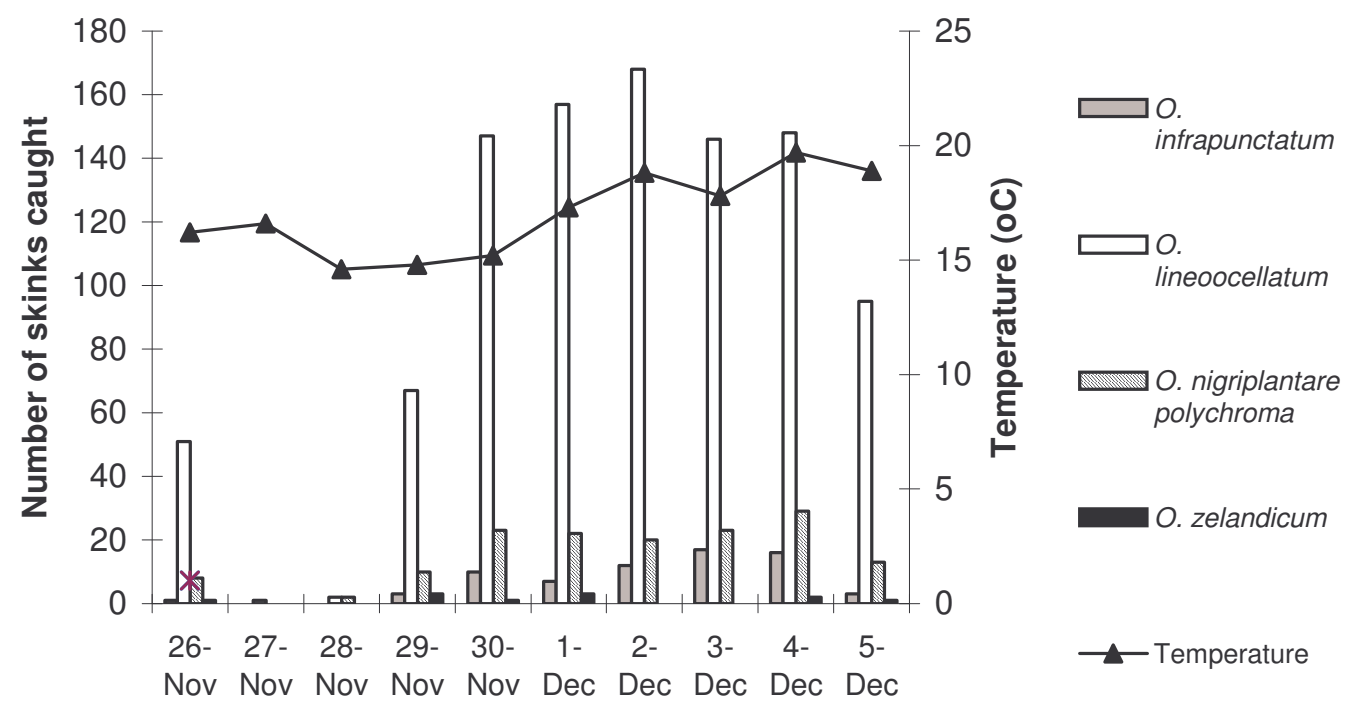

Capture occasion

Figure 4.3 Comparison of skink capture rate with the maximum daily temperature in December.

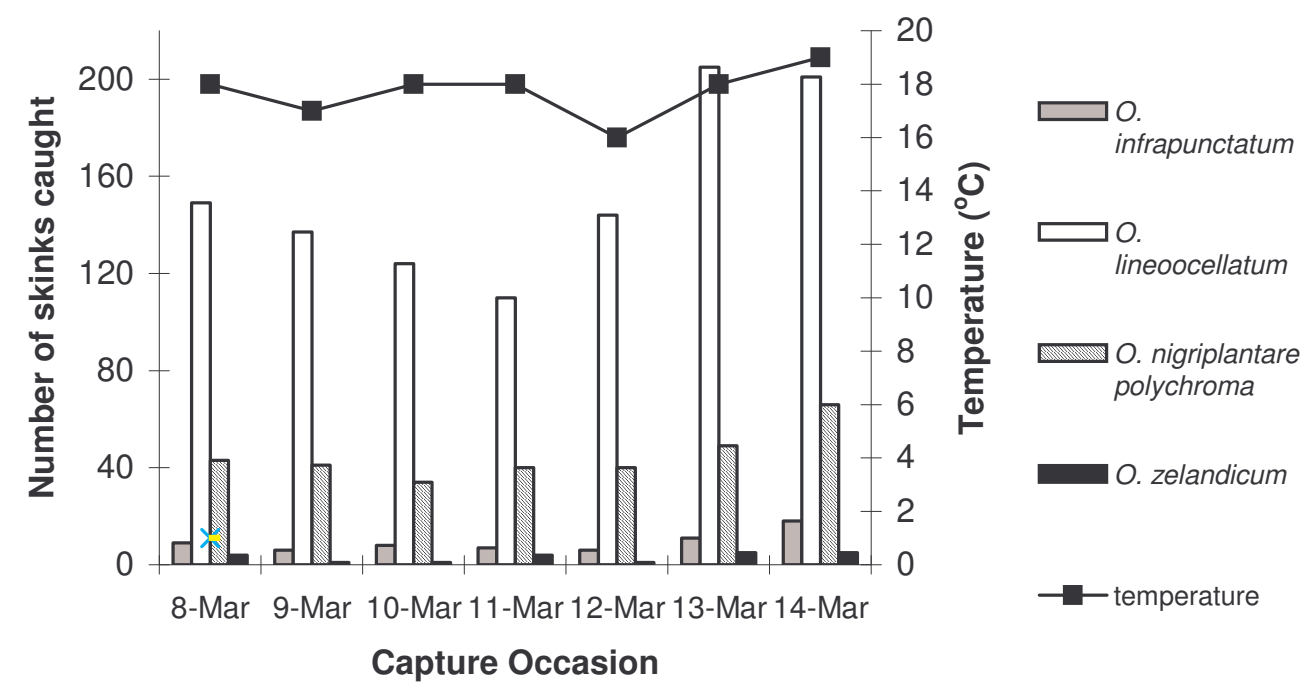

Figure 4.4 Comparison of skink capture rate with the maximum daily temperature in March 


\section{Temperature differences between different grids and habitat types}

The average temperatures were significantly different between the grids $(F=30.08, p<$ 0.005). The forest grids had a smaller temperature range and were cooler than the other grids (Figure 4.5). The average temperature of the habitat types differed significantly over the sampled period $(F=49.49, p<0.005)$, with the forest being the coolest habitat and the pasture the warmest (Table 4.3).

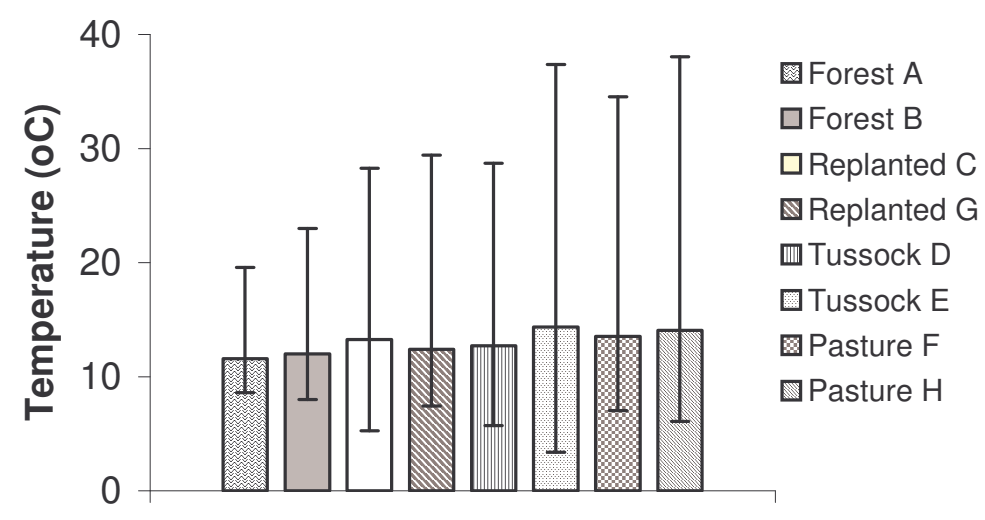

Habitat

Figure 4.5 Average temperatures and temperature range (minimum - maximum) for all grids on Stephens Island between 19/09/03 - 22/11/03

Table 4.3 Comparison of the average temperature from data loggers on Stephens Island, between different habitat types from the 19/09/03 - 22/11/03.

\begin{tabular}{lllll}
\hline Habitat 1 & Habitat 2 & $\begin{array}{l}\text { Mean difference } \\
(1-2)\end{array}$ & $\begin{array}{l}\text { Standard } \\
\text { error }\end{array}$ & P value \\
\hline Forest & Pasture & -2 & 0.18 & 0.00 \\
Forest & Replanted & -1.03 & 0.17 & 0.00 \\
Forest & Tussock & -1.74 & 0.18 & 0.00 \\
Pasture & Replanted & 0.96 & 0.19 & 0.00 \\
Pasture & Tussock & 0.26 & 0.16 & 0.46 \\
Replanted & Tussock & -0.71 & 0.18 & 0.00 \\
\hline
\end{tabular}




\section{Cloud, wind and the skink capture rate}

Wind did not significantly affect the combined capture rate of all the skinks $(F=1.87, p=$ 0.192) (Figure 4.6). Cloud cover was negatively correlated with the combined capture rate of the skinks $(F=14.03, p=0.002)$ (Figure 4.7).

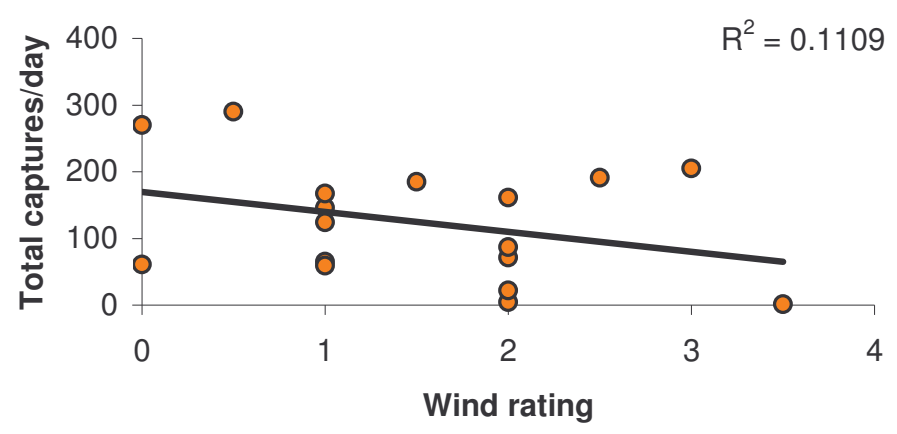

Figure 4.6 The total capture rate of skink species on Stephens Island in relation to the strength of the wind. Findings are not significant.

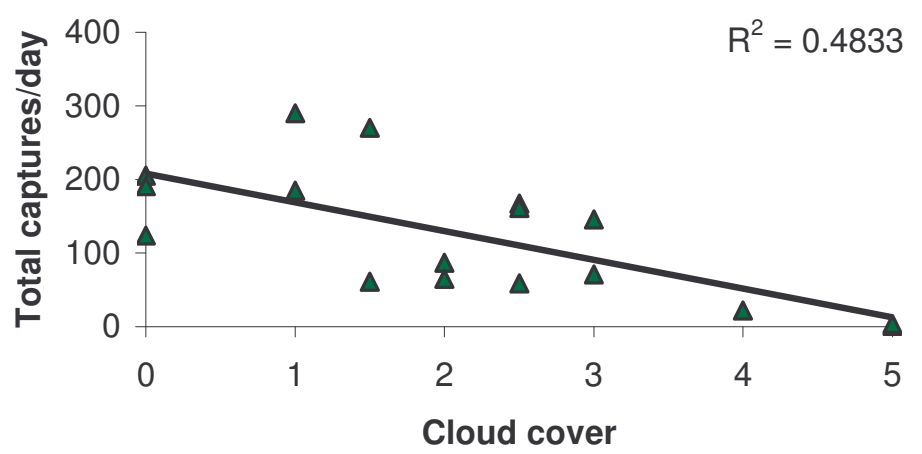

Figure 4.7 The total capture rate of skink species on Stephens Island in relation to the level of cloud cover. Findings are significant. 


\subsubsection{Food sources}

\section{Fruiting plant species}

The forest, tussock and replanted areas all have fruiting plant species present in their grids. The forest had the greatest proportion of fruiting species ( 90\%), however most of these were high above the ground in areas not accessible to skinks. The fruiting species in the replanted grids and tussock grids were on average less than a metre high and more accessible to skinks (Figure 4.8).

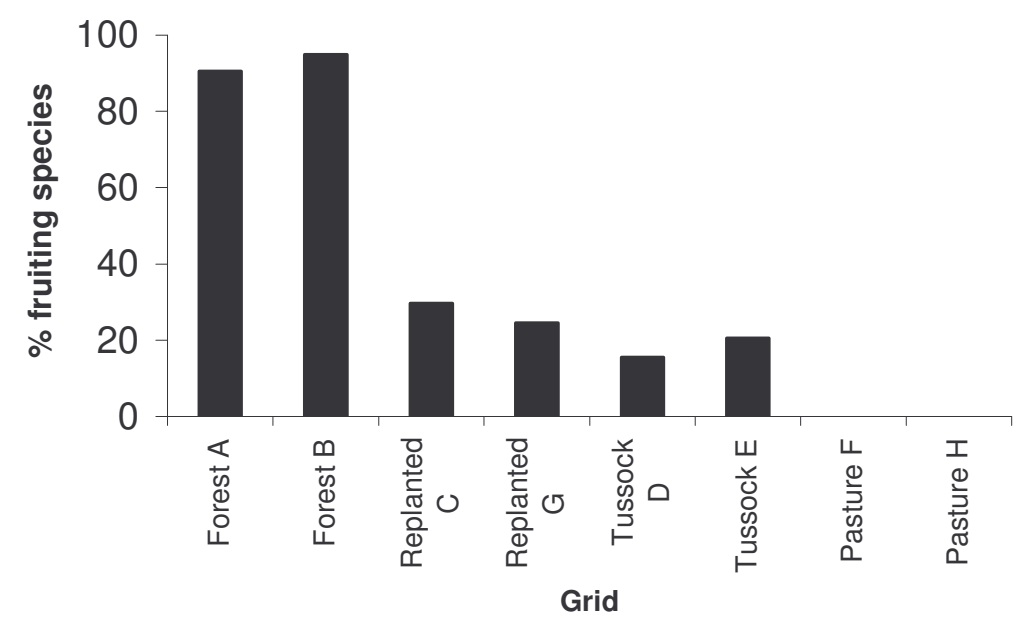

Figure 4.8 The proportion of species that fruit in each of the grids and different habitat types on Stephens Island.

\section{Invertebrate distribution}

Markwell (1999) found 24 families of invertebrate on Stephens Island. Of these, 16 were found in the pasture, 19 in both the grassland and the forest, and 23 in the shrub habitat. Invertebrates numbers were higher in the pasture, than in the other three habitat types (Markwell 1999) (Figure 4.9), due partly to large numbers of Colembola. 


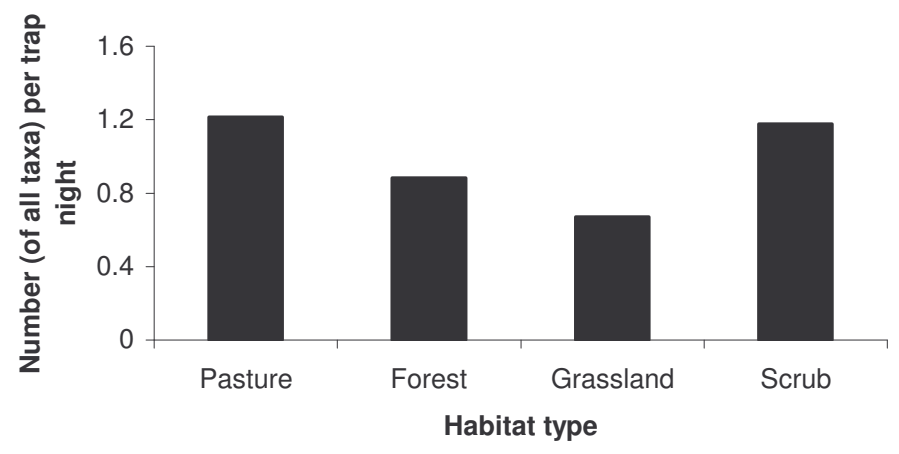

Figure 4.9 The number of invertebrates in each habitat type on Stephens Island (Markwell 1999).

In 2003 , ten orders of invertebrates were found in the replanted habitat, nine in the pasture and seven in the forest. There was no statistical difference in the invertebrate capture rates between the habitat types $(F=0.36, p=0.7)$. The replanted habitat caught the largest number of invertebrates over $2 \mathrm{~mm}$ in size, with a mean of 16.5 animals per trap (s.d. 3.31). The pasture caught 12.9 (6.04) invertebrates per trap, and the forest caught the least with $11.8(4.64)$ invertebrates.

\subsubsection{Bird predation}

One incidence of predation of a lizard by a bird was observed on the $20^{\text {th }}$ of November at 13:20. A red-billed gull was observed catching a lizard (probably a green gecko or large skink) on top of Muehlenbeckia vines near the summit on the western side of the island. Once the lizard was caught, the bird flew out to sea and returned ten minutes later without the lizard. The gull used wind currents to hover and glide low over patches of Muehlenbeckia. The bird was seen pouncing five times over an hour period, but only once seen with a lizard. Other gulls have been seen gliding over patches of 
Muehlenbeckia and a similar incidence of predation has also been seen by Margaret Freeman (pers. comm).

Blackbirds were observed in the forest, and hunting in and on the Muehlenbeckia vines throughout the observation period. During the December 2002 sampling period, a nest of blackbirds was located in the forest. Starlings were seen hunting in the pasture, collecting insects. The starlings nest in the palace (an old store house) and the shearing sheds behind the palace, and were observed feeding their young approximately every 20 minutes with invertebrates. Harriers were observed flying over grass and tussock patches, possibly hunting. They were once seen on the ground (Raewyn sEmpson pers comm). No birds were observed hunting in the replanted habitat with long grass.

\subsection{Discussion}

Key findings from this study indicate there are positive correlations between the skink density, their food sources, and the temperature of the environment, and a negative correlation with the presence of predators. Thermal attributes of the environment and inter or intra-specific competition also play a role in skink distribution.

\subsubsection{Skink density and distribution}

Skink species distribute themselves differently across the habitat types (chapter 2). The forest habitat had less temperature variation and was coolest of the habitats. Size of a lizard may affect the rate of heat exchange, with larger lizards associated with cooler, denser vegetation (Asplund 1974, Scheibe 1987). Oligosoma infrapunctatum (the largest skink species) was the only skink found in the cooler forest habitat. The smallest skink species, O. nigriplantare polychroma, was predominantly found in the warmer tussock habitat. 
Oligosoma lineoocellatum dominates the capture rate in the pasture, replanted and tussock habitats and is the more aggressive species (East et al. 1995). Skink density is highest in the tussock and replanted habitats (chapter 2), which implies greater competition occurs in these habitats. Both inter and intra-specific competition play a role in skink distribution, potentially forcing skinks into sub-optimal habitat. For example, immigration rates of the lizard Lacerta vivipara are negatively affected by density (Massot et al. 1992). The young of the lizard Sceloporus undulates are often driven into suboptimal habitat where there is greater predation risk (Parker 1994). This study did not investigate inter or intra specific competition.

\subsubsection{Predation on lizards}

Predation is assumed to be one of the major causes of lizard mortality (Waide and Regan 1983, Dunham et al. 1988). Birds are important predators of reptiles (Greene 1988, Martin and Lopez 1996, Blomberg and Shine 2000). Birds were seen in the forest and pasture, but not in the replanted habitats. Predators of skinks, such as starlings were recorded feeding in the pasture. Blackbirds and moreporks were sighted in the forest. A starling on Stephens Island was recorded catching three skinks within 1.5 hours in pasture (Thompson 2000). For the rock dwelling gecko Oedura lesueurii, avoiding predation was the most important attribute in habitat selection (Downes and Shine 1998). Lizards living in more conspicuous habitats (such as pasture) have lower survival rates and greater injury rates (Parker 1994).

Birds are unlikely to hunt in areas where they cannot locate food (Selas 2001). Long grass blocks a bird's view of potential prey. The decrease in the number of foraging birds in the Chihuahuan desert was associated with the increase in herbaceous vegetation 
(Brown and Heske 1990). Another potential skink predator, the tuatara, is a visual predator (Meyer-Rochow 1991). Prey items are less visible in long grass and the chance of the prey item escaping may increase as smaller animals have greater mobility. For these reasons predation pressure may be lower in the replanted habitat.

\subsubsection{Food sources}

Invertebrate fauna benefit from revegetation (Collinge 2000), for example, revegetation increased the abundance and species richness of Coleoptera on Matiu-Somes Island (Watts and Gibbs 2002). Skinks are omnivorous and will eat any invertebrate they can overpower (McCann 1956).

Both the current survey and the Markwell (1999) survey found more orders of invertebrates in revegetated or scrub habitat. I found no significant difference between invertebrate numbers and the vegetation type, although numbers were greater in the replanted habitat. This invertebrate survey was small. A more in-depth survey may find greater differences. There were a greater percentage of accessible fruiting plants in the replanted and the tussock habitats. Greater sources of food supply lead to a decreased home range for skinks (Eifler and Eifler 1999) and therefore a greater density of skinks. Food availability has been shown to influence population density and location (Boutin 1990, Pitt 2002).

\subsubsection{Vegetation cover and height}

The capture rate of skinks was not altered by cover or vegetation height surrounding each pitfall trap (with exception of cover for O. nigriplantare polychroma). Reptiles are known to seek out habitats with specific thermal attributes to regulate their body temperature (Huey et al. 1982, Singh et al. 2002). Skink thermoregulatory behaviour may 
hide any interaction between the capture rate and vegetation height or cover; skinks may seek sunshine or shade depending on the temperature of the surrounding environment to obtain optimal temperature. The lizard Lacerta lepida has been shown to select complex habitats (Castilla and Bauwens 1992). Complex habitats, such as the revegetating areas provide a wider thermal range.

\subsubsection{Wind and cloud cover}

Wind did not affect the capture rate, but skinks are small enough for the pasture grass to shelter them. Capture rate was affected by the level of cloud. A positive correlation between cloud cover and temperature was also found in Otago skink Oligosoma grande (Coddlington and Cree 1997). Skinks, being exothermic reptiles, are more likely to be caught when they are not inhibited by thermal inertia.

\subsubsection{Conclusion}

Food sources, threat of predation, competition and thermal attributes play important roles in the selection of a habitat. The replanted and tussock habitats have significantly higher numbers of skinks than the pasture or the forest habitats. Both habitats had accessible fruit, and a variety of invertebrates. Both also have a range of vegetative cover, giving a wider thermal range. Predation is possibly lower in the replanted habitat. Revegetated areas currently support high a density and diversity of skinks due to numerous attributes of the environment. However, should revegetation, through plantations or natural plant succession create more forest habitat it is likely that skink populations will decline (chapter 2). Maintaining a mosaic of habitat types will protect Stephens Island biodiversity. 


\section{Chapter 5.}

\section{The use of toe clips to determine wild skink survival}

Toe clips were used to mark individual skinks for a 1992 mark-recapture study into the distribution and abundance of the reptile species on Stephens Island (East et al. 1995). The skink species were Oligosoma infrapunctatum, $O$. nigriplantare polychroma, $O$. lineoocellatum and O. zelandicum. In 2002-2003 summer, I investigated revegetation effects on skinks. In doing so, I was able to search for the toe clipped skinks from the East et al. (1995) survey to estimate wild skink survival.

Two surveys were undertaken: $26^{\text {th }}$ November $-4^{\text {th }}$ December 2002 and $8^{\text {th }}-15^{\text {th }}$ March 2003. There were eight grids, two in each habitat type (forest, tussock, pasture and replanted) each with 16 pitfall traps. Four grids were replicates of the East et al. (1995) survey, one forest, one replanted, and both tussock grids.

\section{Results}

I found numerous animals with missing toes (11\% or 92 individuals), but none that matched the combinations of the East et al. (1995) survey. Natural toe loss could change the unique toe clip number of a skink through predation (Nemes 2002) or antagonistic encounters (Gvozdik 2000). This possibility was investigated, but without results. From this work, I was unable to determine skink survival in the wild, either because the individual skinks had died or emigrated, or because I could not distinguish between toe clips and natural toe loss so the original toe clip number has been lost. 


\section{Discussion}

Little is known about survival of reptiles in the wild. The longest known record in New Zealand is of tuatara with survival estimated at $80+$ years (Nelson unpubl. data). The Duvaucel's gecko Hoplodactylus duvaucelii (Thompson et al. 1992) and the common gecko $H$. maculatus are known to have survived for at least 36 years in the wild (Bannock 1999). In captivity skinks in New Zealand have been known to live for 30+ years; two skinks, Cyclodina whitakeri and C. macgregori, caught as adults in the late 1960s, are still breeding (Dennis Keall pers.com). Skink survival rate in the wild depends on a variety of factors, including, predation and food supply. Ctenotus species in the Southern Australian arid zone was found to have longevity exceeding three years in $C$. regius, four years in C. schomburgkii and five years in C. leonhardii (Read 1998). Founding individuals of a translocation of three skink species Cyclodina alani, C. oliveri and Oligosoma whitakeri on Korapuki Island (Mercury Islands), New Zealand, were caught 12 years after release (Towns and Ferreira 2001).

This survey suggests that toe clips for skink populations may not provide an accurate measure for long-term studies. Ten years for some species may be too long to track individuals, especially with large populations and low capture probability. The longevity of reptiles in the wild is hard to determine, as marked individuals need to be followed for more than one or two seasons. With the ongoing monitoring of reptile populations more accurate information about New Zealand reptile survival may be formed. 


\section{Chapter 6.}

\section{Summary of results and discussion}

Ecological restoration, which often includes revegetation, is normally considered to be beneficial for native fauna. However, research predicts that only one, Oligosoma infrapunctatum, of the four skink species (Oligosoma lineoocellatum, O. nigriplantare polychroma, $\mathrm{O}$. infrapunctatum and $\mathrm{O}$. zelandicum) will benefit from revegetation on Stephens Island (East et al. 1995). I investigated the impact of revegetation on the distribution, abundance and body condition of skinks on Stephens Island to test this prediction. I also investigated the survival rate of skinks in the wild and potential factors that may influence skink distribution. This information was collected over two survey trips in December 2002 and March 2003. The survey was conducted under Department of Conservation permit number LIZ0203, and Victoria University of Wellington Animal Ethics Approval, permit number 2002R8.

\subsection{Summary results}

A total of 651 individual skinks were caught between $26^{\text {th }}$ November $-5^{\text {th }}$ December, 2002 and 714 individual skinks were caught between $8-14^{\text {th }}$ March 2003 . All captured skinks were weighed, measured, numbered and released. Over both trips $O$. lineoocellatum was the most abundant skink, followed by the $O$. nigriplantare polychroma, O. infrapunctatum and O. zelandicum (Table 6.1) 
Table 6.1: Total number of skink individuals caught //(percentage of total).

\begin{tabular}{llllll}
\hline Trip & O. lineoocellatum & O. infrapunctatum & O. n. polychroma & O. zelandicum & Total \\
\hline December & $501(77 \%)$ & $40(6 \%)$ & $96(15 \%)$ & $14(2 \%)$ & 651 \\
March & $499(70 \%)$ & $33(5 \%)$ & $164(23 \%)$ & $18(2 \%)$ & 714 \\
Totals & $1000(74 \%)$ & $73(5 \%)$ & $260(19 \%)$ & $32(2 \%)$ & 1365 \\
\hline
\end{tabular}

\subsubsection{Abundance, density and distribution of skinks}

Population and density estimates could only be performed on $O$. lineoocellatum as the capture and recapture rates of the other three species of skink were too low. Oligosoma lineoocellatum was the most abundant of the species ( $74 \%$ of all individuals caught). The density of $O$. lineoocellatum was highest in the replanted area (3020/ha in December and $3770 /$ ha in March), followed by the tussock (2690/ha in December and 2560/ha in March). Its density was lowest in the pasture (1740/ha in December and 1960/ha in March). Oligosoma lineoocellatum density in the replanted habitat was significantly higher than in the tussock. In December density was significantly higher in replanted and tussock habitat compared with the pasture.

The replanted and tussock habitats had the greatest diversity of skinks. The tussock habitat had all four skink species present. Oligosoma infrapunctatum was the only skink found in the forest, while $O$. lineoocellatum was the only skink found in the pasture (except for a few O. nigriplantare polychroma in March).

Significantly more $O$. infrapunctatum were caught in the replanted areas than were caught in either the tussock or the forest. The number of $O$. nigriplantare polychroma 
caught was significantly higher in the tussock than the replanted habitats, and higher in the replanted area than the pasture. Oligosoma zelandicum was only found in the tussock and replanted grids, the capture rate was significantly higher in the tussock than the replanted grids.

\subsubsection{Change over time: The impact of revegetation}

There has been little change in the abundance and diversity of skinks since the East et al. (1995) survey in areas where the vegetation has remained unchanged. The forest, tussock and pasture grids recorded similar capture rates and species diversity.

The diversity and abundance of skinks have increased in the area that was previously pasture during the East et al. (1995) survey and has since been replanted. Previously only O. lineoocellatum were caught in this grid. Now all four skink species have been captured. The trap occupancy rates have increased, $O$. lineoocellatum from 0.33 to 2.5 , for $O$. nigriplantare polychroma from 0.03 to 0.11 and for $O$. infrapunctatum from 0.01 to 0.22. Oligosoma zelandicum trap occupancy increased from 0.00 to 0.01 .

The density for $O$. lineoocellatum in the replanted habitat is not significantly different between the two studies. The East et al. (1995) survey found few skinks resulting in a wide density estimate of $224-17363 /$ ha at the $95 \%$ confidence level. This survey gave 95\% density estimates ranging from 2930-4111/ha.

\subsubsection{Morphology and body condition}

Oligosoma infrapunctatum was the largest of the four species of skink with snout-vent length (SVL) ranging from $31-115 \mathrm{~mm}$ over both trips. Oligosoma lineoocellatum had an

SVL range of $22-101 \mathrm{~mm}$, O. nigriplantare polychroma ranged from $34-79 \mathrm{~mm}$. Oligosoma 
zelandicum had a smallest SVL range of $44-68 \mathrm{~mm}$. In most cases the difference in the body condition of the skinks in the different habitats was not significant. Body condition was higher in replanted and tussock habitats for $O$. lineoocellatum and $O$. nigriplantare polychroma in March.

\subsubsection{Tail loss}

The proportion of the population showing evidence of tail loss did not differ among the habitat types or species. Approximately $82 \%$ of the skinks had evidence of tail loss. Juveniles consistently exhibited lower levels of tail loss ( 48\%) than adult skinks. For $O$. lineoocellatum, replanted grid G had lower levels of tail loss compared to the other grids, possibly due to lower levels of competition and predation.

\subsubsection{Other results}

No toe clipped individuals from the East et al. (1995) survey in 1992 were found. There are possibly two explanations for this: (1) the individuals were not there to be found as they had either died or migrated, or (2) the toe clips could no longer be read.

The capture rate of skinks was not affected by the vegetation height or the cover or by wind level. Capture rate was altered by the maximum daily temperature and cloud cover.

Bird predation was observed to be higher in the pasture and forest habitats. Starlings (Sturnus vulgaris) were often observed feeding in the pasture. A red-billed gull (Larus scopulinus) was observed hunting and capturing a lizard basking on top of Muehlenbeckia vines. 
There was no significant difference in the capture of invertebrate among the habitat types. Invertebrate diversity was higher in scrub and replanted habitats. The replanted and tussocks had a greater proportion of accessible fruiting plants than the forest or pasture habitats.

\subsection{General discussion}

Each skink species was predominantly found in one habitat type, either the replanted or the tussock habitat. This may indicate microhabitat specialisation caused either by competition or local adaptation to a particular niche. Oligosoma lineoocellatum may be a generalist species benefiting from disturbance such as vegetation change.

Oligosoma nigriplantare polychroma are found in greatest abundance in the warmer tussock. Oligosoma infrapunctatum was the largest of the four species and was more common in shaded cooler habitats. Larger skink species are often found in cooler habitats (Asplund 1974). Oligosoma zelandicum was the rarest and hardest to catch of the four skink species; it is found primarily in the tussock area in traps surrounded by vine. Rufaut and Clearwater (1998) indicate that $O$. zelandicum may be crepuscular. If this is the case, there is a chance that this survey may have missed $O$. zelandicum.

The height and cover of the surrounding vegetation had no impact on the capture rate of skinks. There was more food in the replanted and tussock habitats. However there was no statistical difference between the habitat types. Birds were observed feeding in the pasture, tussock, and forest habitats. No birds were observed in the replanted habitats. Correlations indicate that food sources, potential predation and thermal attributes play crucial roles in skink distribution. 
Despite the differences among the habitats, there were no differences in either body condition or the proportion of tail loss between the habitats. Changing vegetation did not seem to negatively affect skink body condition. Different habitats may have different causes of stress and these may explain the lack of difference in body condition index or proportion of tail loss between habitats.

\subsection{Limitations of the study}

This project only provides a snap shot in time for the skink species and populations on Stephens Island. I did two surveys of Stephens Island. Greater monitoring would have increased the accuracy of the density estimates. Further replication of the habitats studied would have increased the accuracy of the results and predictions.

Given the numbers of animals caught, time constraints and permit reasons permanent marking would not have been possible. A longer study period with permanent marks is likely to have increased the accuracy of the results, particularly with O. infrapunctatum, O. nigriplantare polychroma and O. zelandicum. Permanent marks would also give survival estimates between trips. Density estimates would be useful for $O$.

infrapunctatum, O. nigriplantare polychroma and O. zelandicum for comparison, but as the captures and recaptures were too low no estimate could be made. Using trap occupancy rates to compare species abundance may be inaccurate as the species may have different probabilities of capture. Future research will be necessary to provide a more accurate picture and account for greater variation in the skink populations on Stephens Island. 


\subsection{Predictions and conservation implications}

When disturbance levels are high, species are in danger of becoming extinct. When disturbance levels are low, the system may enter competitive equilibrium and species of low competitive ability are lost. Intermediate levels of disturbance such as revegetation maximise biodiversity (Krebs 1994). The current mosaic vegetation suggests that Stephens Island is probably at the peak of the intermediate disturbance curve. A fully forested island is likely to decrease biodiversity.

Many reptile species are becoming rare on the mainland, and Stephens Island currently provides a good source for skink translocations. For example, $O$. lineoocellatum is rare in the Wellington region (Whitaker 1982), but is very common on Stephens Island. Forty six Oligosoma infrapunctatum were translocated from Stephens Island to Maud Island in early 2004. Of the four species of skink, $O$. infrapunctatum is the most threatened. Oligosoma infrapunctatum is the only species found in the forest and possibly the only species that could benefit from long term restoration.

All skink species are more abundant in the long grass and young trees of the replanted or the tussock habitat. The greater abundance in the replanted areas suggests that, for now, revegetation benefits skink populations. If revegetation, through plantations or plant succession, creates more forest habitat it is likely that the all four species will decline in numbers. It may be argued that skink density may be higher than it was in pre European times, due to an increase in the proportion in suitable habitat in the island. Each species could potentially be managed by adjusting the proportion of habitat types. A mosaic of vegetation types, where some areas are replanted and others (such as the tussock), are left as they are, is recommended to maintain the current levels of biodiversity. 


\section{References:}

Althoff, D. M., Thompson, J.N., 1994: The effects on tail autotomy on survivorship and body growth of Uta stansburiana under conditions of high mortality. Oecologia 100: 250-255.

Andrews, R. M. 1976. Growth rate in island and mainland anoline lizards. Copeia 1976:477-482.

Arnold, E. N., 1984a: Evolutionary aspects of tail shedding in lizards and their relatives. Journal of Natural History 18: 127-169s.

Arnold, E. N., 1984b: Variation in the clocal and hemipenial muscles of lizards and its bearing on their relationships. ed. Ferguson, M.W.J. In The Structure, development and evolution of reptiles. Zoological Society of London Symposia 52: 47-85.

Asplund, K. K., 1974: Body size and habitat utilization in whiptail lizards (Cnemidophrus). Copeia 1974: 695-703.

Avery, R. A., 1994: Growth in reptiles. Gerontology 40: 193-199.

Ballinger, R., Tinkle, D.W., 1979: On the cost of tail regeneration to body growth in lizards. Journal of Herpetology 13: 374-375.

Ballinger, R., Congdon J.D., 1980: Food resource limitiation of body growth rates in Sceloporus scalaris (Sauria: Iguanidae). Copeia 1980: 921-923.

Bannock, C.A., Whitaker, A.H., Hickling, G.J. 1999: Extreme longevity of the common gecko (Hoplodactylus maculatus). New Zealand Journal of Zoology 23: 101-103.

Bell, B. D., 1996: Blackbird (Turdus merula) predation on the endemic copper skink (Cyclodina aenea). Notornis 43: 213-218.

Bickel, R., Losos, J.B., 2002: Patterns of morphological variation and correlates of habitat use in Chameleons. Biological Journal of the Linnean Society 76: 91-103.

Blomberg, S. P., Shine, R., 2000: Size-based predation by kookaburras (Dacelo novaeguineae) on lizards (Eulamprus tympanum: Scincidae): what determines prey vulnerability? Behavioural Ecology Sociobiology 48: 484-489. 
Boutin, S. 1990: Food supplementation experiments with terrestrial vertebrates: patterns, problems with the future. Canadian Journal of Zoology 68:203-220.

Brown, J. H., Heske, E.J., 1990: Control of a desert- grassland transition by a keystone rodent guild. Science 250: 1705-1707.

Brown, R. M., Taylor, D.H., Gist, D.H., 1995: Effect of caudal autotomy on locomotor performance of wall lizards (Podarcis muralis). Journal of Herpetology 29: 98-105.

Brown, D., 2000: Stephens Island Ark of the Light. Blenheim, New Zealand: Cloudy bay Publishing, pp. 248.

Burnham, K. P., White, G.C., Anderson, D.R., 1995: Model selection of strategy in the analysis of capture-recapture data. Biometrics 51: 888-898.

Burnham, K. P., Anderson, D.R., 1998: Model Selection and Inference: A practical informationtheoretical approach. New York, Springer-Verlag.

Bury, R. B., Pearl, C.A., 1999: Klamath-Siskiyou herpetofauna biogeographic patterns and conservation strategies. Natural Areas Journal 19: 341-350.

Carmicheal, C.K., Gillingham, J.C. and Keall, S.N., 1989: Feeding ecology of the tuatara (Spenodon punctatus) on Stephens Island based on niche diversification. New Zealand Journal of Zoology 16: 269 (abstract).

Carrascal, L. M., Diaz, J.A., Cano, C., 1989: Habitat selection in Iberian Psammodromus species along a Mediterranean successional gradient. Amphibia-Reptilia 10: 231-242.

Castillia, A. M., Bauwens, D., 1992: Habitat selection by the lizard Lacerta lepida in a Mediterranean Oak forest. Herpetological Journal 2: 27-30.

Chase, J. M., 1998: Central-place forager effects on food web dynamics and spatial pattern in Northern California meadows. Ecology 79: 1236-1245.

Christain, K. A., Tracy, C. R., Porter, W.P., 1983: Seasonal shifts in body temperature and use of microhabitats by Galapagos land iguanas (Conolophus pallidus). Ecology 64: 463-468. 
Coddington, E. J., Cree, A., 1997: Population numbers, response to weather, movements and management of the threatened New Zealand skinks Oligosoma grande and O. otagense in tussock grassland. Pacific Conservation Biology 3: 379-391.

Collinge, S. K., 2000: Effects of grassland fragmentation on insect species loss, colonization, and movement patterns. Ecology 81: 2211-2226.

Congdon, J. D., Vitt, L.J., King W.W., 1974: Geckos; Adaptive significance and energetics of tail autotomy. Science 184: 1379-1380.

Craig, J. L., 1990: Potential for ecological restoration of Island for indigenous fauna and flora. In Towns D. R., Daugherty C. H., Atkinson I.A.E. (ed.), Ecological restoration of New Zealand Islands. Department of Conservation, Wellington: Conservation sciences publications, 156-165.

Cummingham, M., Moritz, C., 1998: Genetic effects of forest fragmentation on a rainforest restricted lizard (Scincidae: Gnypetoscincus queenslandiae). Biological Conservation 83: 22112226.

Daugherty, C. H., Towns, D.R., Atkinson, A.E., Gibbs, G.W., 1990: The significance of the biological resources of New Zealand islands for ecological restoration. In Towns D. R., Daugherty C. H., Atkinson I.A.E. (ed.), Ecological restoration of New Zealand islands. Department of Conservation, Wellington: Conservation science publications, 9-21.

Daugherty, C., Patterson G.B, Hitchmough R. A., 1994: Taxonomic and conservation review of the New Zealand herpetofauna. New Zealand Journal of Zoology 21: 317-323.

Dial, B. E., Fitzpatrick, L.C., 1981: The energetic costs of tail autotomy to reproduction in the lizard Coleonyx brevis (Sauria: Gekkonidae). Oecologia 51: 310-317.

Diaz, J. A., Carrascal, L.M., 1991: Regional distribution of a Mediterranean lizard: influence of habitat cues and prey abundance. Journal of Biogeography 18: 291-297.

Dickinson, H.C., Fa, J.E. 2000: Abundance, demographics and body condition of a translocated population of St Lucia whiptail lizards (Cnemidophorus vanzoi). London Journal of Zoology 251: 187-197. 
Downes, S. J., Shine, R., 1998: Heat, safety or solitude? Using habitat selection experiments to identify a lizard's priorities. Animal Behaviour 55: 1387-1396.

Dunham, A.E., 1978. Food availability as a proximate factor influencing individual growth rates in the iguanid Sceloporus merriami. Ecology 59: 770-778.

Dunham, A. E., Miles, D.B., Reznick, D.N., 1988: Life history patterns in squamate reptiles. In Gan, C., Huey R.B. (ed.), Biology of the Reptilia. New York: Alan R. Liss, 441-522.

East, T. K., East M., Daugherty C. H., 1995: Ecological restoration and habitat relationships of Reptiles on Stephens Island, New Zealand. New Zealand Journal of Zoology 22: 249-261.

Eifler, D. A., and Eifler, M. A., 1999: Foraging behaviour and spacing patterns of the lizard Oligosoma grande. Journal of Herpetology 33: 632-639.

Enge, K., M., 2001: The pitfalls of pitfall traps. Journal of Herpetology 35: 467-478.

Fair, S. W., Henke, S. E., 1997: Effects of habitat manipulations on texas horned lizards and their prey. Journal of Wildlife Management 61: 1366-1370.

Freeman, A. B., 1997: Comparative ecology of two Oligosoma skinks in coastal Canterbury: a contrast with Central Otago. New Zealand Journal of Ecology 21: 153-160.

Gill, B. J., 1976: Aspects of the ecology and taxonomy of two skinks (Reptilia: Lacentilia) in the coastal Manawatu area of New Zealand. New Zealand Journal of Zoology 3: 141-157.

Gill, B., Whitaker, T., 2001: New Zealand Frogs and Reptiles. Auckland: Bateman Field guides, pp. 112.

Grant, B. W and Durham, A.E. 1988: Thermally imposed time constraints on the activity of the desert lizard Sceloporus merriami. Ecology 69: 167-176.

Greene, H. W., 1988: Antipredator mechanisms in reptiles. In Gan, C., Huey R.B. (ed.), Biology of the Reptilia. New York: Alan R. Liss, 1-152.

Gvozdik, L., 2000: Intrapopulation variation in injury frequency in the sand lizard, Lacerta agilis (Squamata, Lacertidae). Biologia 55: 557-561. 
Hailey, A., 2000: Assessing body mass condition in the tortoise Testudo hermanni. Herpetological Journal 10: 57-61.

Harlow, P.S., 1996. A harmless technique for sexing skinks. Herpetological Review 27(2), 71-72.

Harvey, P.H., Pagel, M.D. 1991. The comparative method in evolutionary biology. Oxford. Oxford University Press.

Heatwole, H., 1977: habitat Selection in reptiles. In Gan, C. (ed.), Biology of Reptilia. London: Academic Press, 137-155.

Herrel, A., Meyers, J.J., Vanhooydonck, B., 2001: Correlations between habitat use and body shape in a phrynomatid lizard (Urosaurus ornatus): a population level analysis. Biological Journal of the Linnean Society 74: 305-314.

Hoare, J. M., 2002: Biological and environmental influences on body condition of the Brothers Island tuatara, Spenodon guntheri. BSc (Hons), School of Biological Sciences, Victoria University, Wellington.

Hobbs, R. J., Norton, D.A., 1996: Towards a conceptual framework for restoration ecology. Restoration Ecology 4: 93-110.

Hobbs, T. J., James, C. D., 1999: Influence of shade covers on pitfall traps temperatures and capture success of reptiles and small mammals in arid Australia. Wildlife Research 26: 341-349.

Huey, R. B., 1982: Temperature, physiology and ecology of reptiles. In Gan, C., Pough, F.H. (ed.), Biology of Reptilia. London: Academic Press, 441-522.

Irschick, D. J., Macrini, T.E., Koruba, S., Forman, J., 2000: Ontogenetic differences in morphology, habitat use, behaviour and sprinting capacity in two West Indian anolis lizards. Journal of Herpetology 34: 444-451.

Karasov, W. H., Anderson R.A., 1984: Interhabitat differences in energy acquisition and expenditure in a lizard. Ecology 65: 235-247. 
Kohisdorf, T., Garland, T., Navas C., 2001: Limb and tail lengths in relation to substrate usage in tropidurus lizards. Journal of Morphology 248: 151-164.

Krebs, C. J., 1994: Ecology. 4 ed. British Columbia: Benjamin Cummings.

Mac Nally, R., Brown. G.W., 2001: Reptiles and habitat fragmentation in the Box - Ironbark forests of Central Victoria, Australia: predictions, compositional change and faunal nestedness. Oecologia 128: $116-125$.

Majer, J. D., 1990: Rehabilitation of disturbed land: long term prospects for the recolonization of fauna. Proceeding Ecological Society of Australia 16: 509-519.

Markwell, T.J., 1997. Using a miniature video camera to study burrow dwelling fairy prions (Pachyptila turtur) and tuatara (Sphenodon punctatus) on Takapourewa (Stephens Island) New Zealand. New Zealand Journal of Zoology 24, 231-237

Markwell, T. J., 1999. Keystone species on New Zealand offshore islands: ecological relationships of seabirds, rats, reptiles and invertebrates on Cook Strait islands. Unpublished Ph.D thesis. Victoria University of Wellington, Wellington, N.Z.

Markwell, T. J., Daugherty, C.H., 2002: Invertebrate and lizard abundance is greater on seabirdinhabited islands than on seabird-free islands in the Marlborough Sounds, New Zealand. Ecoscience 9: 293-299.

Martin, J., Salvador, A., 1993: Tail loss reduces mating success in the lberian rock-lizards, Lacerta monticloa. Behavioural Ecology and Sociobiology 32: 185-189.

Martin, J., Salvador, A., 1995: Microhabitat selection by the lberian rock lizard Lacerta monticola: effects on density and spatial distribution of individuals. Biological Conservation 79: 303-307.

Martin, J., Lopez, P., 1996: Avian predation on a large lizard (Lacerta lepida) found at low population densities in Mediterranean habitats: an analysis of bird diets. Copeia 3: 722-726.

Martin, J., Lopez P., 1998: Shifts in microhabitat use by the lizard Psammodromus algirus response to seasonal changes in vegetation structure. Copeia 3: 780-786. 
Martin, J., Lopez, P., 2002: The effect of Mediterranean dehesa management on lizard distribution and conservation. Biological Conservation 108: 213-219.

Massot, M., Clobert, J., Pilorge, T., Lecomte, J., Bardault, R., 1992: Density dependence in the common lizard: Demographic consequences of a density manipulation. Ecology, 13: 1742-1756. McCann, C., 1956: Keys to the Lizards of New Zealand. Tuatara 6: 45-51.

Melville, J., Swain, R., 2000: Evolutionary relationships between morphology, performance and habitat openness in the lizard genus Niveoscincus (Scincidae: Lygosominae). Biological Journal of the Linnean Society 70: 667-683.

Meyer-Rochow, V. B., Teh, K.L., 1991: Visual predation by tuatara (Spenodon punctatus) on the beach beetle (Charodes trachyscelides) as a selective force in the production of distinct colour morphs. Tuatara 30: 36-38.

Moseby, K. E., Read J. L., 2001: Factors affecting pitfall capture rates of small ground vertebrates in arid South Australia II. Optimum pitfall trapping effort. Wildlife Research 28: 61-71.

Neilson, K. A., 2002: Evaporative water loss as a restriction on habitat use in endangered New Zealand endemic skinks. Journal of Herpetology 36: 342-348.

Nemes, S., 2002: Morphometry of metamorphosed smooth newts Triturus vulgaris (Amphibia: Salamandridae) with notes on limb, toe and tail injury and frequency. Biologia 57: 615-619.

Neil, K. F. 1997. Restoration and the skinks of Matiu-Somes Island: the potential impacts of revegetation. Unpublished Ecology BSc Honours project, Victoria University of Wellington, Wellington.

Parker, W. S., 1994: Demography of the fence lizard, Sceloporus undulatus, in Northern Mississippi. Copeia 1: 136-152.

Patterson, G. B., 1985: The ecology and taxonomy of the common skink Leiolopisma nigriplantare maccanni in tussock land in Otago. Unpublished PhD thesis, School of Biological Sciences, University of Otago, Dunedin, New Zealand.

Patterson, G. B., 1992: The ecology of a New Zealand grassland lizard guild. Journal of the Royal Society of New Zealand 22: 91-106. 
Patterson, G. B., Daugherty, C. H., 1995: Reinstatement of the genus Oligosoma (Reptilia: Lacertilia, Scincidae). Journal of the Royal Society of New Zealand 25: 327-331.

Phillpot, P., 2000: The skinks of North Brother Island: Abundance, habitat use and species interactions. Unpublished MSc thesis, School Of Biological Sciences, Victoria University, Wellington, New Zealand.

Pickard, C. R., Towns, D.R., 1988: Atlas of the Amphibians and Reptiles of New Zealand. Wellington: Science and Research Directorate Department of Conservation.

Pitt, W. C., Ritchie, M. E., 2002: Influence of prey distribution on the functional response of lizards. OIKOS 96: 157-163.

$R$ Development Core Team. 2003. R: a language and environment for statistical computing. $R$ Foundation for Statistical Computing, Vienna, Austria.

Read, J. L., 1998: The ecology of sympatric scincid lizards (Ctenotus) in arid South Australia. The Australian Journal of Zoology, 46: 617-629.

Read, J. L., Moseby, K.E., 2001: Factors affecting pitfall capture rates of small ground vertebrate in arid Australia. I. The influence of weather and moon phase on capture rates of reptiles. Wildlife Research 28: 53-60.

Robb, J., 1986. New Zealand Amphibians Reptiles in colour. Collins Publishing. Auckland

Rufaut, C.G., Clearwater, S.G. 1997: Chetwode Islands Recovery: The response of lizards and invertebrates following the eradication of kiore and weka from the Chetwode Islands. Department of Conservation occasional publications No. 41. Nelson.

Sarre, S. D., 1996: Habitat fragmentation promotes fluctuation asymmetry but not morphological divergence in two geckos. Ecology 38: 57-64.

Sarre, S. D., 1998: Demographics and population of Gehyra variegate (Gekkonidae) following habitat fragmentation. Journal of Herpetology 32: 153-161. 
Scheibe, J. S., 1987: Climate, competition and the structure of temperate zone lizard communities. Ecology 68: 1424-1436.

Schlaepfer, M., Gavin, T. A., 2001: Edge effects on lizards and frogs in tropical forest fragments. Conservation Biology 15: 1079-1090.

Selas, V., 2001: Predation on reptiles and birds by the common buzzard, Buteo buteo, in relation to changes in its main prey, voles. Canadian Journal of Zoology 79: 2086-2093.

Simberloff, D., 1990a: Community effects of biological introductions and their implications for restoration. In Towns D. R., Daugherty C. H., Atkinson I.A.E. (ed.), Ecological Restoration of New Zealand Islands. Department of Conservation, Wellington: Conservation Sciences Publication, 128-165.

Simberloff, D., 1990b: Reconstructing the ambiguous: can island ecosystems be restored? In Towns D. R., Daugherty C. H., Atkinson I.A.E. (ed.), Ecological restoration of New Zealand islands. Department of Conservation, Wellington: Conservation science publications.

Singh, S., Smyth, A. K., Blomberg, S. P., 2002: Thermal ecology and structural habitat use of two sympatric lizards (Carlia vivax and Lygisaurus foliorum) in subtropical Australia. Austral Ecology 27: 616-623.

Sinclair, E.A. 1998. Morphological variation among populations of the quokka, Setonix brachyururs (Macropodidae: Marsupialia) in western Australia. Australian Journal of Zoology 46: 439-449.

Smith, G. R., Ballinger, R.E., 1994: Temporal and spatial variation in individual growth in the spiny lizard, Sceloporus jarrovi. Copeia 4: 1007-1013.

Spencer, N. J., Thomas, B.W., Mason, R.F., Dugdale, J.S., 1998: Diet and life history variation in the sympatric lizards Oligosoma nigriplantare polychroma and Oligosoma lineoocellatum. New Zealand Journal of Zoology 25: 457-463.

Stamps, J. A. 1983: The relationship between ontogenetic habitat shifts, competition and predator avoidance in a juvenile lizard (Anolis aeneus). Behavioural Ecology and Sociobiology 12: 19-34. 
Stow, A. J., Sunnucks, P., Briscoe, D.A., Gardner, and M.G., 2001: The impact of habitat fragmentation on dispersal of Cunningham's skink (Egernia cunninghamı): evidence from allelic and genotypic analyses of microsatellites. Molecular Ecology 10: 867-878.

Sumner, J., Moritz, C., Shine, R., 1999: Shrinking forest shrinks skinks: morphology fragmentation in the prickly forest skink (Gnypetoscincus queenslandiae). Biological Conservation 91: 159-167.

Thompson, M. B., Daugherty, C.H., Cree, A., French, D.C., Gillingham, J.C., Barwick, R.E., 1992: Status and longevity of the tuatara, Sphenodon guntheri, and Duvaucel's gecko, Hoplodactylus duvaucelii, on North Brother Island, New Zealand. Journal of the Royal Society of New Zealand 22: 123-130.

Thompson, M. B. 2000. Oligosoma Predation. Herpetological review 31:3: 175.

Towns, D. R., Atkinson I.A.E., Daugherty C. H., 1990: The potential for ecological restoration in the Mercury Islands. In Towns D. R., Daugherty C. H., Atkinson I.A.E. (ed.), Ecological restoration of New Zealand Islands. Wellington, New Zealand. Department of Conservation: Conservation sciences publications, 91-108.

Towns, D. R., Daugherty, C. H., 1994: Patterns of range contractions and extinctions in the New Zealand herpetofauna following human colonisation. New Zealand Journal of Zoology 21: 325339.

Towns, D. R., Elliott, G.P., 1996: Effects of habitat structure on distribution and abundance of lizards at Pukerua, Wellington, New Zealand. New Zealand Journal of Ecology 20: 191-206.

Towns, D. R., Daugherty, C. H., Cree, A., 2001: Raising the prospects for a forgotten fauna: a review of 10 years of conservation effort of New Zealand reptiles. Biological Conservation 99: 316.

Towns, D. R., Ferreira, S., 2001: Conservation of New Zealand lizards (Lacertilia Scincidae) by translocation of small populations. Biological Conservation 98: 211-222.

Van Sluys, M., 1998: Growth and body condition of the Saxicolous lizard Tropidurus itambere in south-eastern Brazil. Journal of Herpetology 32: 359-365. 
Vanhooydonck, B., Van Damme, R., Aerts, P., 2000: Ecomorphological correlates of habitat partitioning in Corscian lacertid lizards. Functional Ecology 14: 358-368.

Vitt, L. J., Congdon, J.D., Hulse, A.C., Platz, J.E., 1974: Territorial aggressive encounters and tail breaks in the lizard Sceloporus magister. Copeia 1974: 990-993.

Waide, R. B., Reagan, 1983: Competition between West Indian anoles and birds. American Naturalist 121: 133-138.

Walls, G., 1988: Vegetation and flora of Stephens Island (Takapourewa) with Management Schemes. Department of Conservation Report. Wellington.

Watts, C. H., Gibbs, G.W., 2002: Revegetation and its effect on the ground dwelling beetle fauna of Matiu-Somes Island, New Zealand. Restoration Ecology 10: 96-106.

Whitaker, T., 1967: Baiting pitfall traps for small lizards. Herpetological Journal 23: 309-311.

Whitaker, A.H., 1982. Interim results from a study of Hoplodactylus maculatus (Boulenger) at Turakirae Head, Wellington. In D.G. Newman (Ed) New Zealand Herpetology: p363-374. New Zealand Wildlife Service occasional publication No. 2.

White, G. C., Anderson, D. R., Burnham, K. P., Otis D.L., 1982: Capture-Recapture and removal methods for sampling closed populations. New Mexico: Los Alamos.

White, G. C., 2001: MARK v. 2.1. Colorado State University: Fort Collins. http://www.cnr.colostate.edu/ gwhite/mark/mark.htm (2002).

Wilson, B. S., 1992: Tail injuries increase the risk of mortality in free ranging lizards. Oecologia 92: 145-152.

Zar, J. H., 1999: Biostatistical Analysis. 4 ed. New Jersey: Prentice Hall Inc. 
Appendix A

Table of the percentage plant species found in each grid.

\begin{tabular}{|c|c|c|c|c|c|c|c|c|}
\hline & Grid A & Grid B & Grid C & Grid D & Grid E & Grid F & Grid G & Grid $\mathrm{H}$ \\
\hline Tetragonia trigyna & & & & 2.3 & & & & \\
\hline Bromus sp. & & & 58.3 & & & & 73.8 & \\
\hline Cassinia leptophylla & & & 12 & & & & 1.9 & \\
\hline Coprosma repens & 20.3 & & 14.7 & & & & 12.9 & \\
\hline Taraxacum officinate & & & & & & & & 7.7 \\
\hline Dysoxylum spectabile & 9.9 & 6.3 & & & & & & \\
\hline Elymus solandri & & & & 27.3 & 43.3 & & & \\
\hline Macropiper excelsum & 16.5 & 18.6 & & & & & & \\
\hline Melicope ternata & 4.7 & 0.16 & & & & & & \\
\hline Melicytus obovatus & & & & 4.5 & & & & \\
\hline Melicytus ramiflorus & 25.3 & 47.5 & & & & & & \\
\hline $\begin{array}{l}\text { Muehlenbeckia } \\
\text { australis }\end{array}$ & & 0.83 & & 10.7 & 20.5 & & & \\
\hline Myoporum laetum & 18.5 & 2 & 3 & & & & 9.8 & \\
\hline Phormium cookianum & & & 8.8 & & & & 0.6 & \\
\hline $\begin{array}{l}\text { Pittosporum } \\
\text { tenuifolium }\end{array}$ & 2.6 & 4.4 & 2.3 & & & & & \\
\hline Poa cita & & & & 56.7 & 36.2 & & & \\
\hline Rhopalostylis sapida & & 18.9 & & & & & & \\
\hline Festuca arundinacea & & & & & & 67 & & 51.2 \\
\hline Lolium perenne & & & & & & 12 & & 27.8 \\
\hline Ground cover & $\begin{array}{l}\text { Leaf litter } \\
\text { and soil }\end{array}$ & $\begin{array}{l}\text { Leaf } \\
\text { litter } \\
\text { and soil }\end{array}$ & $\begin{array}{l}\text { soil } \\
(15.2 \%)\end{array}$ & soil (2\%) & $\begin{array}{l}\text { soil } \\
(19.8)\end{array}$ & $\begin{array}{l}\text { Dirt } \\
(12 \%)\end{array}$ & soil 3\% & $\operatorname{Dirt}(13 \%)$ \\
\hline Relative cover & 69 & 76 & 39 & 29.6 & 30.3 & 4.8 & 17.8 & 3 \\
\hline
\end{tabular}




\begin{tabular}{|l|l|l|l|l|l|l|l|l|}
\hline Height $(\mathrm{m})$ & 3.76 & 2.6 & 0.9 & 0.26 & 0.23 & 0.16 & 0.91 & 0.15 \\
\hline Slope (std dev) & 12.25 & $\begin{array}{l}8.25 \\
(2.36)\end{array}$ & $\begin{array}{l}11.5 \\
(2.38)\end{array}$ & $21(1.41)$ & $\begin{array}{l}6.75 \\
(0.96)\end{array}$ & $\begin{array}{l}20.75 \\
(1.26)\end{array}$ & $\begin{array}{l}25.5 \\
(1.26)\end{array}$ & $20.5(1.3)$ \\
\hline Aspect & $\mathrm{NW}$ & $\mathrm{NE}$ & $\mathrm{W}$ & $\mathrm{SSW}$ & $\mathrm{S}$ & $\mathrm{E}$ & $\mathrm{E}$ & $\mathrm{E}$ \\
\hline Burrows & $10^{*}$ & $10^{*}$ & 0 & 19 & 20 & 18 & 0 & 9 \\
\hline
\end{tabular}

* Traps were placed in areas were there were few burrows to avoid disturbing nesting birds.

\section{Appendix B}

Normality graphs for the body condition index (lgwgtsvl) for Oligosoma lineoocellatum 


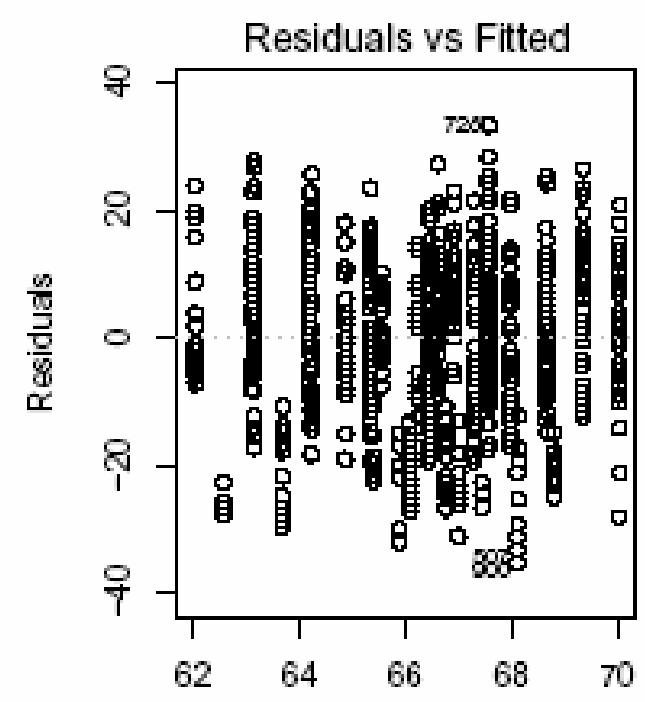

Fitted values

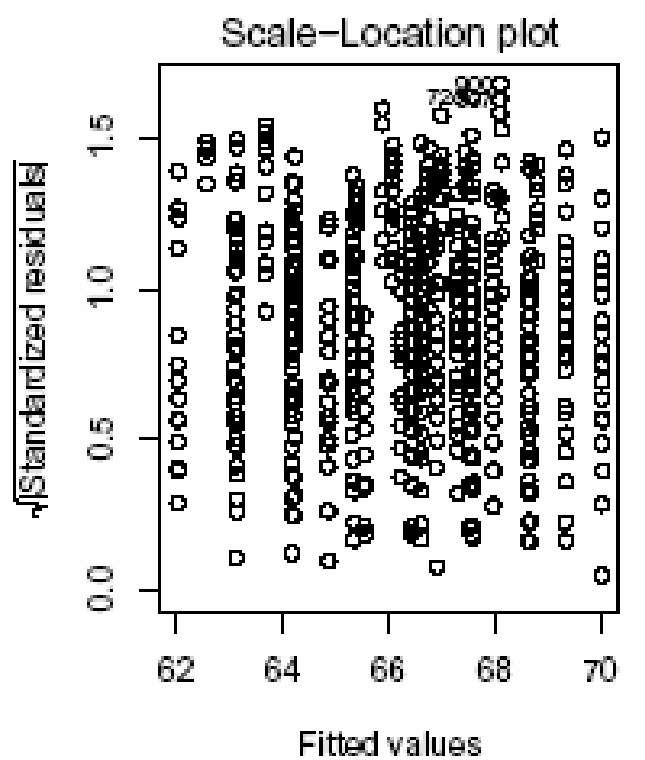

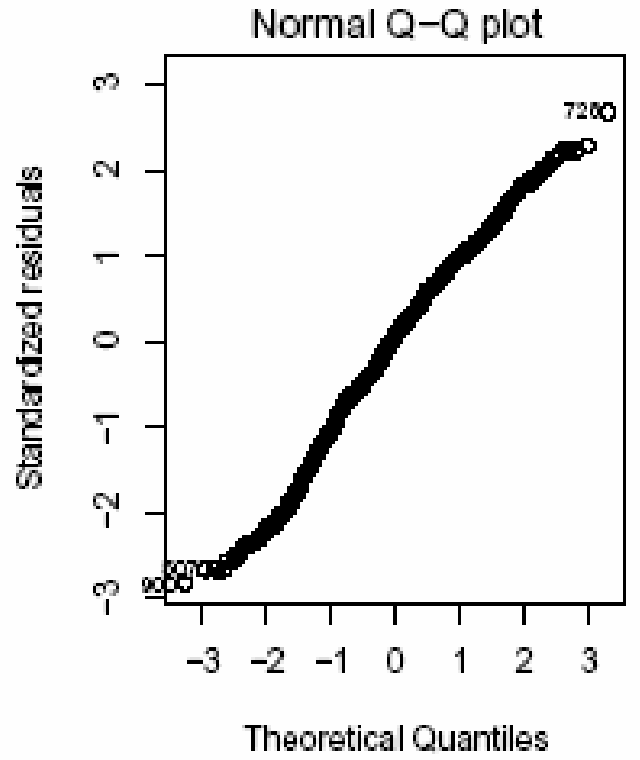

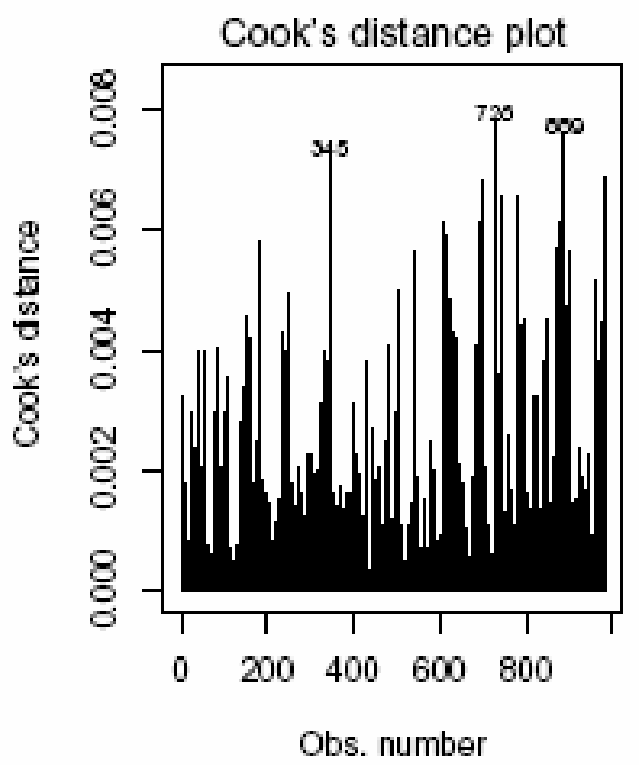

Normality graphs of the body condition index (lgwgtsvl) for O. nigriplantare polychroma 

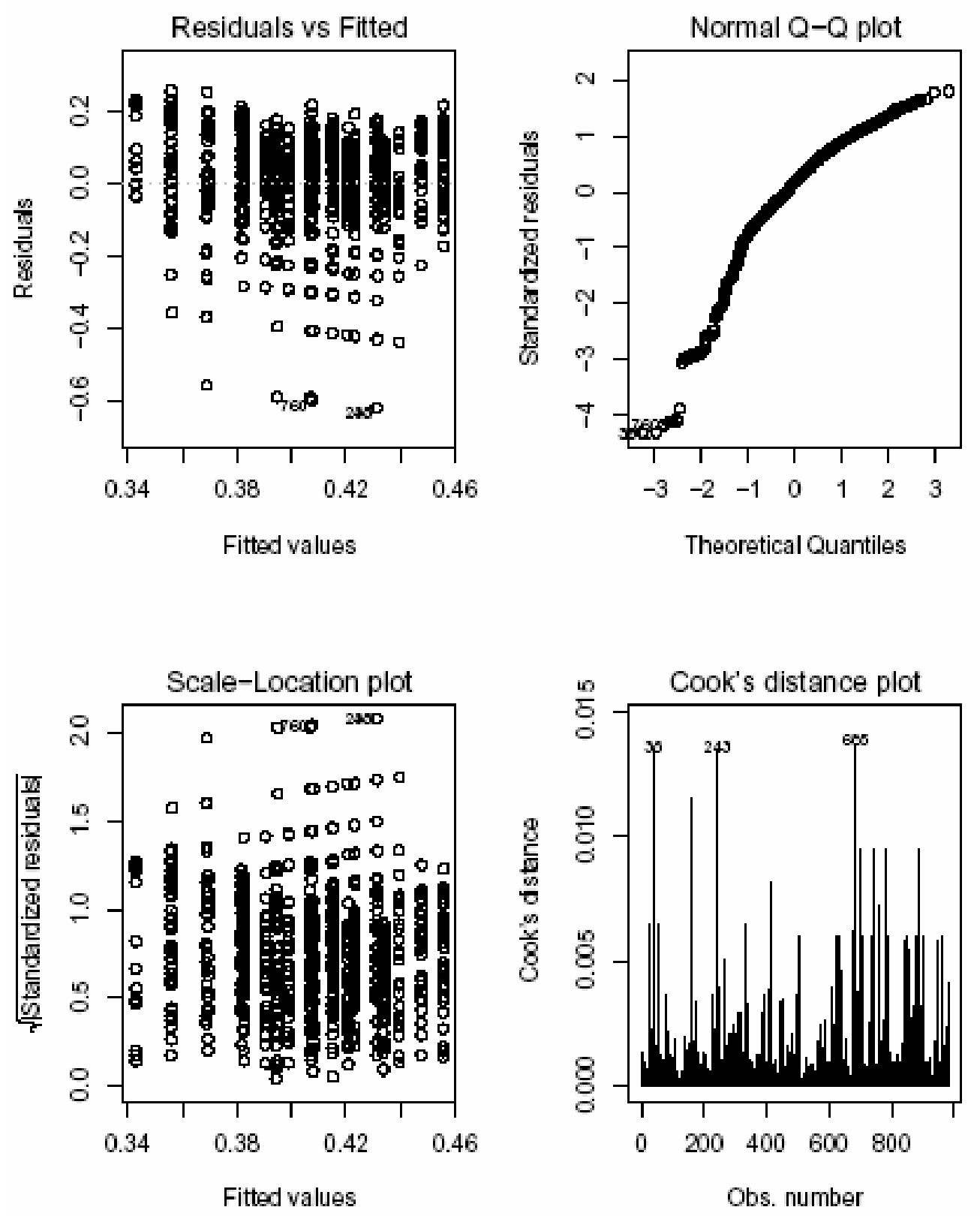
Normality graphs for the body condition index of $O$. infrapunctatum
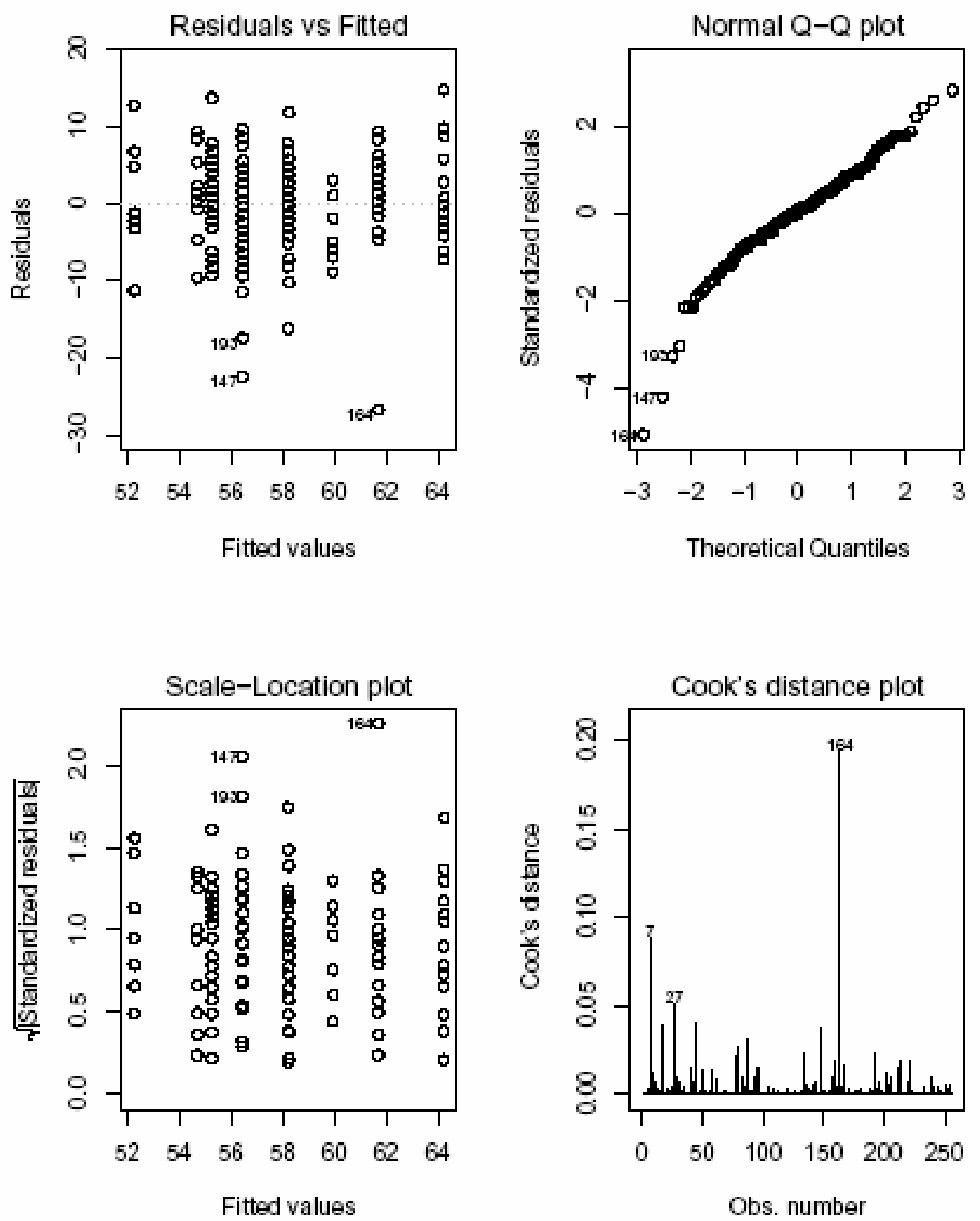
Normality graphs for the body condition index (lgwgtsvl) for O. zelandicum

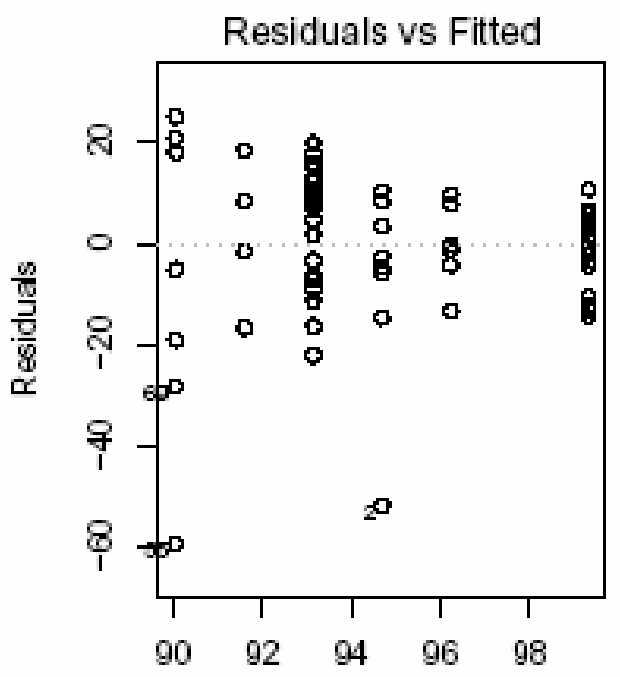

Fitted values

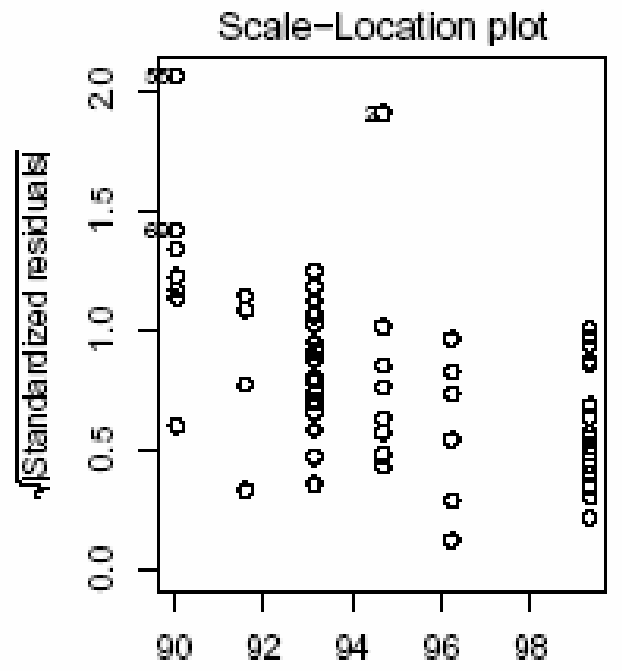

Fitted values

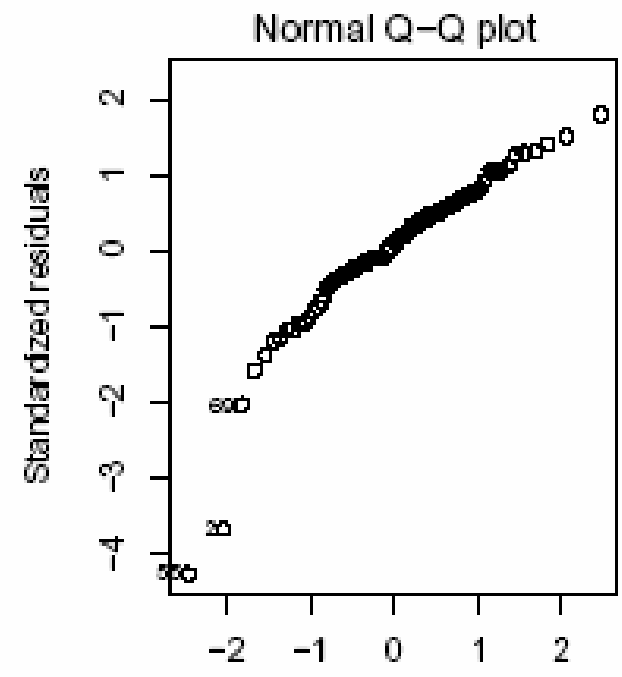

Theoretical Quantiles

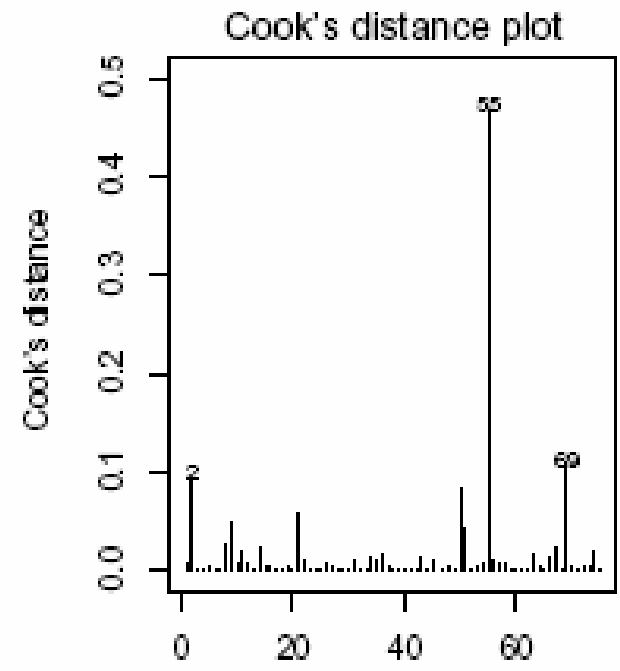

Obs. number 